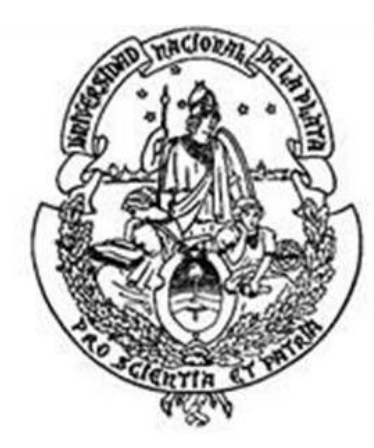

\title{
“MAPEO DIGITAL DE CARBONO ORGÁNICO DEL SUELO MEDIANTE IMÁGENES SATELITALES Y ALGORITMOS DE AUTOAPRENDIZAJE EN EL ECOSISTEMA HERBAZAL DEL PÁRAMO, PROVINCIA DE CHIMBORAZO, ECUADOR"
}

\author{
Tesis de Maestría
}

\begin{abstract}
JOHANNA ELIZABETH AYALA IZURIETA
Presentada ante la Facultad de Ingeniería y la Facultad de Ciencias Astronómicas y Geofísicas de la Universidad Nacional de La Plata como requisito para la obtención del Grado Académico de
\end{abstract}

\section{MAGÍSTER EN GEOMÁTICA}

Director de Tesis: Dr. Prof. Víctor García

Codirector de Tesis: Dr. Prof. Jorge Sisti

Jurado de Tesis: Dra. Prof. Adriana Aleksa

Dra. Prof. Analía Argerich

Dr. Prof. Horacio Bozzano

Lugar y fecha de presentación oral y pública: La Plata, 02 de julio del 2019 


\section{RESUMEN}

Se presenta una metodología para predecir de manera cuantitativa el almacenaje del Carbono Orgánico del Suelo (COS) en zonas alto andinas, en donde, la complejidad paisajística evidenciada por la topografía irregular, dificultades de acceso, clima frío - frío intenso, alta nubosidad, así como su geología, hacen de dicha tarea un gran desafío. La zona de estudio corresponde al ecosistema Herbazal del Páramo (HP) de la provincia de Chimborazo, Ecuador. La metodología emplea variables espectrales derivadas de imágenes satelitales Landsat 8 (sensores OLI y TIRS), Modelo Digital de Elevación (MDE), datos de secuestro de COS in situ en el perfil $0-30 \mathrm{~cm}$ y variables meteorológicas. Las variables son obtenidas mediante el procesamiento de imágenes satelitales y Sistemas de Información Geográfica (SIG), éstas variables son usadas en la calibración de un algoritmo de autoaprendizaje con Random Forest Regression (RFR) para la predicción de COS. Se logró encontrar 9 variables que controlan la dinámica de distribución de COS en el área de estudio, y a través de ellas generar el modelo final de predicción de COS con una precisión del 82 \%, validada mediante muestreo aleatorio simple (MAS). Las variables halladas son: Formación Geológica, Taxonomía, Precipitación, Altura, Orientación, Factor LS, Índice BI, Temperatura Ambiente, Temperatura Superficial - TOA Brightnees Temperature. Mediante SIG se generó el mapa de COS en la zona de estudio y se cuantificó la extensión de las mayores concentraciones de COS, en donde, el mayor porcentaje del área de estudio tiene altas reservas de COS, entre los $150-205 \mathrm{Mg} / \mathrm{ha}$, equivalente al $57 \%$ del área total.

A través del presente estudio y sus resultados se presenta una nueva alternativa de cuantificación de COS. El modelo calibrado puede ser extendido sin necesidad de muestrear in situ, muy útil en zonas complejas como el ecosistema páramo. El mapeo digital de COS permitió revelar las elevadas reservas de COS existentes en el ecosistema de estudio, representando un gran aporte en la caracterización de los suelos del territorio nacional.

Finalmente, los resultados obtenidos pueden ser utilizados para crear normativas provinciales y nacionales, para evitar la degradación del suelo en este tipo de ecosistemas, considerando la importancia del HP en la estabilización de las estructuras del suelo, regulación hídrica y su aporte en la mitigación del cambio climático.

Palabras clave: Landsat 8, Random Forest, índices multiespectrales, SIG, árboles de decisión análisis espacial. 


\section{ABSTRACT}

The methodology presented is used to predict the storage of Organic Soil Carbon (SOC) in quantitative form, in high Andean areas, where a landscape matter evidenced by irregular topography, access difficulties, cold weather - intense cold weather, high cloudiness and its geology, make this task a great challenge. The study area corresponds to the Herbazal del Páramo (HP) ecosystem of the province of Chimborazo, Ecuador. The methodology uses spectral variables derived from Landsat 8 satellite images (OLI and TIRS sensors), Digital Elevation Model (DEM), SOC sequester data in situ in the profile $0-30 \mathrm{~cm}$ and meteorological variables. The variables are obtained by satellite image processing and Geographic Information Systems (GIS), these variables are used in the calibration of a self-learning algorithm applying Random Forest Regression (RFR) for the SOC prediction. It was possible to find nine variables that control the dynamics of SOC distribution in the study area, and with them generate the final SOC prediction model with a precision of $82 \%$, which was validated by simple random sampling (MAS). The found variables are Geological Formation, Taxonomy, Precipitation, Height, Orientation, LS Factor, BI Index, Temperature, Surface Temperature - TOA Brightness Temperature. Using GIS, the SOC map was generated in the study area and quantify the surface area of the largest SOC values, where, the highest percentage of the study area has high SOC reserves between 150-205 $\mathrm{Mg} / \mathrm{ha}$, equivalent to $57 \%$ of the total area.

With the present study and its results is possible to present a new alternative of SOC quantification. The calibrated model can be extended without need to sample in situ, useful in complex areas such as the Paramo geosystem. The digital mapping of SOC allows us to reveal the high reserves of SOC in the ecosystem of study, representing a great contribution to the soil characterization of the national territory.

Finally, the obtained results could be used to create provincial and national regulations to avoid the soil degradation in these types of ecosystems, considering the importance of HP on the soil structure stabilization, water regulation and its contribution on climate change mitigation.

Key words: Landsat 8, Random forest, multispectral indexes, GIS, decision trees, spatial analysis. 


\section{DEDICATORIA}

Para mis grandes amores mi hijo Arturito y mi esposo Carlitos, su amor, sacrificio y apoyo fueron la fuerza que necesité en todo momento para seguir adelante...

A mis padres, por formarme, amarme y por acompañarme en todas las fases de mi vida... 


\section{AGRADECIMIENTOS}

A la Secretaría de Educación Superior, Ciencia, Tecnología e Innovación- SENESCYT, como entidad auspiciante de la beca internacional de estudios dentro del Programa de Becas "CONVOCATORIA ABIERTA 2014-SEGUNDA FASE", bajo la cual fue posible estudiar el presente Posgrado y cumplir esta nueva meta profesional.

Al Dr. Víctor García de la Universidad Nacional de Chimborazo (UNACH) - Ecuador y al Dr. Jorge Sisti de la Universidad Nacional de la Plata (UNLP) - Argentina, en calidad de "Director" y "Codirector" de tesis respectivamente, por la contribución, asesoramiento, orientación y seguimiento brindado en todas las fases de la investigación.

A la Dra. Omaira Márquez, experta en suelos y miembro del proyecto SOCEPE-UNACH por su asesoramiento y guía en todas las temáticas ambientales vinculadas a la investigación.

Al Proyecto SOCEPE-UNACH, para el cual se destina el presente estudio, por su colaboración tanto de personal como de laboratorio y sus insumos, que fueron destinados en el desarrollo de la investigación. 


\section{TABLA DE CONTENIDO}

RESUMEN

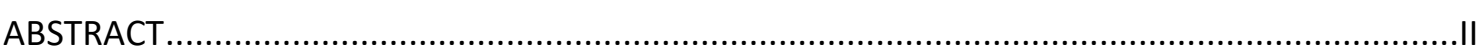

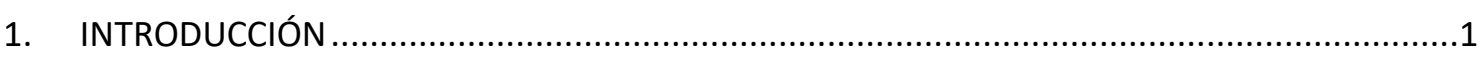

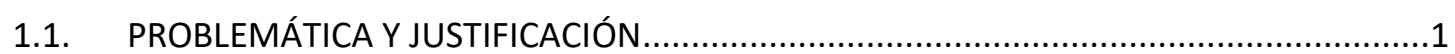

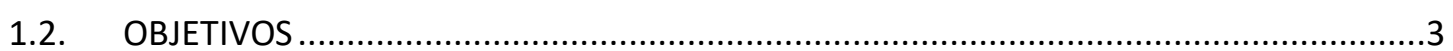

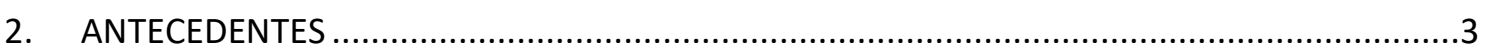

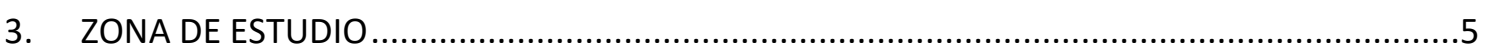

3.1. DESCRIPCIÓN GENERAL DE LA ZONA DE ESTUDIO....................................................

3.2. DESCRIPCIÓN DEL ECOSISTEMA HERBAZAL DEL PÁRAMO EN EL ECUADOR ..................6

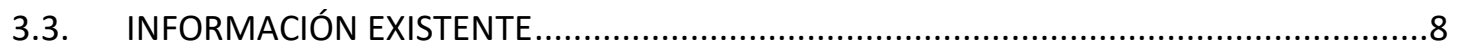

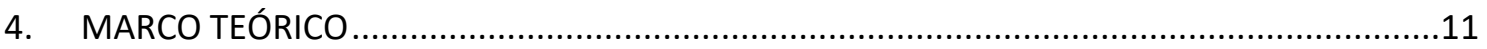

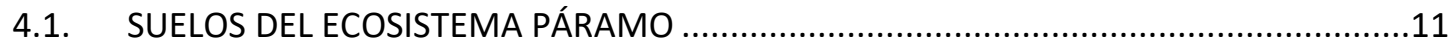

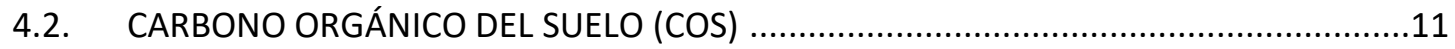

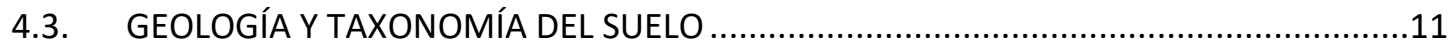

4.4. ESPECTRO ELECTROMAGNÉTICO Y SU RELACIÓN CON LAS FIRMAS ESPECTRALES ....12

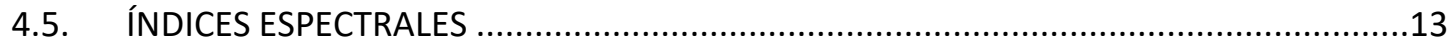

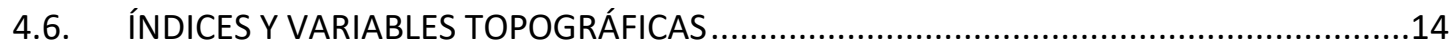

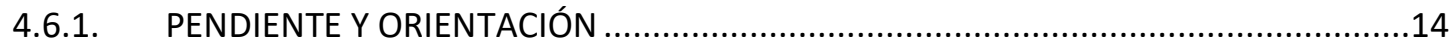

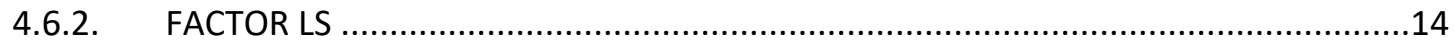

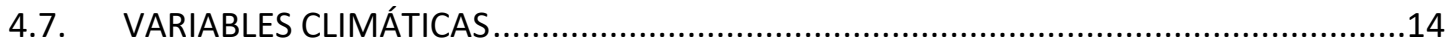

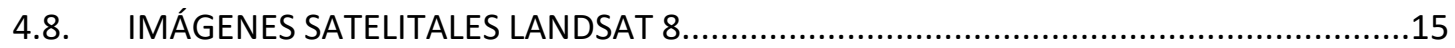

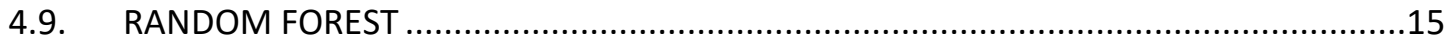

4.9.1. ALGORITMO DE PREDICCIÓN DE RANDOM FOREST ..........................................16

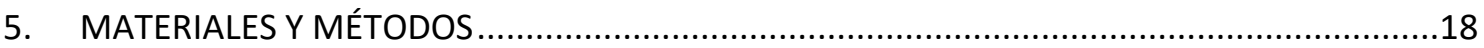

5.1. DESCARGA Y PROCESAMIENTO DE IMÁGENES SATELITALES ...................................19

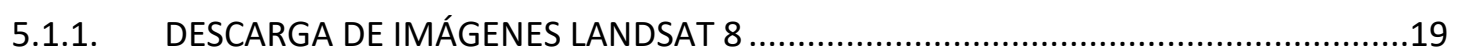

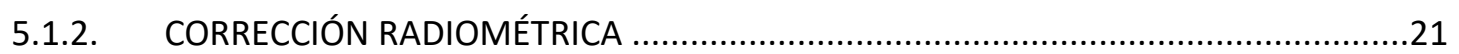

5.1.3. ENMASCARAMIENTO Y VALIDACIÓN DE PIXELES ...................................................24

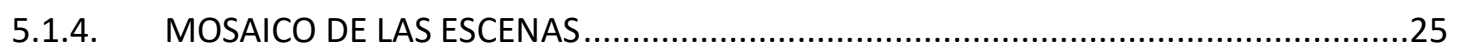

5.1.5. EXTRACCIÓN DE NUBOSIDAD Y RELLENO DE IMAGENES........................................25

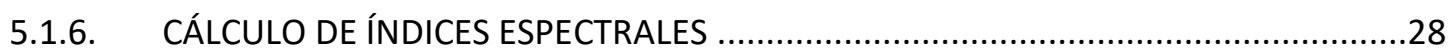

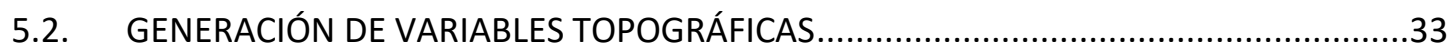




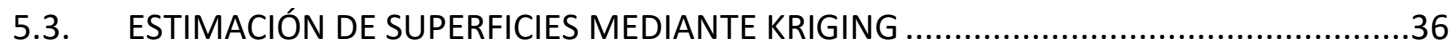

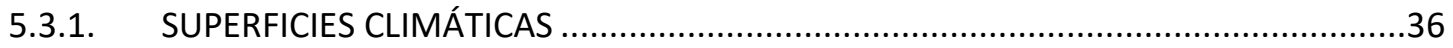

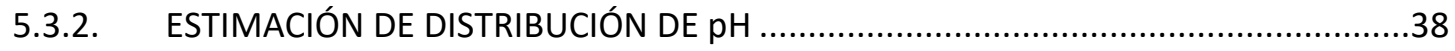

5.4. ENTRENAMIENTO DEL ALGORITMO DE AUTOAPRENDIZAJE PARA PREDICCIÓN DE $\cos 39$

5.4.1. TRATAMIENTO DE INFORMACIÓN IN SITU .39

5.4.2. GENERACIÓN DEL ARCHIVO PARA CALIBRACIÓN DEL ALGORITMO CON RANDOM FOREST 39

5.4.3. CALIBRACIÓN DEL ALGORITMO DE AUTOAPRENDIZAJE . .40

5.5. OBTENCIÓN DE LA PREDICCIÓN DEL COS CON EL MODELO GENERADO (ALGORITMO

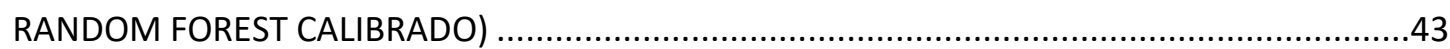

5.6. VALIDACIÓN DE RESULTADOS POR MUESTREO DE CAMPO ......................................44

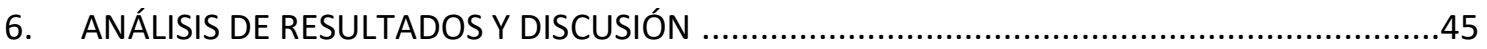

6.1. RESULTADOS DEL MUESTREO DE VALIDACIÓN ........................................................50

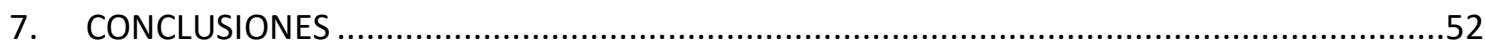

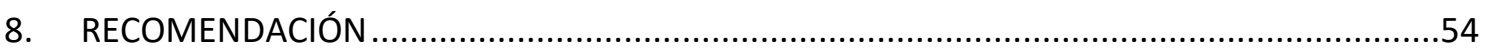

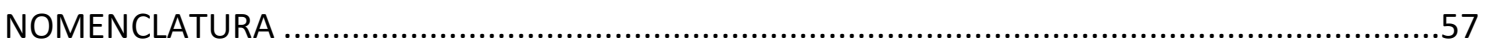

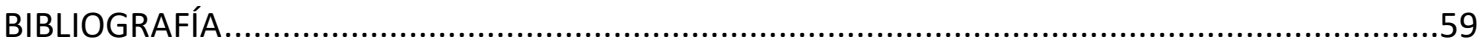

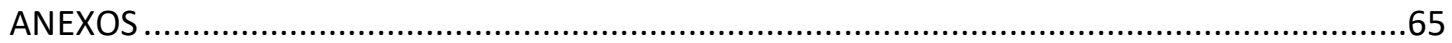




\section{ÍNDICE DE FIGURAS}

Figura 3. 1. Área de estudio-provincia de Chimborazo

Figura 3. 2. a), b), c) Ecosistema Herbazal del Páramo-Chimborazo; d) En coloración roja la distribución del ecosistema Herbazal del Páramo en el Ecuador. .7

Figura 3. 3. a) y b) Recolección de muestras de suelo in situ; c) y d) Análisis de laboratorio para determinar COS a partir de las muestras de suelo recolectadas in situ; e) Mufla marca Thermo Scientific -Lab Servicios Ambientales-UNACH; f) Estufa marca Memmert- Lab Servicios Ambientales-UNACH; g) pHachímetro- Lab Servicios Ambientales-UNACH; h) Muestras de suelo de la zona de estudio. .10

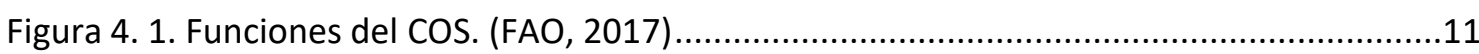

Figura 4. 2. Firmas espectrales de distintas cubiertas, (Chuvieco, 2008) .................................13

Figura 4. 3. Algoritmo de selección del mejor Split. (SALFOR SYSTEMS A MINITAB, 2017) ........17

Figura 4. 4. Síntesis procedimental del algoritmo de regresión de RF. (SALFOR SYSTEMS A

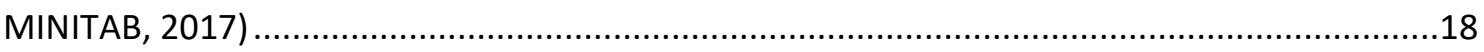

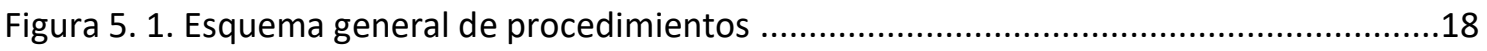

Figura 5. 2. Flujograma de trabajo: a) generación de insumos para la predicción y mapeo de COS;

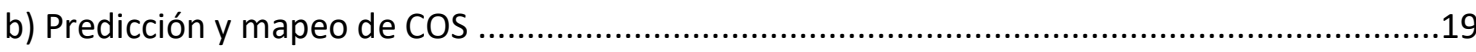

Figura 5. 3. Sitio web USGS GloVis, escenas de imágenes base descargadas .............................20

Figura 5. 4. (a) Codificación de las cartas topográficas del IGM, de la provincia de Chimborazo, (b) Cartas topográficas utilizadas, (c). Ubicación de las catas topográficas con respecto las

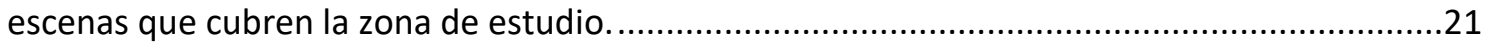

Figura 5. 5. Configuración de la herramienta Radiometric Calibration utilizada ........................22

Figura 5. 6. Configuración del módulo FAASH Atmospheric Correction ENVI 5.1.....................23

Figura 5. 7. Resultado de la corrección radiométrica, firma espectral en uno de los píxeles de la escena superior

Figura 5. 8. Banda QA de la escena Norte path, row 010, 061.

Figura 5. 9. (a) Acople de las escenas N y S para mosaico; (b) Acople de las máscaras de pixeles validados de zona $\mathrm{N}$ y $\mathrm{S}$ para mosaico.

Figura 5. 10. Modelado cartográfico utilizado, en el mosaico de referencia y las imágenes de relleno. Aplicación ModelBuilder- ArcGis 10.2

Figura 5. 11. A la izquierda pixeles de relleno. A la derecha, mosaico de referencia con vacíos de información por concepto de extracción por nubosidad.

Figura 5. 12. Configuración del relleno. Mosaico de referencia es la imagen a rellenar y las imágenes para el relleno son de ajuste 
Figura 5. 13. Combinación falso color $(7,5,3)$. En el lado izquierdo, la imagen satelital corregida de la provincia de Chimborazo (el sector Oeste del cantón Cumandá no es considerado por encontrarse fuera de la zona del estudio); del lado derecho se presenta la imagen cortada con la zona objetivo del estudio, ecosistema Herbazal del Páramo de Chimborazo.........................28

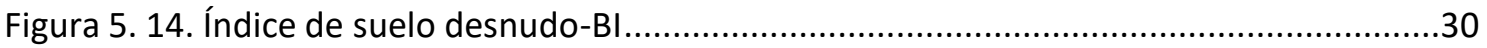

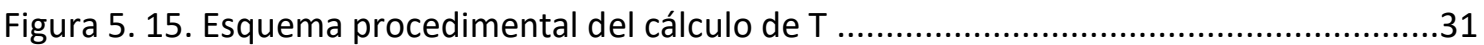

Figura 5. 16. Mapa de T en el Ecosistema Herbazal del Páramo ................................................32

Figura 5. 17. Esquema procedimental del cálculo del Factor LS ................................................34

Figura 5. 18. Mapa del Factor LS del Ecosistema Herbazal del Páramo ........................................35

Figura 5. 19. (a) Ubicación de las estaciones meteorológicas con datos de temperatura respecto al ecosistema de estudio. (b) Ubicación de las estaciones con mediciones pluviométricas respecto al ecosistema de estudio.

Figura 5. 20. (a) Superficie de temperatura en el Ecosistema Herbazal del Páramo. (b) Superficie

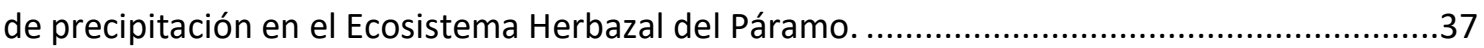

Figura 5. 21. Mapa de pH en el Ecosistema Herbazal del Páramo...............................................38

Figura 5. 22. Diagrama procedimental de la generación del archivo de calibración para el algoritmo RF . .40

Figura 5. 23. Distribución de puntos de entrenamiento del algoritmo RF y captura del archivo

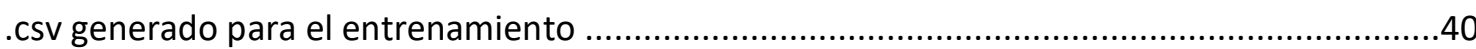

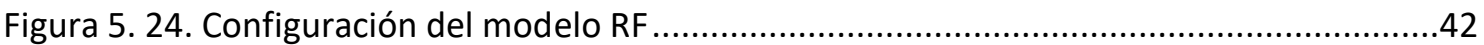

Figura 5. 25. Configuración de características de testeo para validación del modelo RF ...........42

Figura 5. 26. Configuración de parámetros del modelo RF .......................................................43

Figura 5. 27. Configuración de parámetros para la predicción .....................................................44

Figura 6. 1. Importancia de las variables de predicción................................................................46

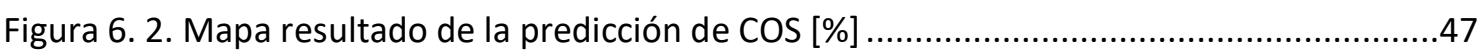

Figura 6. 3. Mapa de resultado de la predicción de $\cos [\mathrm{Mg} / \mathrm{ha}]$.............................................48

Figura 6. 4. Ubicación de puntos de validación en la zona de estudio .....................................50

Figura 6. 5. Valores de COS en los puntos de validación vs COS predicho, unidades [\%] ...........51

Figura 6. 6. Gráficas de error de $\operatorname{COS~[\% ]~en~función~de~las~muestras~de~validación~...................51~}$

Figura 6. 7. Valores de COS de puntos de validación vs COS predicho, unidades $[\mathrm{Mg} / \mathrm{ha}]$.........51

Figura 6. 8. Gráficas de error de $\cos [\mathrm{Mg} / \mathrm{ha}]$ en función de las muestras de validación ...........52 


\section{ÍNDICE DE TABLAS}

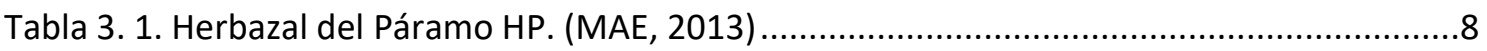

Tabla 4. 1. Descripción de las bandas de las imágenes Landsat 8, (Survey, 2016)......................15

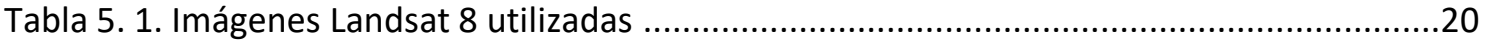

Tabla 5. 2. Índices espectrales calculados y su expresión de acuerdo a las bandas de Landsat 8 29

Tabla 6. 1. Ensayos para la presentación del modelo de COS . .46 


\section{INTRODUCCIÓN}

\subsection{PROBLEMÁTICA Y JUSTIFICACIÓN}

Los ecosistemas de páramo (EP) dominantes se encuentran en un rango altitudinal de 3,000 $-4,700$ msnm, con una extensión superior a 75,000 $\mathrm{km}^{2}$ abarcando territorio en países como Costa Rica, Colombia, Ecuador, Venezuela y Perú. En el Ecuador, el EP ocupa la mayor extensión con respecto a su extensión total (Beltrán et al., 2009). El ecosistema de páramo en Ecuador (EPE) cubre una superficie de $13,372 \mathrm{~km}^{2}$, correspondiente al $5 \%$ del territorio nacional (Hofstede et al., 2014).

El ecosistema páramo es el mayor proveedor de agua del Ecuador, sus suelos son relativamente jóvenes especialmente en zonas de volcanismo activo y la ceniza volcánica aumenta la acumulación de materia orgánica por la formación de complejos organometálicos con aluminio (Al) y hierro ( $\mathrm{Fe}$ ) liberados durante el desgaste de la ceniza. En el Ecuador, los suelos del centro y norte se desarrollaron a partir de la intemperización de las cenizas volcánicas (Hofstede et al., 2014). Actualmente, la zona de transición entre bosque y páramo está bastante afectada, especialmente en las vertientes interandinas. Las actividades actuales en los páramos se encaminan a la ganadería que viene asociada también con la quema de cubierta vegetal; así mismo, los cultivos distintos a los endémicos (Hofstede et al., 2014), producen una modificación en la estructura del suelo, afectando la funcionalidad de los servicios ecosistémicos del EP, la disminución de la capacidad de retención y regulación del agua, así como la acumulación de carbono orgánico.

El clima en el EP es frío con una variación media anual entre $2{ }^{\circ} \mathrm{C}$ y $10{ }^{\circ} \mathrm{C}$ y la temperatura baja entre $0.5^{\circ} \mathrm{C}$ y $0.7{ }^{\circ} \mathrm{C}$ por cada $100 \mathrm{~m}$ de altitud a partir de los $2,000 \mathrm{~m}$ (Mena et al., 2000). Las bajas temperaturas de los EP, reducen la actividad biológica. Como consecuencia, la mineralización de la materia orgánica baja y eso permite su acumulación en grandes cantidades. Así mismo, por efecto de la neblina y lloviznas persistentes, así como la lluvia que varía entre $500 \mathrm{~mm}$ y más de 3,000 mm/año, la humedad del suelo en el EP es permanente y permite su evolución rápida (Mena et al., 2000). Los EP actúan como sumideros por su gran capacidad de retención de carbono en el suelo, incluso similar a la cantidad retenida en la vegetación de una extensión equivalente de bosque húmedo tropical (Hofstede, 2004).

Existe una correlación directa entre el grado de conservación del suelo y la materia orgánica que dispone: a mayor estado de conservación del suelo, éste dispone de mayor cantidad de 
materia orgánica, y por ende mejor almacenamiento de carbono y mejor regulación hídrica. El carbono orgánico del suelo (COS) tiene que ver con el potencial de captura de $\mathrm{CO}_{2}$ por lo tanto,

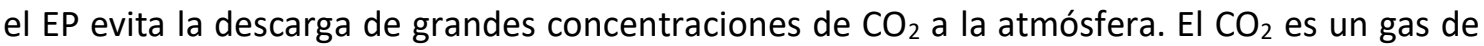
efecto invernadero, pero que en aumento exagerado tiene impacto ambiental negativo por su alta influencia en el cambio climático (González et al., 2003; Herrán, 2012). Estudios indican que 1 ton de $\mathrm{COS}$ equivale a la captura de 3.67 ton de $\mathrm{CO}_{2}$ (Africano et al., 2016). En el Ecuador, la cantidad de carbono que el EP es capaz de almacenar está sobre los 143 ton/ha (0-30 cm de profundidad).

Las estimaciones espaciales del COS son cada vez más importantes para reconocer el potencial de almacenamiento de carbono de los suelos del EP en el contexto del cambio climático. El conocer el estado de conservación del ecosistema permite tomar decisiones y elaborar planes de manejo y gestión ambiental para la preservación de los EP. Sin embargo, los datos de carbono en los suelos de los EP son escasos y los correspondientes a la capa orgánica apenas existen (Ließ et al., 2016). Estudiar la situación actual del EP del Ecuador es una actividad que permitirá la toma de decisiones para el manejo de las tierras en los Andes ecuatorianos (Mcknight, 2015).

Así mismo, es necesario indicar que la dificultad de acceso puede ser abordada mediante el uso de herramientas y análisis a través de los Sistemas de Información Geográfica (SIG), así como la incorporación de imágenes satelitales (Chuvieco, 1995). La posibilidad de estudiar la tierra desde el espacio permite obtener modelos matemáticos y algoritmos que facilitan los procesos mecánicos de las investigaciones (Chuvieco, 2008). Desde este punto de vista, la obtención de resultados precisos junto a la reducción de años en el tiempo de estudio requerido por análisis basados únicamente en técnicas in situ y laboratorio, es una gran ventaja. Encontrar la conexión entre características internas y superficiales en la tierra, ligadas al COS, y poder modelarla sería un gran hallazgo.

Por lo tanto, la necesidad de conocer la distribución espacial del COS en los páramos de Ecuador ha llevado a un equipo de investigación de la Universidad Nacional de ChimborazoEcuador a desarrollar el proyecto de investigación "Soil Organic Carbon Evaluation and Sequestration in Ecuadorian Páramo Ecosystems"- SOCEPE, a través de la dirección del PhD. Víctor García, respaldado por Universidades como ESPOCH-Ecuador, Brock University de Canadá, Universidad Verona y Alcalá de España, UNESCO y a través del Convenio Universidades de la República Popular China con el Gobierno del Ecuador. Este proyecto tiene como objetivo 
la estimación espacial y evaluación del COS en todo el ecosistema páramo ecuatoriano (UNACH, 2016).

El presente estudio es de vital importancia para el cumplimiento de los objetivos del proyecto SOCEPE. La metodología integra técnicas de procesamiento de imágenes multiespectrales, análisis espacial mediante SIG y el uso de algoritmos de autoaprendizaje, para obtener un mapeo digital del COS en el EP Herbazal del Páramo en la provincia de ChimborazoEcuador. Los resultados obtenidos servirán para extender la predicción de COS mediante el algoritmo calibrado en el ecosistema de estudio a nivel nacional. Así mismo, el estudio será referente para nuevas investigaciones a nivel nacional e internacional.

\subsection{OBJETIVOS}

El objetivo principal de este trabajo es mapear de manera digital el carbono orgánico del suelo mediante imágenes satelitales y algoritmos de autoaprendizaje en el ecosistema Herbazal del Páramo, provincia de Chimborazo, Ecuador.

Los objetivos específicos que permitirán alcanzar el objetivo principal son:

- Generar información geográfica georreferenciada a partir de datos in situ, imágenes LANDSAT 8, Modelo Digital de Elevación e información ambiental, relevante en el almacenamiento de COS.

- Calibrar el algoritmo de aprendizaje automático Random Forest, entrenado para la predicción del COS y evaluar su precisión.

- Seleccionar variables indicadoras relevantes en la distribución espacial del COS en el EPE tipo Herbazal del Páramo de la zona de estudio.

- Estimar la cantidad de almacenamiento de COS distribuido en la capa superficial (0-30 cm bajo suelo) del EPE tipo Herbazal del Páramo en el área de estudio.

\section{ANTECEDENTES}

La predicción cuantitativa del carbono del suelo puede lograrse mediante modelos empíricos o mecánicos o una combinación de ambos. El mapeo digital del coS consiste en la aplicación de un modelo empírico que conlleva la utilización de una base de datos de observaciones COS sobre un área de interés, variables relevantes para el área de estudio, la calibración o entrenamiento de una función o modelo de predicción espacial para toda la zona 
de estudio, y finalmente un proceso de validación. Los mapas digitales de COS pueden utilizarse en modelos mecánicos de paisaje simulando la evolución orgánica del carbono (Minasny et al., 2014).

El mapeo digital de COS en los suelos a escala global se considera de vital importancia para la toma de decisiones adecuadas y correctas sobre los usos de la tierra a nivel mundial (Ramifehiarivo et al., 2017). Los métodos utilizados para llegar a mapear el COS son diversos y el reto es encontrar la manera más apropiada y de mejor precisión. El COS obtenido a partir de datos de perfiles de suelo y una generalización de resultados mediante SIG es aplicado a escala regional o nacional. Uno de los métodos es realizar una distribución espacial en SIG a través de una interpolación de muestreos de campo, como es el caso del método inverso de la distancia (Segura et al., 2005). Estudios enfocados en la dinámica de nutrientes de los suelos, en donde el COS es uno de los parámetros más relevantes, obtuvieron una cobertura territorial del COS usando kriging (Arbelo et al., 2008). De este modo, varios países a nivel mundial han empezado a realizar estimaciones de COS en su intento de encontrar metodologías más precisas, como por ejemplo el uso de simulaciones estocásticas, un plan de muestreo y modelos matemáticos (Chartin et al., 2017).

Considerando que la cantidad de secuestro de $\operatorname{COS}$ en el suelo puede estar relacionada a variantes ambientales, investigaciones han incorporado en el mapeo del COS, variables geomorfométricas, variables climáticas, también usos y tipos de suelo, en donde se encontró que algoritmos como Random Forest y máquinas de vectores de soporte, ofrecen mejores resultados (Blanco et al., 2014). Una reciente revisión de modelos predictivos indicó que los modelos de árbol CART y Random Forest, son muy potentes para mapear COS y que además pueden obtener resultados favorables incluso en presencia de conjuntos de datos con inclusión de ruido (Zhang et al., 2017). Con respecto a las variables predictivas para COS, se encontró que la temperatura, precipitación, el Índice de Vegetación de Diferencia Normalizada NDVI (Rouse et al., 1974), podrían estar relacionadas (Ramifehiarivo et al., 2017). La aplicación de los índices derivados de imágenes multiespectrales es muy importante a la hora de realzar y analizar tipos y usos de suelo (Ayala et al., 2017), la capacidad indicadora de los tipos de cubierta vegetal u otros tipos de cubierta del suelo en determinados rangos del espectro electromagnético, hace posible su estudio y discriminación a través de un ajuste matemático entre bandas. Así el suelo desnudo, tipos de cubiertas vegetales, nieve, entre otros, pueden ser evaluados (CONAE, 2016).

Estudios de mapeo digital de COS en el EP son escasos, en los cuales se investiga al COS de manera puntual con análisis estadístico. En el Ecuador, el conocimiento a escala nacional de las 
reservas de COS en el EP es inexistente y a escala regional el conocimiento es reducido. Existen estudios que analizan el COS en el EPE sin tomar en cuenta su distribución espacial (Farley et al., 2004). Luego de identificar el gran potencial del EP como sumidero de COS, así como la necesidad latente de avanzar a una amplia investigación experimental en el tema (Farley et al., 2012), se han desarrollado avances en el análisis de metodologías para la predicción del COS en el EPE (Ließ et al., 2016). La complejidad paisajística del suelo en los EPE y su difícil accesibilidad plantean un desafío para el análisis de distribución espacial (Ließ et al., 2016), por eso una metodología adecuada con el hallazgo de indicadores adecuados para este tipo de ecosistema se considera un gran aporte científico.

En el Ecuador, el EP tipo Herbazal del Páramo (HP) de código HsSn02 según el Ministerio del Ambiente del Ecuador (MAE, 2013), identificado también como Páramo Herbáceo y conocido como pajonales altimontanos y montanos paramudos; cubre una superficie de 10,520.06 km², de los cuales el 15.9 \% se encuentra concentrado en la provincia de Chimborazo, razón por la que la provincia de Chimborazo ha sido tomada por el proyecto SOCEPE como referente para el mapeo digital del COS en todo el territorio Ecuatoriano.

\section{ZONA DE ESTUDIO}

\subsection{DESCRIPCIÓN GENERAL DE LA ZONA DE ESTUDIO}

La zona de estudio corresponde al ecosistema páramo, subtipo de ecosistema Herbazal del Páramo (HP) en la provincia de Chimborazo, Ecuador, sobre la cordillera de los Andes, ver Figura 3.1. Chimborazo está situada a $135 \mathrm{~km}$ al sur de la ciudad de Quito y se extiende entre las coordenadas: $78^{\circ} 39^{\prime}$ de longitud Oeste y $1^{\circ} 39^{\prime}$ de latitud Sur, definida entre las coordenadas UTM Zona 17 Sur, Datum WGS84 ( $X=694,531 ; Y=9,840,051)$ y $(X=789,975 ; Y=9,714,929)$ y su capital es la ciudad de Riobamba. La provincia de Chimborazo se encuentra en la zona centro del país, tiene una superficie aproximada de $6,499.7 \mathrm{~km}^{2}$, de los cuales $1,667.6 \mathrm{~km}^{2}$ corresponden al HP, equivalente al $25.7 \%$ de la superficie total de la provincia.

La provincia de Chimborazo tiene topografía irregular que se encuentra en un rango altitudinal de 143 a 6,263 msnm. El ecosistema Herbazal del Páramo comprende alturas que varían entre los 2,303 a 4,501 msnm. El clima es propio de la sierra ecuatoriana, registrando en el HP una temperatura media entre $2{ }^{\circ} \mathrm{C}$ y $16{ }^{\circ} \mathrm{C}$ según las isotermas del Instituto Nacional de Meteorología e Hidrología del Ecuador (INAMHI) (SNI ECUADOR - INFOPLAN, 2011). 


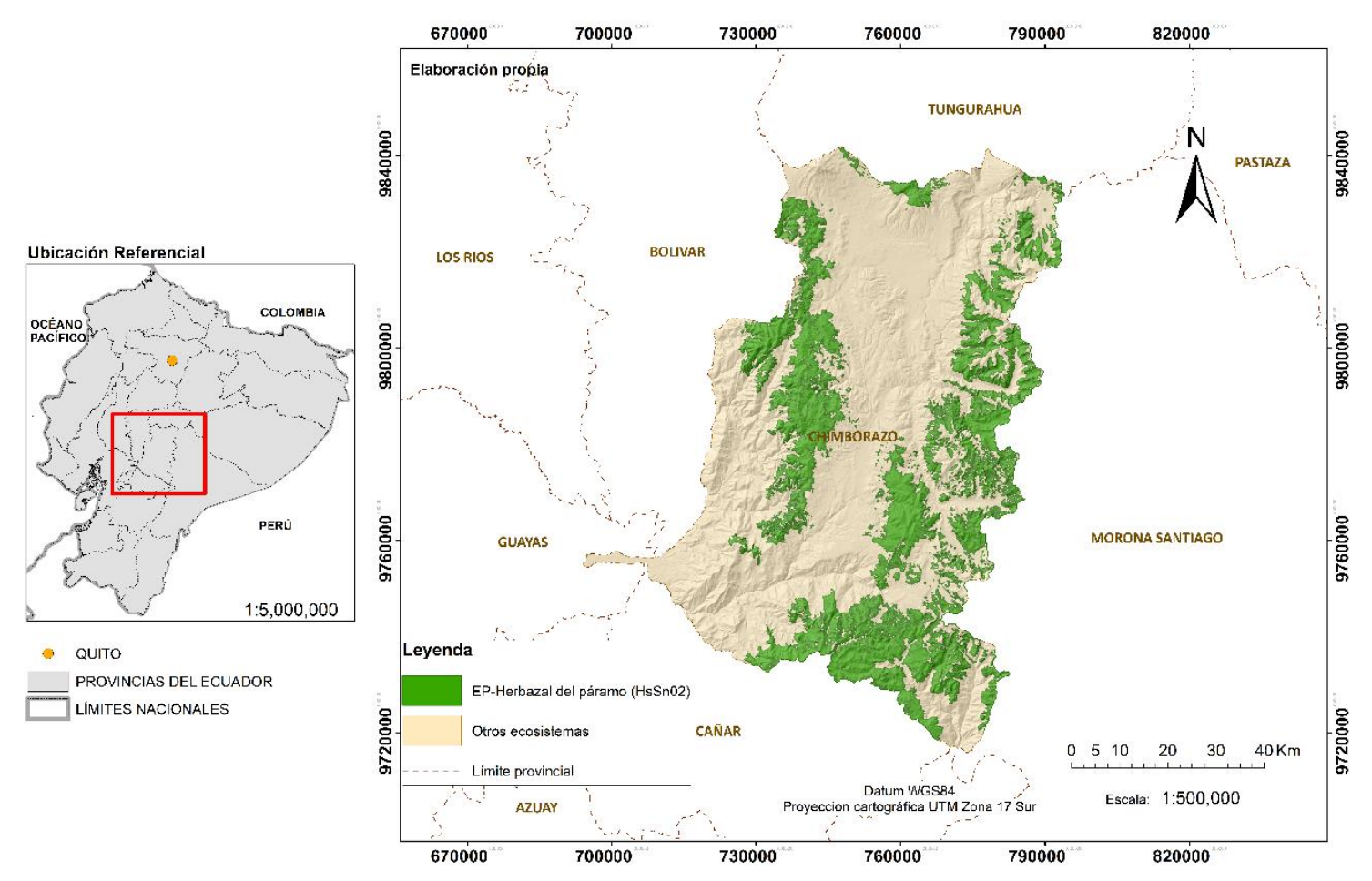

Figura 3. 1. Área de estudio-provincia de Chimborazo

\subsection{DESCRIPCIÓN DEL ECOSISTEMA HERBAZAL DEL PÁRAMO EN EL ECUADOR}

El ecosistema HP abarca la mayor extensión de los ecosistemas de montaña en el Ecuador y se extiende a lo largo de las dos cordilleras de los Andes, desde la provincia del Carchi hasta la provincia de Loja (Beltrán et al., 2009). Se caracteriza por el paisaje de los ecosistemas altoandinos del Ecuador y se localiza generalmente en los valles glaciares, laderas y llanuras montañosas sobre los 3,300 m de elevación, ver Figura 3.2. Son ricos en carbono orgánico (COS) y las condiciones climáticas de alta humedad y la alta concentración de carbono orgánico en el suelo determinan que este ecosistema se caracterice por contener una gran cantidad de agua por unidad de volumen y con excelente capacidad de regulación hídrica (Ministerio de Ambiente del Ecuador, 2012). 


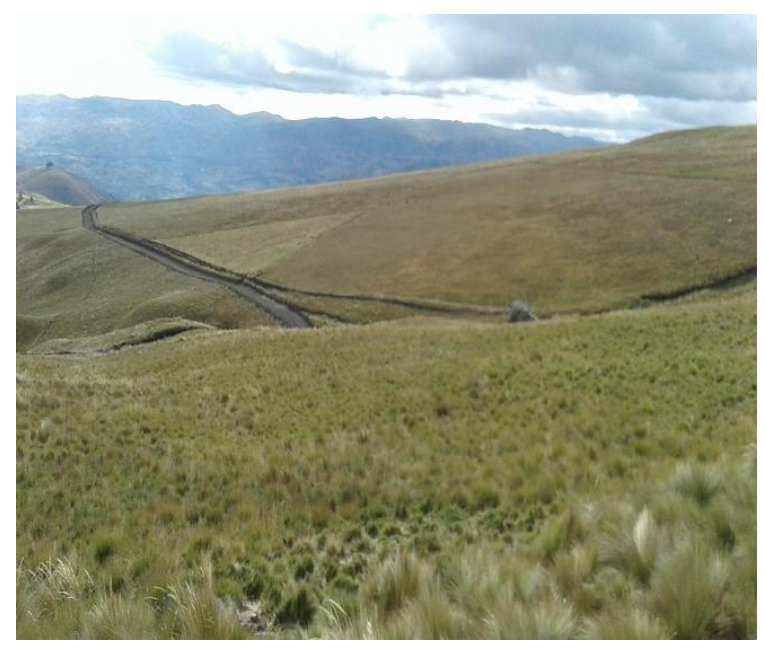

a)

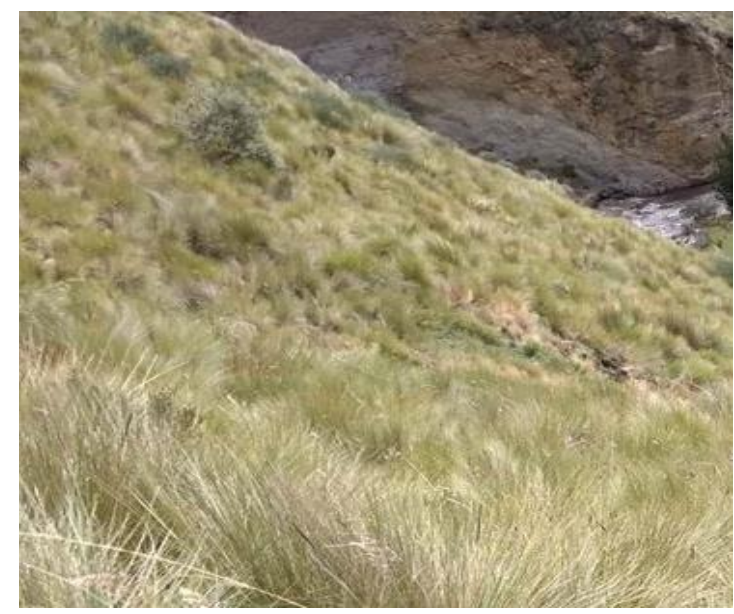

c)

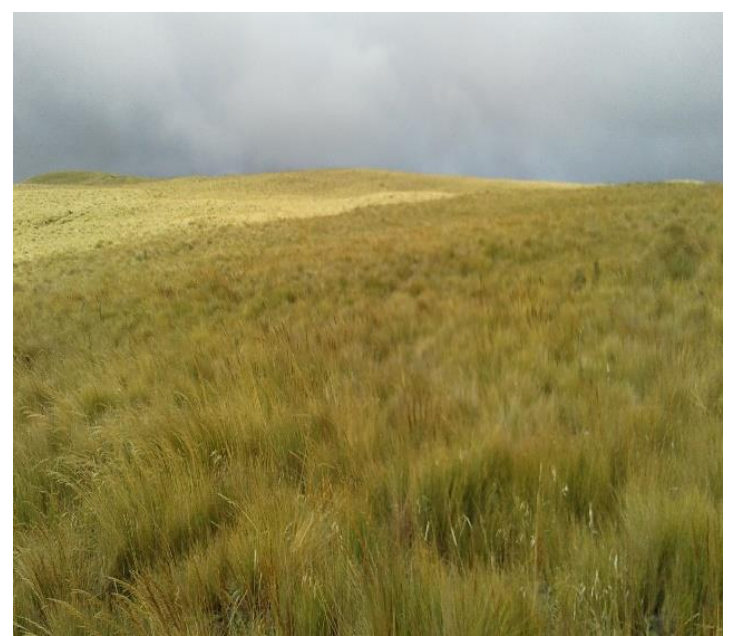

b)

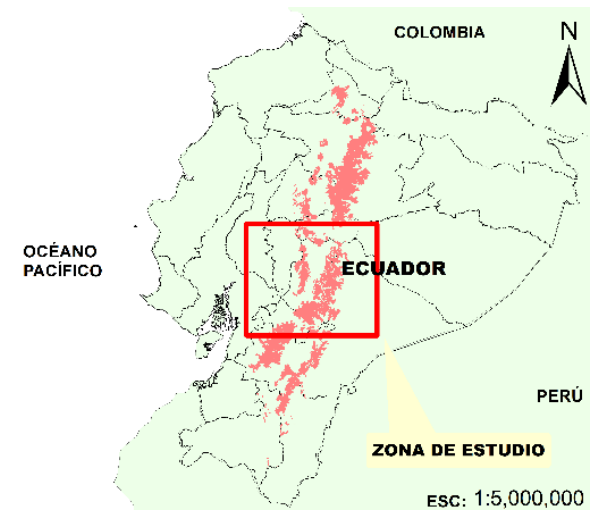

d)

Figura 3. 2. a), b), c) Ecosistema Herbazal del Páramo-Chimborazo; d) En coloración roja la distribución del ecosistema Herbazal del Páramo en el Ecuador.

Actividades antrópicas como quemas de coberturas de suelo y actividades ganaderas pueden afectar la estructura y composición de la vegetación de este ecosistema. En lugares donde existe una mayor intensidad en las quemas y el pastoreo, los herbazales tienen una menor altitud, han perdido biomasa y el estrato arbustivo está ausente. Este ecosistema está caracterizado por tener una vegetación densa dominada por gramíneas amacolladas. Los arbustos y las pajas amacolladas desaparecen gradualmente a lo largo del gradiente de elevación y son reemplazados en importancia por los cojines, rosetas acaulescentes, arbustos postrados y hierbas de tallo corto. La composición y fisonomía de estos herbazales difieren altitudinal y latitudinalmente, así como también factores tales como el clima, la historia geológica, la diversidad de hábitats junto con la influencia humana configuran la diversidad de la biota del páramo (MAE, 2012). 
El Herbazal del Páramo es un ecosistema clasificado como ecosistema de formación vegetal y sus características se observan en la Tabla 3. 1.

Tabla 3. 1. Herbazal del Páramo HP. (MAE, 2013)

\begin{tabular}{|c|c|}
\hline Fisonomía & Herbácea \\
\hline Bioclima & Pluvial. Ombrotipo: Hiperhúmedo \\
\hline Biogeografía & $\begin{array}{l}\text { Región: Andes } \\
\text { Provincia: Andes del Norte. } \\
\text { Sector: Páramo }\end{array}$ \\
\hline Fenología & Siempreverde \\
\hline Piso bioclimático & $\begin{array}{l}\text { Montano alto y montano alto superior (3,400-4,300 msnm N - 2900-3,900 msnm S) } \\
\text { Termotipo (It): supratropical a orotropical }\end{array}$ \\
\hline Geoforma & $\begin{array}{l}\text { Relieve general: de montaña } \\
\text { Macrorelieve: Valle Glaciar, Cordillera } \\
\text { Mesorelieve: Llanura subglaciar, Vertientes disectadas }\end{array}$ \\
\hline $\begin{array}{l}\text { Inundabilidad } \\
\text { general }\end{array}$ & Régimen de Inundación: no inundable \\
\hline
\end{tabular}

\subsection{INFORMACIÓN EXISTENTE}

$\underline{\text { Información }}$

El proyecto SOCEPE cuenta con información de datos in situ, que corresponden muestreos de carbono orgánico del suelo (COS) en el EPE tipo HP, basados en muestras recolectadas en el horizonte de capa superficial ( $0-30 \mathrm{~cm}$ bajo suelo) y con las lecturas de $\mathrm{pH}$ del suelo asociadas a las muestras.

La información entregada proviene de una estratificación de unidades de muestreo en el ecosistema Herbazal del Páramo basada en la geología y taxonomía del suelo; utilizando un muestreo aleatorizado considerando el error de muestreo y un nivel de confianza del $95 \%$ (Galmés, 2011). La recolección de muestras in situ es obtenida mediante barrenación, ver Figura 3.3 a) y b). En el laboratorio de servicios ambientales de la UNACH, el personal del proyecto 
SOCEPE obtuvo el porcentaje (\%) de COS almacenado en el suelo a través de la cuantificación de la materia orgánica (MO) por calcinación y el factor Van Bemmelen (Van Bemmelen, 1891), para cada una de las muestras, ver Figura 3.3 c), d), e), f) y g). La posición asociada a las muestras de suelo fue registrada mediante GPS en forma aislada, con el GPS de mano marca Trimble JUNO, SW Terrasinc Profesional. Las muestras fueron tomadas en las zonas céntrica de las unidades, evitando errores asociados a la precisión de la posición. Suman un total de 501 puntos de muestreo que corresponden a las 501 muestras de suelo procesadas en laboratorio, ver Figura $3.3 \mathrm{~h}$ ), con su respectiva información de posición espacial (coordenadas UTM zona 17 S, WGS84) y su correspondiente valor porcentual [\%] de COS, así como COS en [Mg/ha].

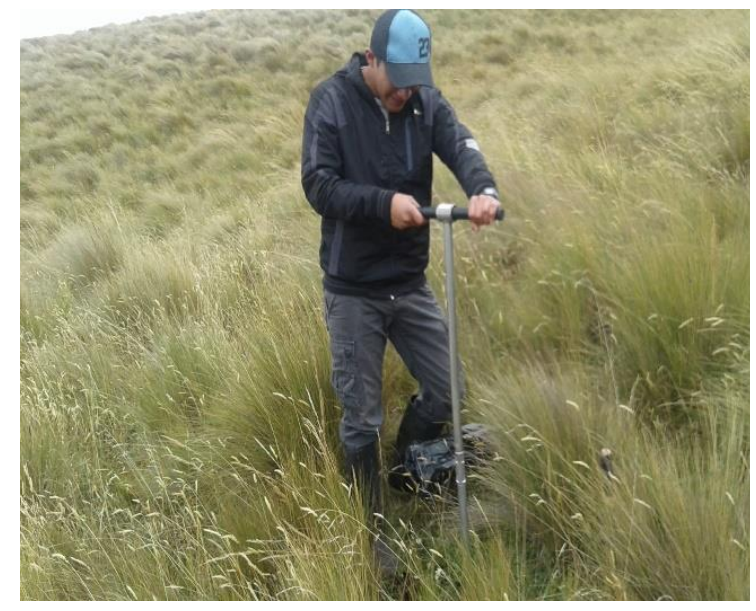

a)

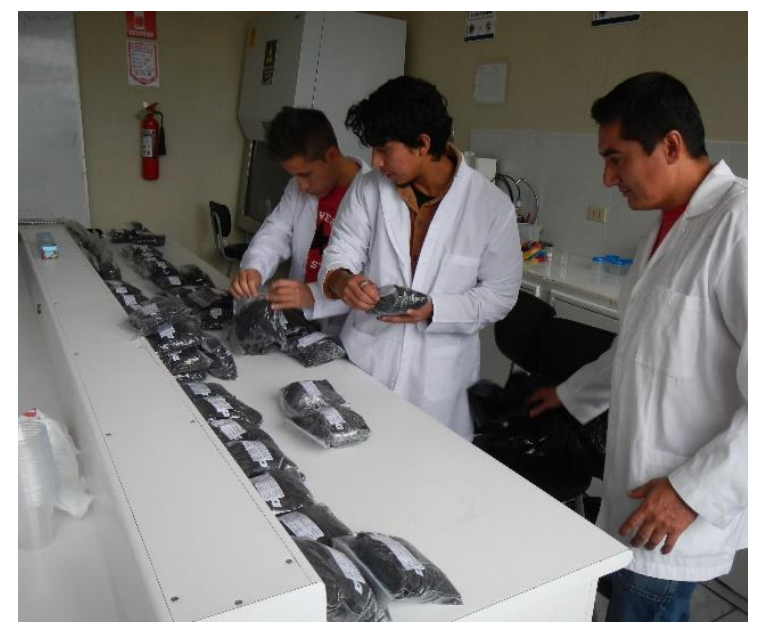

c)

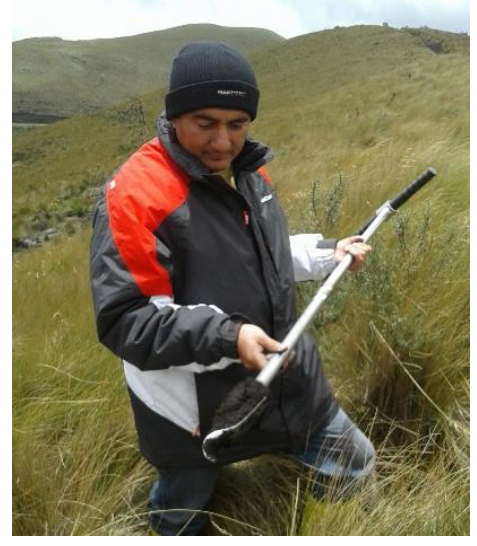

b)

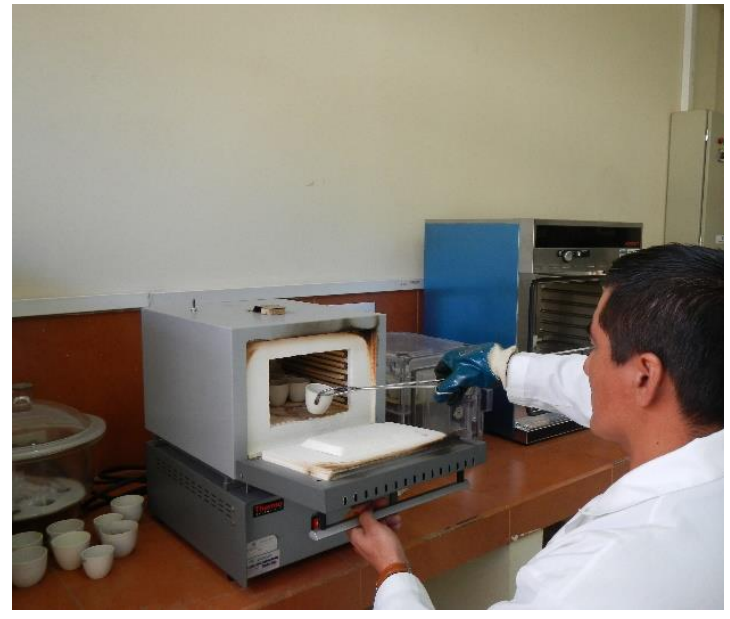

d) 


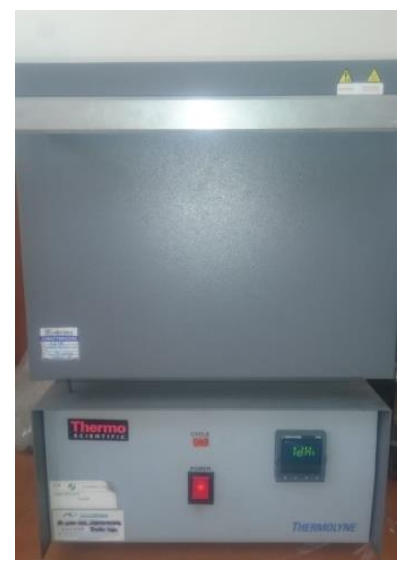

e)

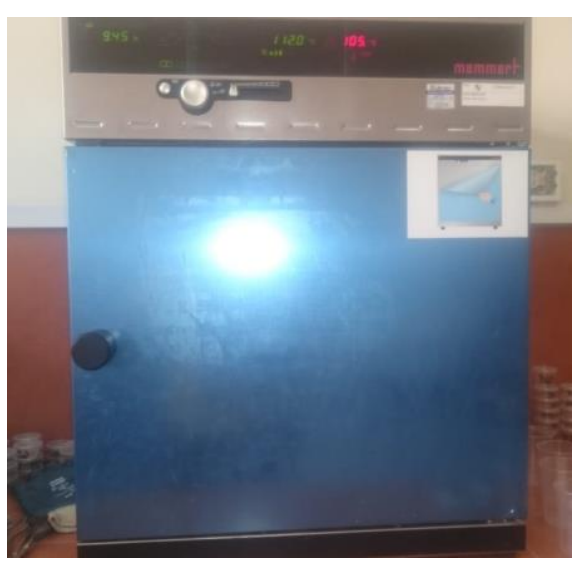

f)

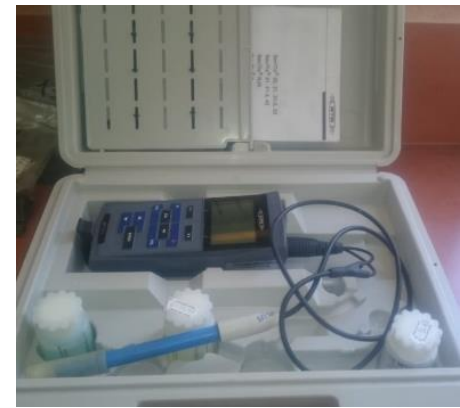

g)

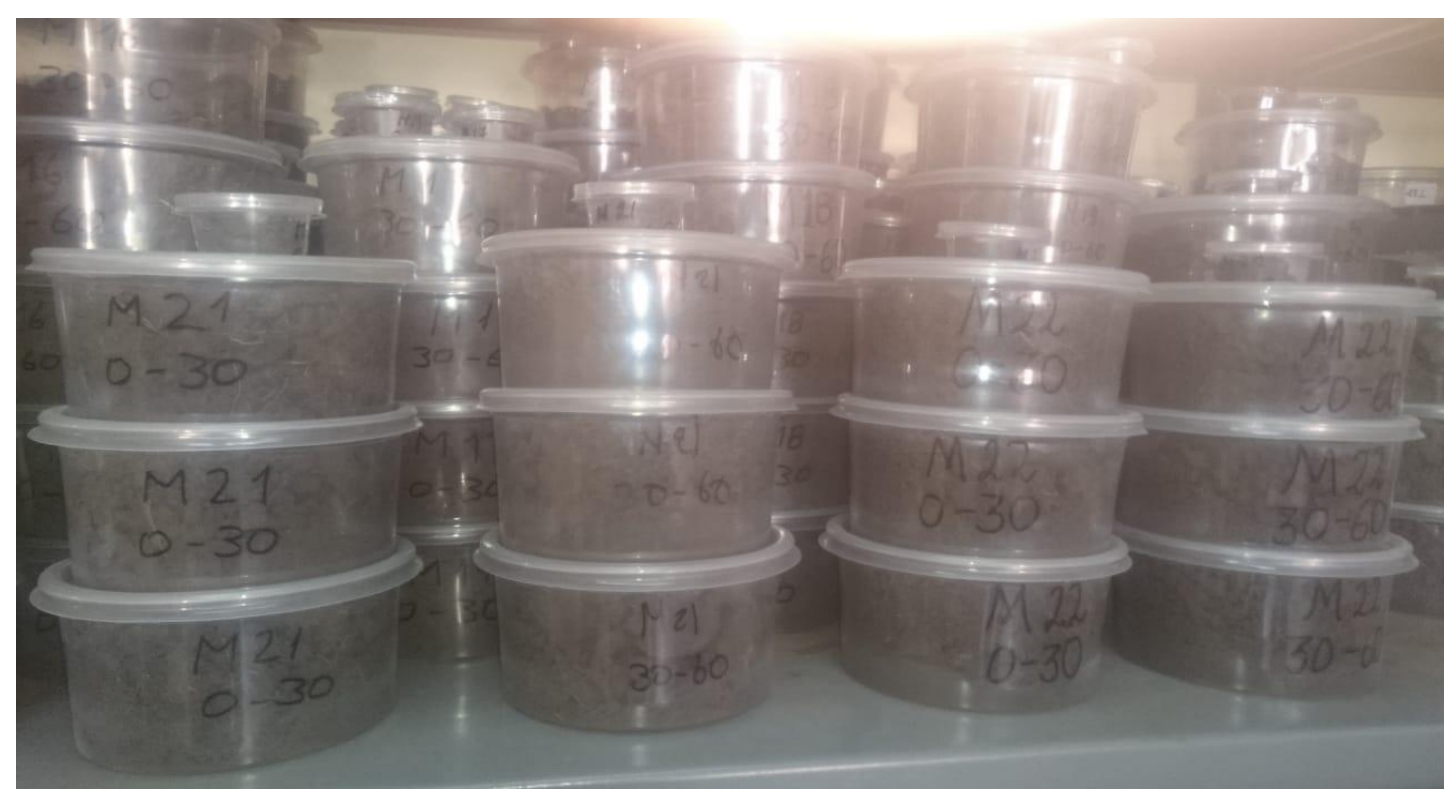

h)

Figura 3. 3. a) y b) Recolección de muestras de suelo in situ; c) y d) Análisis de laboratorio para determinar cOS a partir de las muestras de suelo recolectadas in situ; e) Mufla marca Thermo Scientific -Lab Servicios AmbientalesUNACH; f) Estufa marca Memmert- Lab Servicios Ambientales-UNACH; g) pHachímetro- Lab Servicios AmbientalesUNACH; h) Muestras de suelo de la zona de estudio.

\section{Información geográfica}

Se dispone de la cartografía base de la provincia de Chimborazo, así también de todo el Ecuador que incluyen ecosistemas, geología, taxonomía del suelo, incluyendo el modelo digital de elevación (MDE) en una resolución de $30 \mathrm{~m}$ a través de INFOPLAN Ecuador. (SNI ECUADOR INFOPLAN, 2011) 


\section{MARCO TEÓRICO}

\subsection{SUELOS DEL ECOSISTEMA PÁRAMO}

Los suelos del páramo son jóvenes, su formación se inicia 10,000 años atrás, con la meteorización de roca descubierta al cabo de las últimas glaciaciones (Pleistoceno), cuando la totalidad de la extensión de páramo estuvo cubierta de hielo. En zonas donde hay volcanismo activo, el suelo tiene que formarse con cenizas volcánicas de edad todavía más reciente. De igual manera, gracias a las bajas temperaturas, el proceso de formación de suelo es lento. Al contrario de lo que sucede con las tierras bajas, los suelos de páramo tienen esta elevada concentración de materia orgánica y además son muy profundos (hasta varios metros). Gracias a esto, la cantidad total de carbono almacenada por hectárea de páramo puede ser mayor que la de una selva tropical (Hofstede et al., 2014).

\subsection{CARBONO ORGÁNICO DEL SUELO (COS)}

El COS es el carbono (C) que permanece en el suelo después de la descomposición parcial de cualquier material producido por organismos vivos. Constituye un elemento primordial del ciclo global del carbono a través de la atmósfera, vegetación, suelo, ríos y océano. El COS es el componente principal de la materia orgánica del suelo (MOS) y, como tal, constituye el combustible de cualquier suelo. La MOS contribuye a funciones clave del suelo, ya que es fundamental para la estabilización de la estructura del suelo, la retención y liberación de nutrientes vegetales, y permite la infiltración y almacenamiento de agua en el suelo. La pérdida de COS indica un cierto grado de degradación del suelo (FAO, 2017).

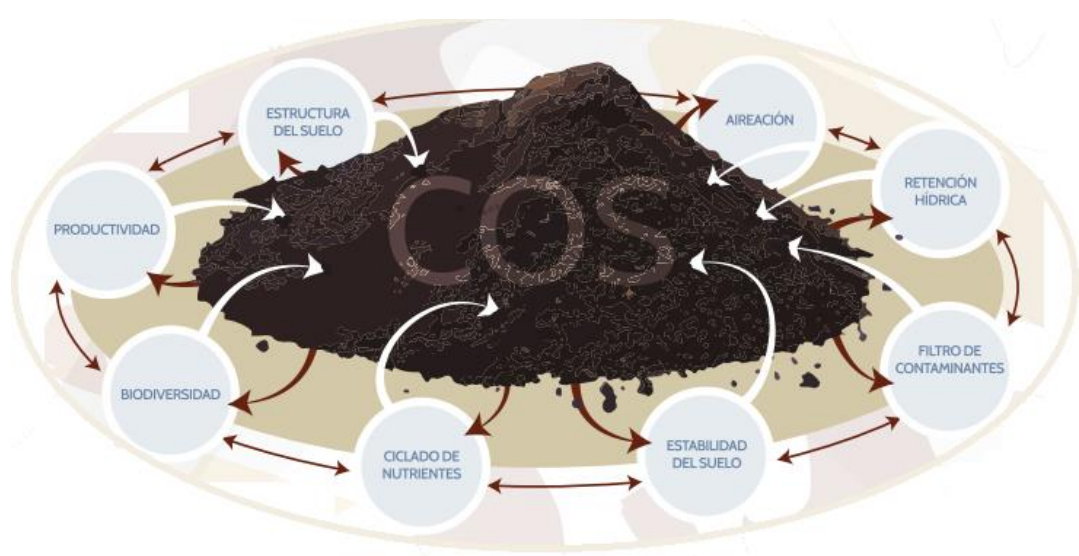

Figura 4. 1. Funciones del COS. (FAO, 2017)

\subsection{GEOLOGÍA Y TAXONOMÍA DEL SUELO}

La geología de los suelos tiene que ver con su origen y evolución en el paso de los tiempos. En el Ecuador se encuentran los siguientes geosistemas: (a) Las frías cimas de las cordilleras 
andinas con presencia de conos de volcanes de diferentes edades y poco desarrollados, suelos negros con alto contenido de materia orgánica; (b) Laderas exteriores de los Andes, con modelado vigoroso sobre diversas rocas antiguas muy diseccionadas. El clima es húmedo a húmedo con presencia de nubes pesadas, condición que favorece la formación de zonas boscosas perennes. Se tiene cobertura parcial de cenizas volcánicas recientes y rejuvenecidos por la erosión; (c) Cuencas interandinas de la Sierra norte con rellenos de sedimentos de origen volcánico, donde la evidente morfogénesis volcánica fue promovida por la presencia de estratovolcanes recientes, grandes y activos; (d) Cuencas interandinas de la sierra central sobre una base antigua, volcánica y metamórfica, sin la presencia de volcanes activos o reciente cobertura piroclástica. Esta zona está fragmentada en dos conjuntos de cuencas sedimentarias paralelas con un relieve distribuido en una secuencia topo-climática donde los suelos de la parte superior son ferralíticos, a menudo con alto contenido de humus, los suelos de la zona media evolucionan moderadamente y los suelos de la parte inferior están poco desarrollados; (e) Muescas y valles fluviales interandinos, con suelos aluviales relativamente ricos y con actividad agrícola diversa; (f) Alivios de la Sierra Sur, ubicados en una secuencia de suelos paleo-topoclimáticos de valles grandes y depresiones ortogonales donde existe una clara estratificación del clima húmedo al árido. (Moreno et al., 2018)

Los nombres de las formaciones geológicas suelen relacionarse al sitio al que pertenecen, la zona de estudio abarcando 31 formaciones geológicas según la cartografía de INFOPLAN (SNI ECUADOR - INFOPLAN, 2011).

La taxonomía del suelo es un sistema de clasificación de suelos, en donde, se considera que el suelo es un cuerpo natural que comprende a sólidos (minerales y materia orgánica), líquidos y gases que ocurren en la superficie de las tierras, que ocupa un espacio y que se caracteriza por uno o ambos de los siguientes: horizontes o capas que se distinguen del material inicial como resultado de adiciones, pérdidas, transferencias y transformaciones de energía y materia o por la habilidad de soportar plantas en un ambiente natural (USDA \& NRCS, 2014). La Taxonomía de Suelos de USDA es el sistema nacional de clasificación de los suelos de Estados Unidos y es reconocido en América Latina y Asía.

\subsection{ESPECTRO ELECTROMAGNÉTICO Y SU RELACIÓN CON LAS FIRMAS ESPECTRALES}

El espectro electromagnético se puede expresar como cualquier tipo de energía radiante en función de la longitud de onda o frecuencia, aunque la sucesión de valores de longitud de onda es continua, se pueden establecer una serie de bandas en donde la radiación 
electromagnética presenta un comportamiento similar. La organización de bandas de longitudes de onda o frecuencia se denomina espectro electromagnético. En teledetección ambiental suele utilizarse mucho el espectro visible (0.4-0.7 $\mu \mathrm{m})$ distinguiendo las bandas azul, verde y rojo; también el espectro correspondiente al infrarrojo cercano $(0.7-1.3 \mu \mathrm{m})$ por su capacidad para discriminar masas vegetales y concentraciones de humedad; el infrarrojo medio (IRM) (3-5 $\mu \mathrm{m})$ en la detección de focos de temperatura; también el espectro infrarrojo de onda corta (SWIR) (1.3-2.5 $\mu \mathrm{m})$ usado para detectar humedad en los suelos y/o vegetación. (Chuvieco, 2008)

Las firmas espectrales vienen a ser la manera en la que se comportan las diferentes superficies a distintas longitudes de onda y de esta manera las superficies pueden ser estudiadas por su firma espectral en términos de reflectividad (ver Figura 4.2). La vegetación presenta un comportamiento cromático con baja reflectividad en el espectro visible, en el infrarrojo cercano se tienen valores más elevados y menores en el infrarrojo medio.

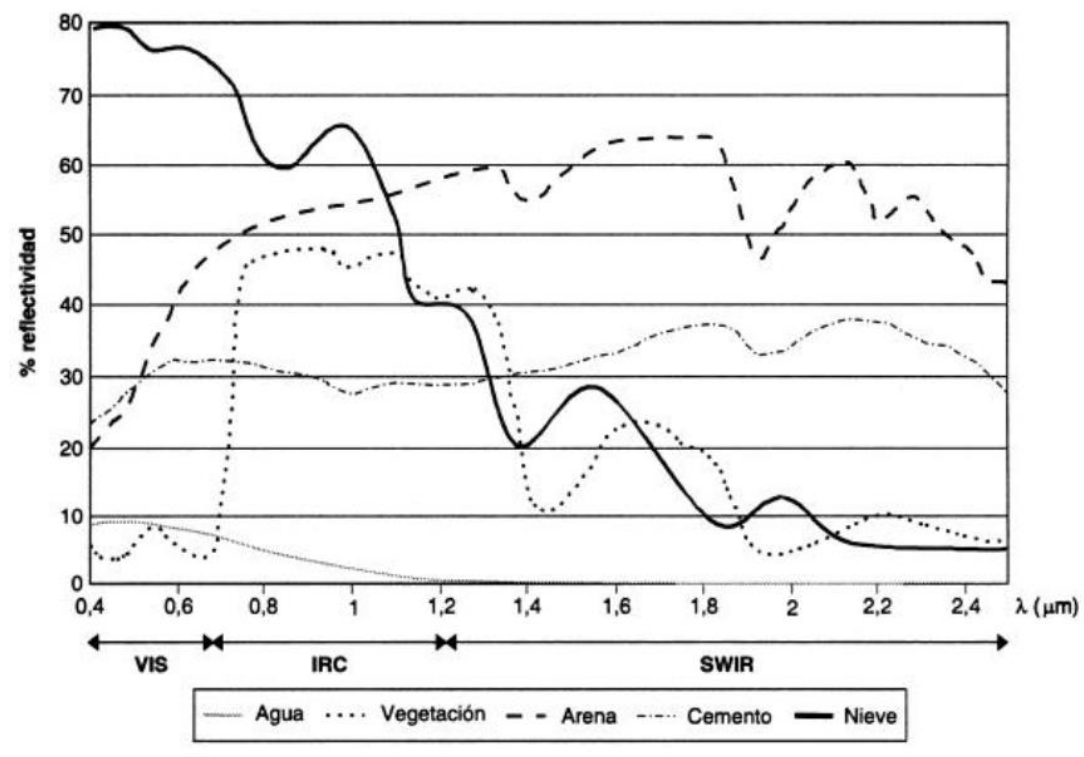

Figura 4. 2. Firmas espectrales de distintas cubiertas, (Chuvieco, 2008)

\section{5. ÍNDICES ESPECTRALES}

Las observaciones ambientales a través de sensores remotos pueden llegar a ser muy complejas dado que el comportamiento de una cubierta ya sea de origen vegetal u otra depende de otros factores externos que modifican el comportamiento espectral teórico, así es el caso de factores relacionados al relieve, ángulos de iluminación, variaciones ambientales, influencia atmosférica, condiciones fenológicas, características edáficas, entre otros (Chuvieco, 2008). 
El ecosistema de estudio desde el punto de vista superficial es una cubierta de tipo vegetal en donde actividades antrópicas tales como la quema de cobertura podrían alterar su estructura y características en condiciones naturales.

Los índices de vegetación (IV) permiten discriminar el comportamiento reflectivo de la vegetación evaluándola de manera cualitativa y cuantitativa a través de los canales espectrales. Los IV disponibles son numerosos, existen varias comparaciones de los mismos que discuten su utilidad (Bannari et al., 1995). Con el fin de detectar un IV más adecuado para el Herbazal del Páramo, varios IV fueron evaluados. También, es posible usar índices espectrales para otras cubiertas del suelo como es el caso del suelo desnudo a través del Bare Index (Li \& Chen, 2014) o lugares quemados (López \& Caselles, 1991).

\section{6. ÍNDICES Y VARIABLES TOPOGRÁFICAS}

Los índices y variables topográficas permiten conocer distintas cualidades del suelo basados en su topografía. El ecosistema de estudio se encuentra en zonas alto andinas, el uso de variables topográficas en forma aislada como es el caso de la elevación, pendiente y orientación, así como en forma conjunta a través de índices; permiten caracterizar el suelo desde este punto de vista y buscar una posible relación con cantidad de COS.

\subsubsection{PENDIENTE Y ORIENTACIÓN}

Para cada punto del paisaje topográfico $\{X, Y\}$ la tasa de cambio de la elevación en las direcciones $X, Y$ puede usarse para identificar la magnitud y la dirección del gradiente más inclinado del campo de elevación topográfica, $\mathrm{h}(\mathrm{X}, \mathrm{Y})$. La pendiente local S se define como la magnitud del gradiente mientras que el aspecto u orientación $(\alpha)$ es su dirección (Vico \& Porporato, 2009).

\subsubsection{FACTOR LS}

El Factor LS describe el efecto de la topografía en la erosión del suelo; el factor $L$ da el impacto de la longitud de la pendiente mientras que el factor $\mathrm{S}$ explica el efecto de la inclinación de la pendiente (Panagos et al., 2015), que es muy útil a la hora de explicar la erosión del suelo en topografías complejas (Desmet \& Govers, 1996).

\subsection{VARIABLES CLIMÁTICAS}

La temperatura y la precipitación, son factores que determinan en alto grado a la distribución de la vegetación (MAE, 2012). El COS es cuantificado en función de la MO presente en los suelos (Van Bemmelen, 1891). A bajas temperaturas la actividad biológica se reduce, 
disminuyendo la mineralización de la materia orgánica; esto permite la acumulación de COS en grandes cantidades.

El estudio observacional de las variables temperatura y precipitación se basa en mediciones de estaciones meteorológicas, distribuidas sobre y en torno de un territorio de interés a través de sensores de temperatura ambiente y sensores pluviométricos para el caso de la precipitación. La temperatura de la superficie terrestre puede ser estudiada a través de sensores térmicos en las plataformas satelitales como es el caso de Landsat 8 Sensor Thermal Infrared Sensor (TIRS) (Survey, 2016).

\subsection{IMÁGENES SATELITALES LANDSAT 8}

El satélite Landsat 8 de órbita helio-sincrónica a 705 km del ecuador terrestre incorpora dos instrumentos de barrido: Operational Land Imager (OLI) con 9 bandas que capturan el espectro visible, infrarrojos y espectros de radiación de ondas bajas y un sensor Thermal Infrared Sensor (TIRS) que detecta infrarrojos térmicos y es usado para medir la temperatura de la superficie de la Tierra. La resolución radiométrica de las imágenes Landsat 8 es de 16 bits, la resolución temporal es de 16 días y son imágenes de acceso libre, cuyas características se resumen en la Tabla 4.1. (Survey, 2016)

Tabla 4. 1. Descripción de las bandas de las imágenes Landsat 8, (Survey, 2016)

\begin{tabular}{lllll}
\hline Sensor & \# Banda & $\begin{array}{l}\text { Resolución } \\
\text { espacial }\end{array}$ & Banda & $\begin{array}{l}\text { Longitud de } \\
\text { onda }(\mu \mathrm{m})\end{array}$ \\
\hline \multirow{6}{*}{ OLI } & Banda 1 & $30 \mathrm{~m}$ & Aerosol costero & $0.435-0.451$ \\
& Banda 2 & $30 \mathrm{~m}$ & Azul & $0.452-0.512$ \\
& Banda 3 & $30 \mathrm{~m}$ & Verde & $0.533-0.590$ \\
& Banda 4 & $30 \mathrm{~m}$ & Rojo & $0.636-0.673$ \\
& Banda 5 & $30 \mathrm{~m}$ & Infrarrojo Cercano (NIR) & $0.851-0.879$ \\
& Banda 6 & $30 \mathrm{~m}$ & SWIR-1 & $1.566-1.651$ \\
& Banda 7 & $30 \mathrm{~m}$ & SWIR-2 & $2.107-2.294$ \\
& Banda 8 & $15 \mathrm{~m}$ & Pancromática & $0.503-0.676$ \\
& Banda 9 & $30 \mathrm{~m}$ & Cirrus & $1.363-1.384$ \\
& Banda 10 & $100 \mathrm{~m}$ & Infrarrojo térmico (TIRS) 1 & $10.60-11.19$ \\
& Banda 11 & $100 \mathrm{~m}$ & Infrarrojo térmico (TIRS) 2 & $11.50-12.51$ \\
\hline
\end{tabular}

\subsection{RANDOM FOREST}

Random Forest $(R F)$, es un algoritmo de autoaprendizaje basado en la combinación de árboles de decisión. Cada árbol depende de los valores de un vector aleatorio muestreado en forma independiente y que tiene la misma distribución para todos los árboles del bosque. El error depende de la importancia de los árboles individuales y la correlación entre ellos. La predicción mediante RF busca obtener un valor cuantitativo como resultado de la predicción 
(regresión), el predictor de árbol toma valores numéricos en lugar de etiquetas de clase y el conjunto de entrenamiento se extrae independientemente de la distribución del vector aleatorio. Una de las ventajas de RF es que es robusto ante la presencia de ruido, es decir la presencia de datos anómalos (Breiman, 2001).

\subsubsection{ALGORITMO DE PREDICCIÓN DE RANDOM FOREST}

El algoritmo de aprendizaje automático que emplea RF en regresiones tiene en su estructura árboles de clasificación y regresión (Clasification and Regression Trees-CART) (Breiman et al., 2017). CART, es un algoritmo basado en árboles de decisión. En una regresión, CART escoge las mejores variables y los puntos de división para reducir el criterio de error cuadrático y absoluto. Las divisiones o particiones de las variables predictivas $\left(x_{1}, x_{2}, \ldots x_{n}\right)$ generan regiones con las que la variable dependiente $(\mathrm{Y})$ puede ser predicha con mayor precisión. En el presente estudio la variable (COS) es la variable dependiente.

\section{Algoritmo de CART}

A partir del conjunto de datos de entrenamiento compuesto de la variable dependiente $(\mathrm{Y})$ $\mathrm{y}$ los predictores $\left(\mathrm{X}_{1}, \mathrm{X}_{2}, \ldots \mathrm{X}_{n}\right)$, se genera un árbol. Empieza en un nodo de inicio (root node), los nodos son las bases en donde se construyen los árboles de decisión. Los árboles de decisión pueden tener ramificaciones también conocidas como particiones (Split de la variable) y si no tienen ramificación son llamados nodos terminales. En la creación del árbol todas las variables son consideradas en la selección de cada Split. Cada Split se realiza en referencia a una sola variable y un valor o conjunto de valores. El Split usado es el que genera menor error en el modelo. El árbol crece hasta que no se puede volver a particionar o bajo especificación externa (del usuario). La Figura 4.3, muestra el proceso seguido para calcular el mejor Split.

En sí, en el proceso de creación del árbol todas las variables son consideradas en cada Split, pero cada quiebre se realiza usando una sola variable y un valor o conjunto de valores. El mejor quiebre se escoge cuando el modelo minimiza el error. El software internamente entonces, por predictor, ordena sus valores de manera ascendente, con ellos sus valores correspondientes a la variable dependiente (COS) y a su vez los demás predictores $\left(X_{1}, X_{2}, \ldots X_{n}\right)$ del registro; luego, se busca el mejor Split basado en un ajuste por mínimos cuadrados. Cuando el proceso es realizado para todos los predictores, CART ha evaluado todos los posibles puntos de partición para cada variable predictiva y determinado el mejor Split de cada una; CART hace una comparación entre los mejores Split de cada posible predictor y elije el Split basado en el indicativo de la desviación estándar de cada opción. 


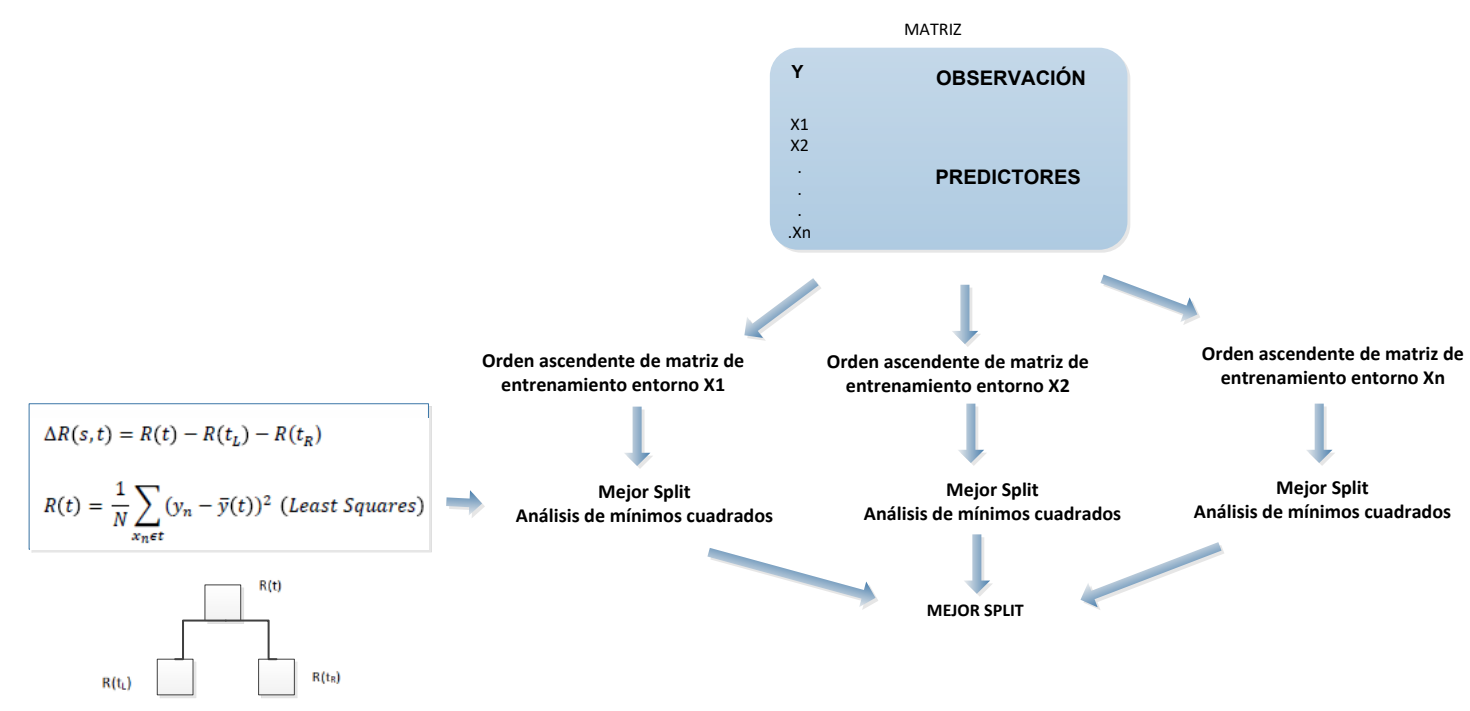

Figura 4. 3. Algoritmo de selección del mejor Split. (SALFOR SYSTEMS A MINITAB, 2017)

\section{Algoritmo de regresión de Random Forest (RF)}

El algoritmo ajusta múltiples arboles CART a muestras independientes bootstrap de datos y luego combina las predicciones. Un bootstrap es una muestra aleatoria con fines de reemplazo, se crea seleccionando de manera aleatoria un registro por vez de los datos originales y una observación puede ser elegida más de una ocasión; el proceso es realizado hasta completar la misma cantidad de registros de los datos originales.

En cada bootstrap se crea un árbol CART, y en cada partición del árbol se consideran solo $\mathrm{K}$ variables seleccionadas al azar en lugar de todas. El proceso es realizado $\mathrm{M}$ veces de acuerdo al número de bootstrap creados. Al final se tiene un registro de predicción por cada árbol, la predicción final es el resultado del promedio de M predicciones, ver Figura 4.4. El rendimiento del algoritmo depende de parámetros como $\mathrm{K}$ y M, configurados. De esta manera la predicción de Random Forest es un promedio de la predicción de los árboles CART creados en cada bootstrap (de 1 - M).

Es decir, cada uno de los registros de la matriz a predecir el valor de COS, son sometidos hacia abajo en cada árbol de decisión de los bootstrap, generando al final de su paso una predicción basada en el CART del bootstrap (1-M), luego las predicciones son promediadas generando una predicción de COS para la combinación de predictores dada por el usuario y que desde luego deben hacer referencia a los predictores del modelo hallado. (SALFOR SYSTEMS A MINITAB, 2017) 


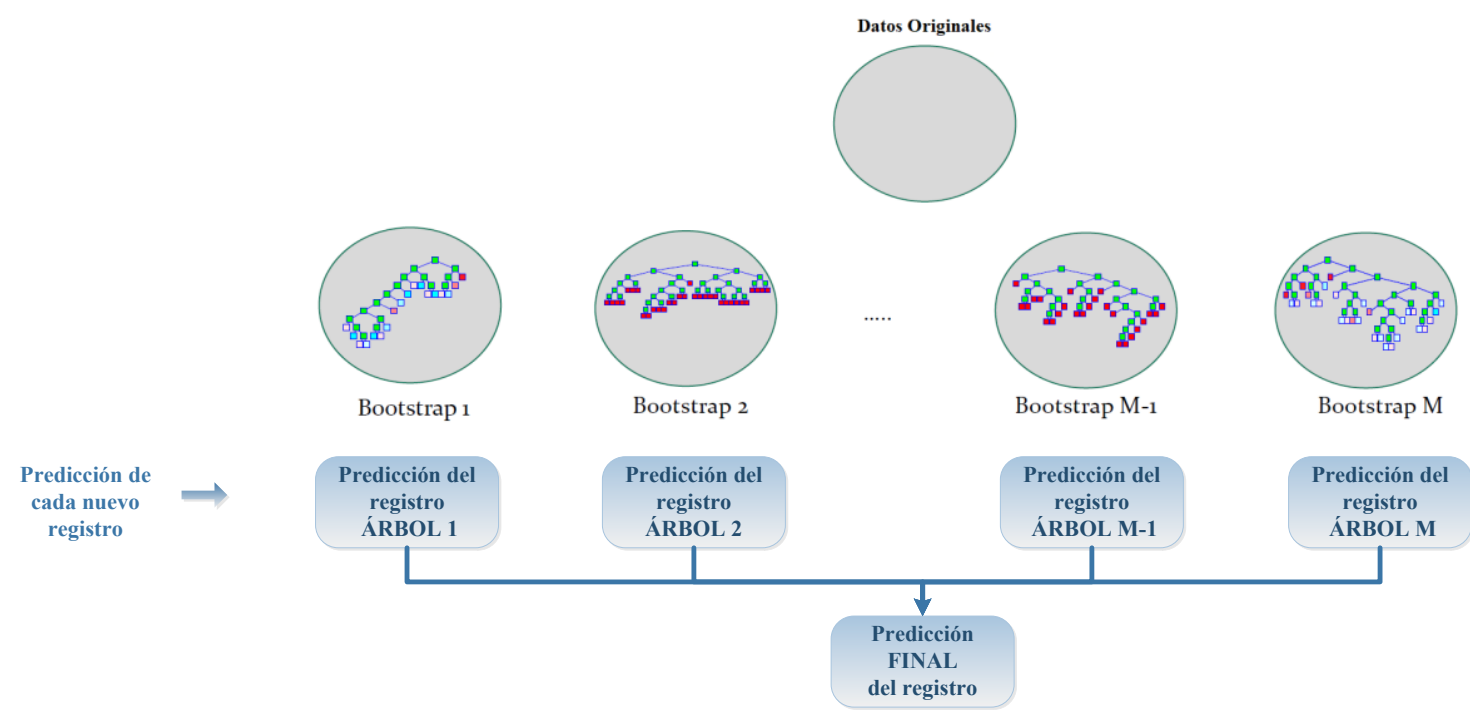

Figura 4. 4. Síntesis procedimental del algoritmo de regresión de RF. (SALFOR SYSTEMS A MINITAB, 2017)

\section{MATERIALES Y MÉTODOS}

A continuación, se presenta el esquema general de los procedimientos, ver Figura 5.1, así como el flujograma de trabajo realizado basado en entrada, proceso y salida de datos e información, ver Figura 5.2; utilizados en la investigación para mapear de manera digital el COS en el ecosistema Herbazal del Páramo (HP) de la zona de estudio.

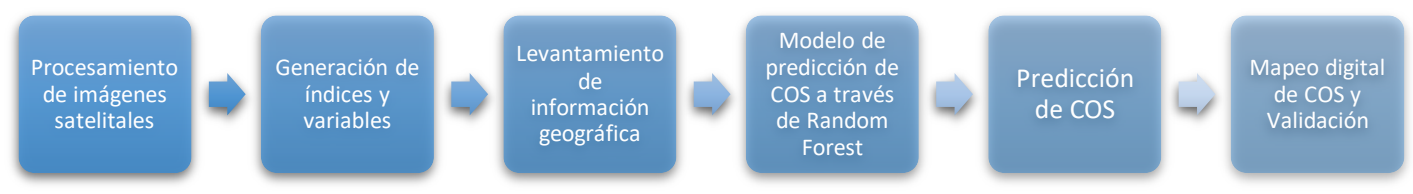

Figura 5. 1. Esquema general de procedimientos 


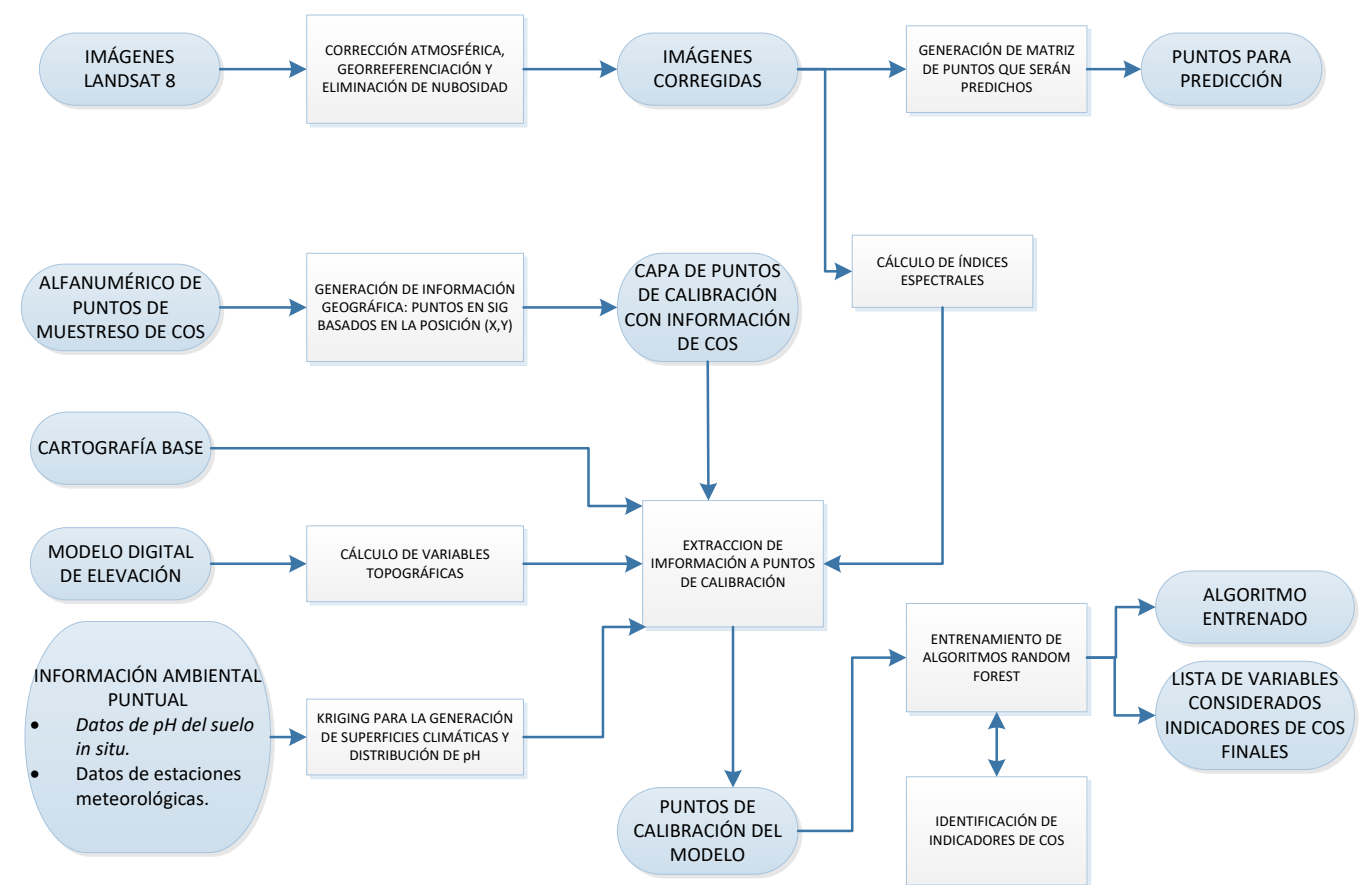

a)

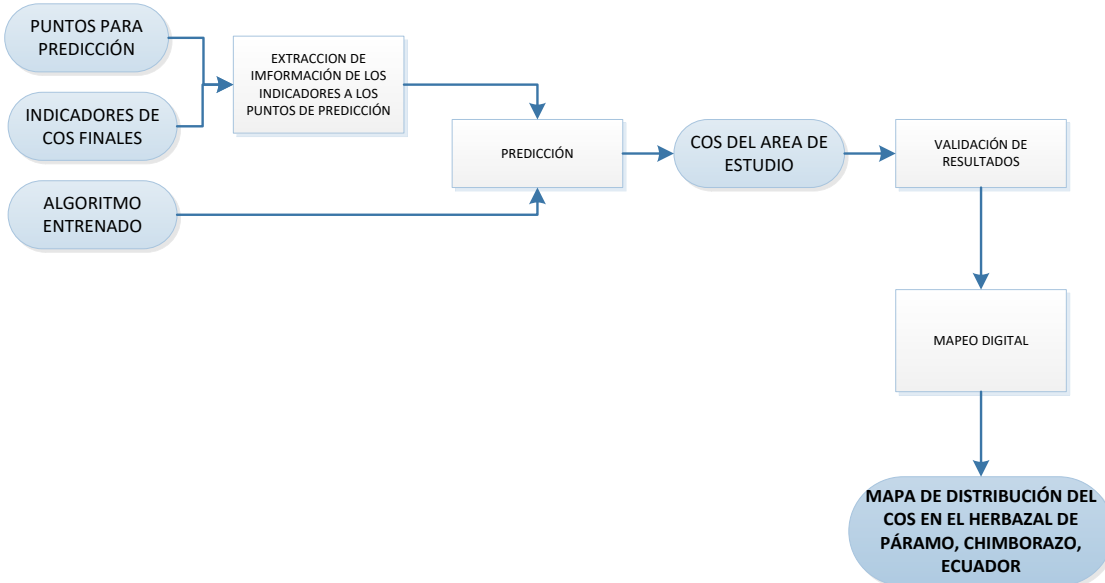

b)

Figura 5. 2. Flujograma de trabajo: a) generación de insumos para la predicción y mapeo de cos; b) Predicción y mapeo de COS

\subsection{DESCARGA Y PROCESAMIENTO DE IMÁGENES SATELITALES}

\subsubsection{DESCARGA DE IMÁGENES LANDSAT 8}

Las imágenes multiespectrales utilizadas corresponden al satélite Landsat 8, sensores OLI y TIRS. Para cubrir la zona de estudio fue necesario utilizar dos escenas definidas en el path, row $(010,061)$ y el path, row $(010,062)$ del sistema WRS-2 que usa Landsat para catalogar las escenas de los sensores en los satélites Landsat 4 al 8 (Survey, 2016). Aproximadamente el 75 \% de la zona de estudio se localiza en escena superior path, row $(010,061)$. La descarga de las imágenes Landsat 8 fue realizada desde el servicio web Global Visualization Viewer- GloVis del Departamento Geológico de los Estados Unidos de Norte América- USGS (USGS, 2017) ver Figura 5.3, del año 2016, teniendo como precedente que los datos in situ de COS y pH corresponden a 
dicho año. Adicional a ello, fue necesario seleccionar y descargar dos imágenes del año 2017 con fines de relleno en la escena path, row $(010,061)$, debido a que las condiciones atmosféricas propias de las zonas de páramo introducen grandes concentraciones de nubes en la escena, generando pérdida de información de interés. Las imágenes utilizadas en el estudio y sus características se resumen en la Tabla 5. 1.

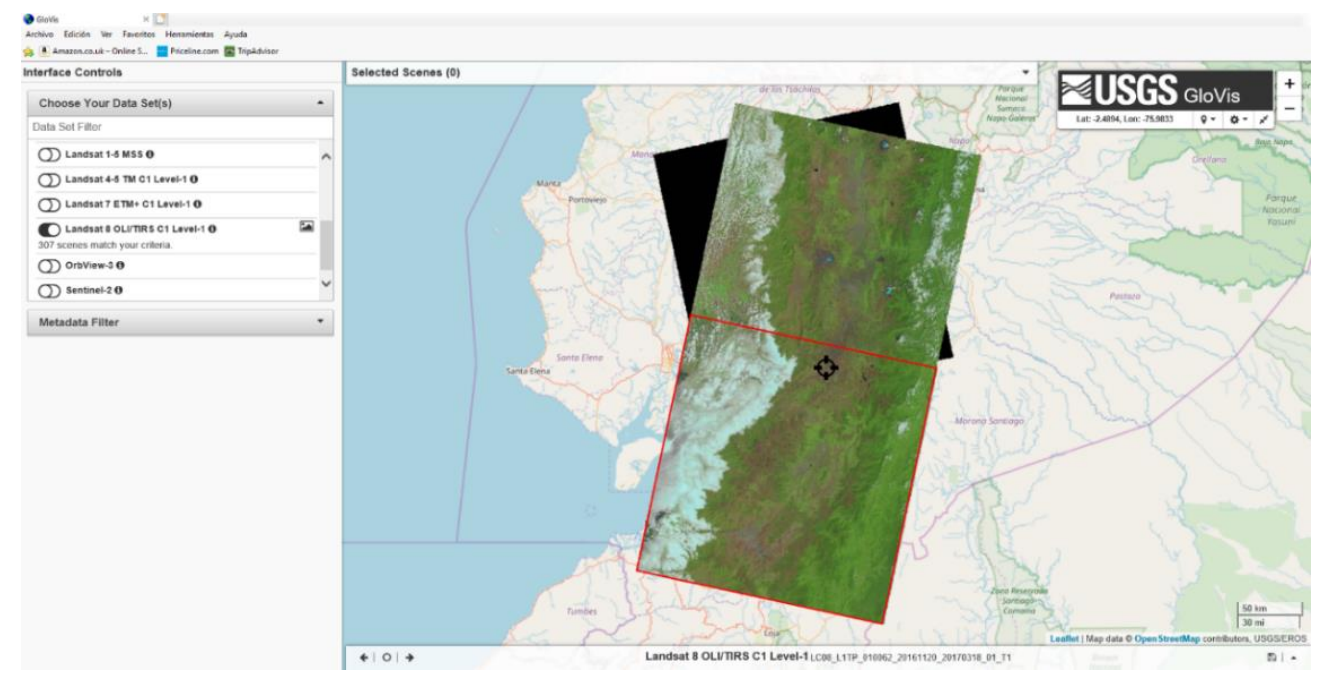

Figura 5. 3. Sitio web USGS GloVis, escenas de imágenes base descargadas

Tabla 5. 1. Imágenes Landsat 8 utilizadas

\begin{tabular}{llc}
\hline Id de la escena L8 & Uso - path, row & Fecha de captura \\
\hline LC80100612016325LGN01 & Imagen base -010, 061 & $2016 / 11 / 20$ \\
LC80100622016325LGN01 & Imagen base -010, 062 & $2016 / 11 / 20$ \\
LC80100612017263LGN00 & Relleno - 010, 061 & $2017 / 09 / 20$ \\
LC80100612017023LGN01 & Relleno - 010, 061 & $2017 / 01 / 23$
\end{tabular}

Las imágenes descargadas en formato GEOTIFF poseen un nivel de pre-procesamiento L1T. Estas imágenes tienen una corrección sistemática radiométrica y geométrica mediante la incorporación de puntos de control GPC's (USGS-USA, 2018) y también orto-rectificación a través del Modelo Digital de Elevación-MDE (SRTM). Se hizo una verificación mediante las cartas topográficas y cartografía base de ríos y vías, a escala 1:50,000, georreferenciadas en la proyección UTM Datum WGS84, del Instituto Geográfico Militar del Ecuador- IGM, (IGM, 2016), ver Figura 5.4. 


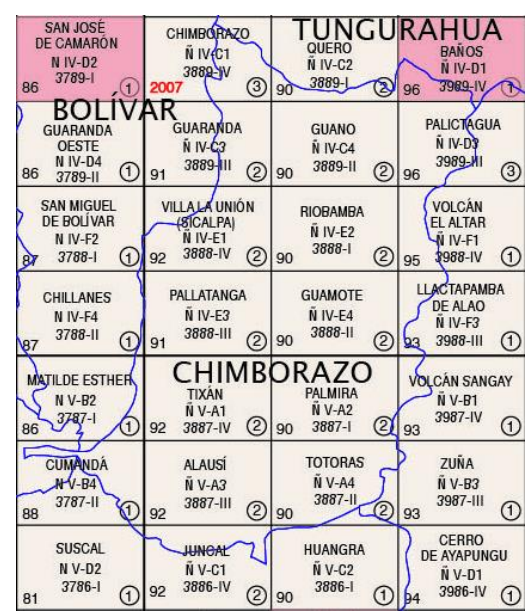

(a)

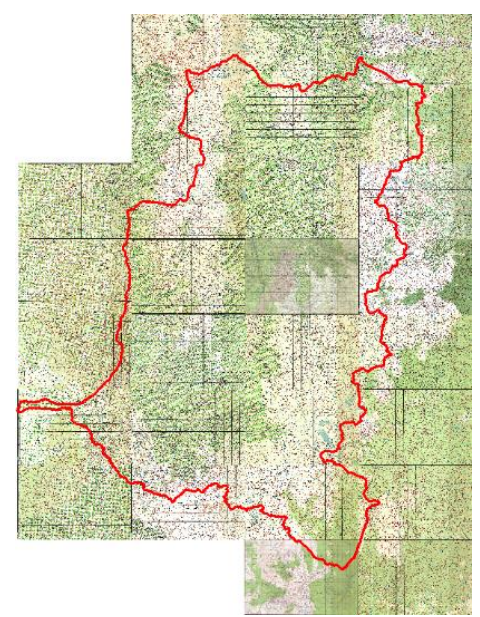

(b)

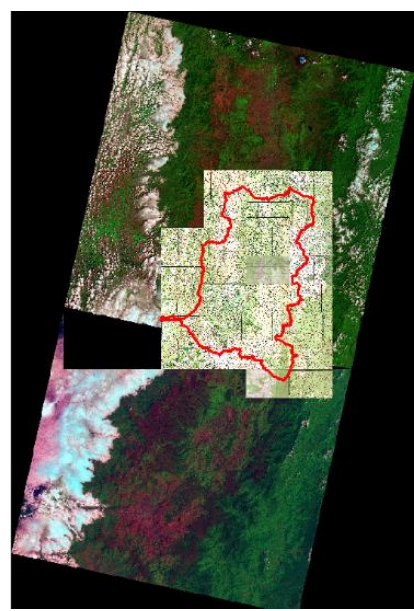

(c)

Figura 5. 4. (a) Codificación de las cartas topográficas del IGM, de la provincia de Chimborazo, (b) Cartas topográficas utilizadas, (c). Ubicación de las catas topográficas con respecto las escenas que cubren la zona de estudio.

\subsubsection{CORRECCIÓN RADIOMÉTRICA}

Las imágenes satelitales poseen un escalado de la radiancia, almacenada mediante una representación discreta de números digitales (ND). Esta es una escala artificial definida por las características específicas de cada sensor (Aguilar Arias et al., 2014) y para el caso de los sensores de Landsat 8 es de 16 bits (Survey, 2016). Dichos ND deben ser pasado a unidades físicas como la radiancia y reflectancia. Ya que los ND son proporcionales a la radiancia de la señal percibida en el sensor, es posible su recuperación en las escenas. La calibración radiométrica consiste en convertir los ND a valores de radiancia $(L)$ al tope de la atmósfera (TOA) y para ello se usó el software ENVI.5.1 (Harris Geoespacial Solutions, 2014), herramienta Radiometric Calibration, ver Figura 5.5. Se usa la codificación de imagen BIL, que toma la información de filas y columnas en la imagen y almacena todos los valores de la primera fila de la imagen para la banda 1 , luego lo repite para la banda 2 , hasta la banda final. 


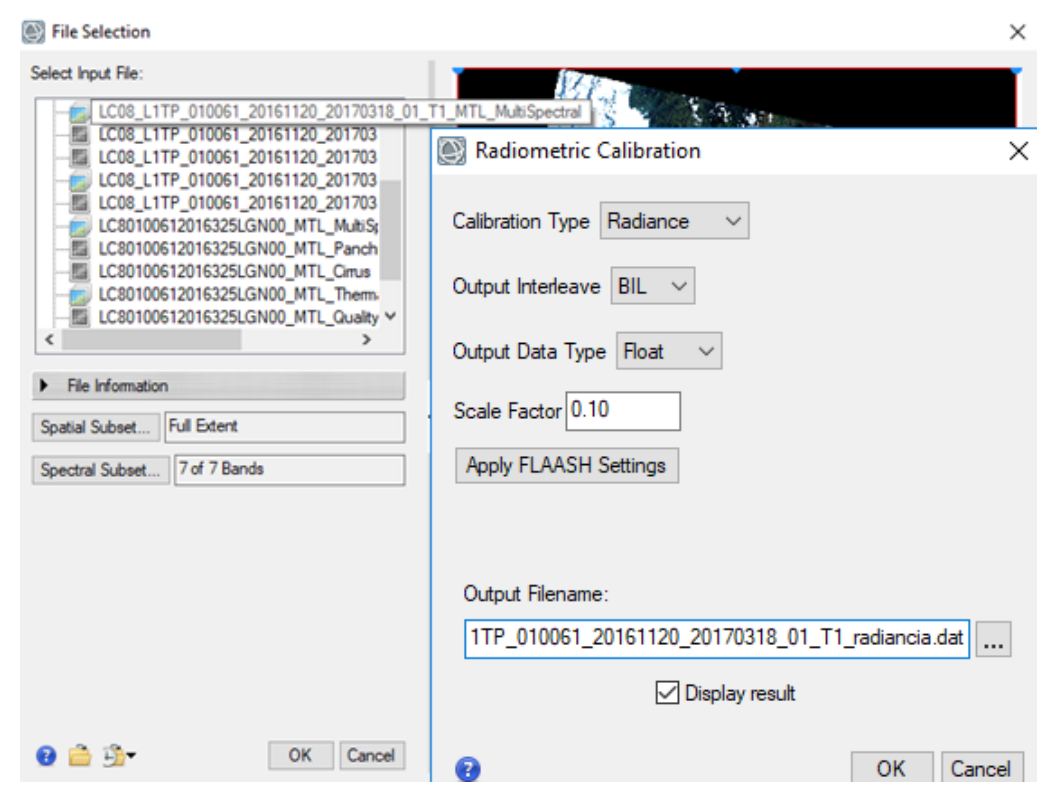

Figura 5. 5. Configuración de la herramienta Radiometric Calibration utilizada

Los valores de radiancia son convertidos a valores de reflectancia al tope de la atmósfera (TOA) por medio la herramienta FLAASH Atmosfetic Correction, ver Figura 5.6. Para hacer una remoción de la dispersión atmosférica el modelo se compone de dos factores que son la radiancia reflejada por la cubierta o superficie terrestre hasta el sensor y la radiancia que resulta dispersa por la atmósfera antes de llegar al sensor; para el caso de la radiancia reflejada el modelo utiliza el valor medio de altura sobre el suelo obtenido mediante el MDE, altura del sensor sobre el nivel del mar y la información de la fecha de captura, obtenidos de los metadatos de la imagen. Para el caso del factor por radiación dispersa, es necesario conocer la cantidad de vapor de agua existente en la atmósfera: FLAASH cuenta con las aproximaciones de acuerdo a latitudes y épocas de captura de las imágenes, usándose el modelo de invierno por las condiciones frías de los páramos.

Se realiza también la compensación de las distorsiones por aerosoles y partículas atmosféricas que producen deformaciones heterogéneas en la imagen y que se asocian a las fuentes de influencia presentes en la superficie. Ya que no hay fuerte influencia urbana e industrial para el caso de la zona de estudio se aplica el modelo de aerosol rural. Este modelo recupera la cantidad estimada de aerosol / neblina de los píxeles terrestres oscuros seleccionados en la escena (Exelis Visual Information Solutions, 2013). 


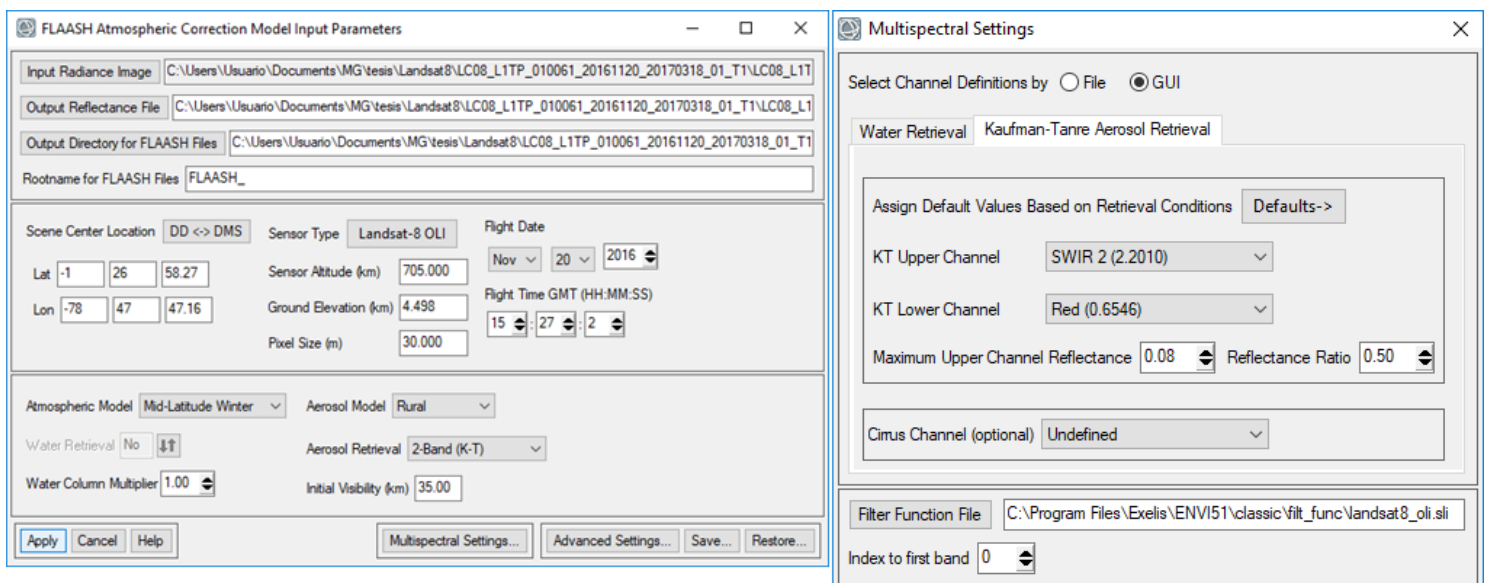

Figura 5. 6. Configuración del módulo FAASH Atmospheric Correction ENVI 5.1

Los valores de reflectancia en las imágenes resultantes poseen valores entre 0 y 10,000 , por lo que son rescaldados a un rango entre 0 y 1 mediante la Ec:5.1, obteniendo escenas con reflectancias TOA como se muestra en la Figura 5.7.

banda $=($ b le 0$) * 0+($ b1 ge 10000 $) * 1+($ b1 gt 0 and b1 lt 10000 $) *$ float(b1) $/ 10000 \quad E c: 5.1$

Donde:

le: menoro igual

ge: mayor o igual

gt: mayor que

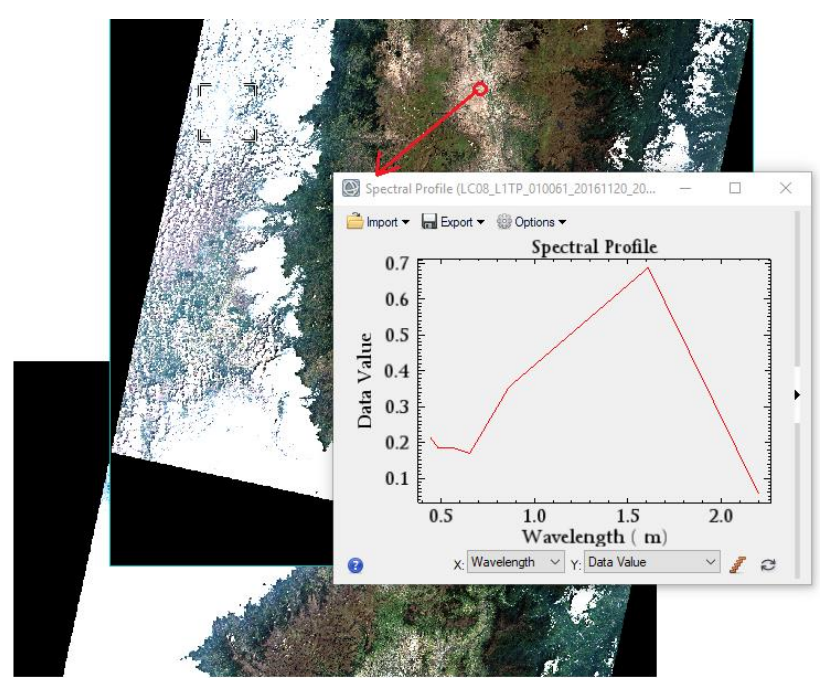

Figura 5. 7. Resultado de la corrección radiométrica, firma espectral en uno de los píxeles de la escena superior 


\subsubsection{ENMASCARAMIENTO Y VALIDACIÓN DE PIXELES}

Las zonas montañosas por sus condición climática y atmosférica son las superficies en las cuales la captura de imágenes satelitales se ve muy intervenida por la presencia de nubes. El análisis del histograma de las imágenes permitió encontrar concentraciones de nubes, dentro del ecosistema Herbazal del Páramo, en la escena norte.

La banda Quality Assessment (QA) es una banda de 16 bits, de igual dimensión a las bandas del producto L1T. Denominada banda de control de calidad, tiene en cada píxel un valor decimal que representa las combinaciones de bits de relleno de la superficie, la atmósfera y las condiciones de sensores que pueden afectar a la utilidad general de un píxel (Survey, 2016). Estos valores pueden ser utilizados con eficacia para mejorar la integridad del análisis, ya que suministra información sobre cuáles de los píxeles pueden verse afectados por las coberturas nubosas: los niveles claros son susceptibles o afectados por nubosidad, ver Figura 5.8. Se procedió a discriminar el rango de traducción decimal de las cadenas binarias presentes en la banda QA bajo el cual cada una de las escenas presenta problemas de calidad por concepto de nubes. Como resultado es posible generar una máscara de nubes basado en el valor decimal en el histograma en donde se encuentran pixeles afectados. Para este caso fue el rango $>2750$, fuera de ello, los pixeles no tienen problemas de nubosidad. Se genera en ENVI 5.1, herramienta Apply Mask la máscara para los pixeles validados en las imágenes tanto de referencia como de relleno.

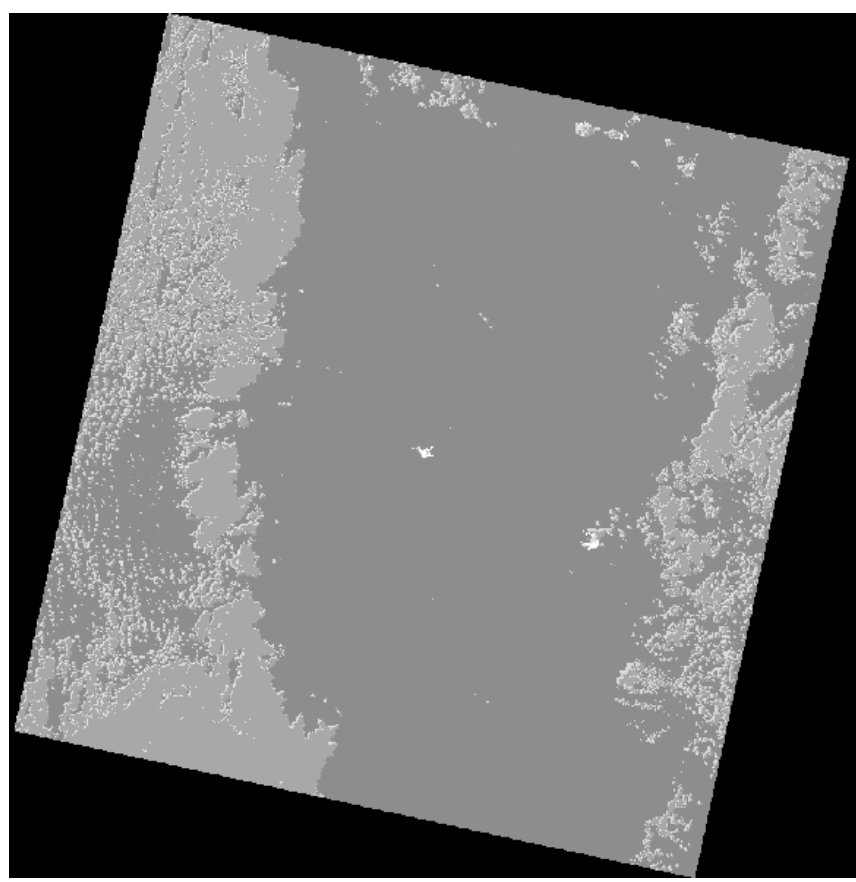

Figura 5. 8. Banda QA de la escena Norte path, row 010, 061. 


\subsubsection{MOSAICO DE LAS ESCENAS}

Las escenas Norte y Sur (path, row: 010, 061; path, row: 010, 062), son acopladas con el fin de obtener una sola imagen completa que cubra la zona de estudio. Se utilizó la herramienta Seamless Mosaic de ENVI 5.1, generando el mosaico de las escenas. La escena norte es tomada como referencia o base sobre la que se ajusta la escena sur. Del mismo modo, se genera un mosaico a partir de las máscaras generadas en las escenas Norte y Sur en ENVI por medio de la banda QA, ver Figura 5.9.

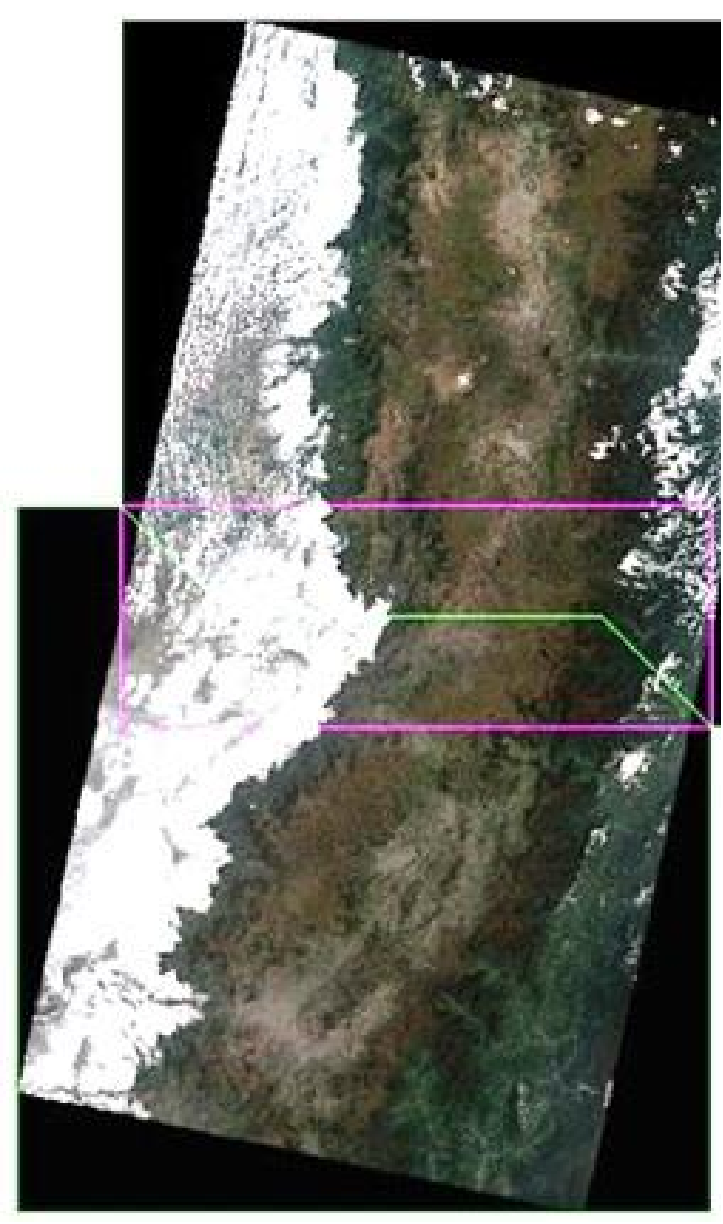

(a)

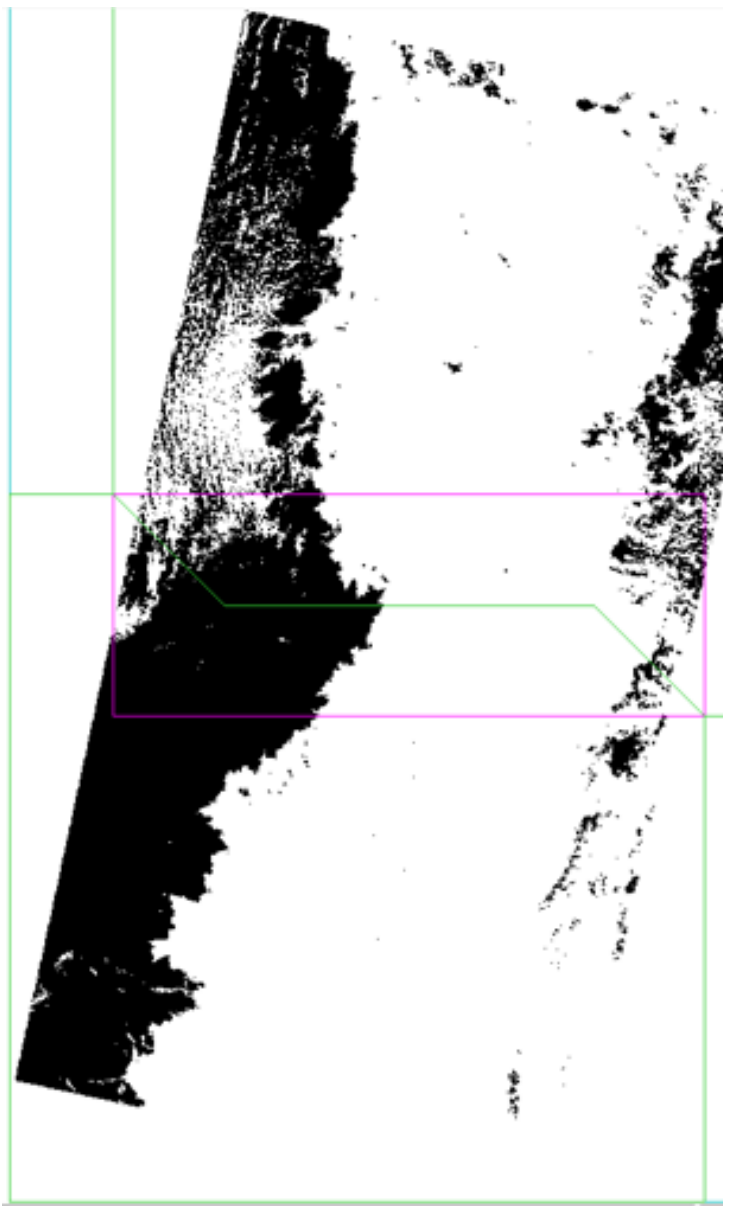

(b)

Figura 5. 9. (a) Acople de las escenas N y S para mosaico; (b) Acople de las máscaras de pixeles validados de zona Ny S para mosaico.

\subsubsection{EXTRACCIÓN DE NUBOSIDAD Y RELLENO DE IMAGENES}

El proceso de extracción de nubosidad fue realizado con la aplicación ModelBuilder en el software ArcGis 10.2 (ESRI, 2013), ver Figura 5.10. A través de la herramienta Extract by mask, se extrae la información sin nubes en el mosaico obtenido con las imágenes a través del mosaico 
de las máscaras de pixeles validados por la banda QA. Se hizo también un recorte de la provincia Chimborazo. Los pixeles no validados ubicados en ecosistema Herbazal del Páramo de la provincia de Chimborazo, son rellenados a través de las escenas LC80100612017263LGN00 y LC80100612017023LGN01, ver Figura 5.11. El relleno fue realizado en ENVI bajo la herramienta Seamless Mosaic, ver Figura 5.11 y Figura 5.12. A la salida se tiene la imagen en formato.TIFF, lista para los procesos de reclasificación y cálculos de índices espectrales de interés en el HP, ver Figura 5.13.
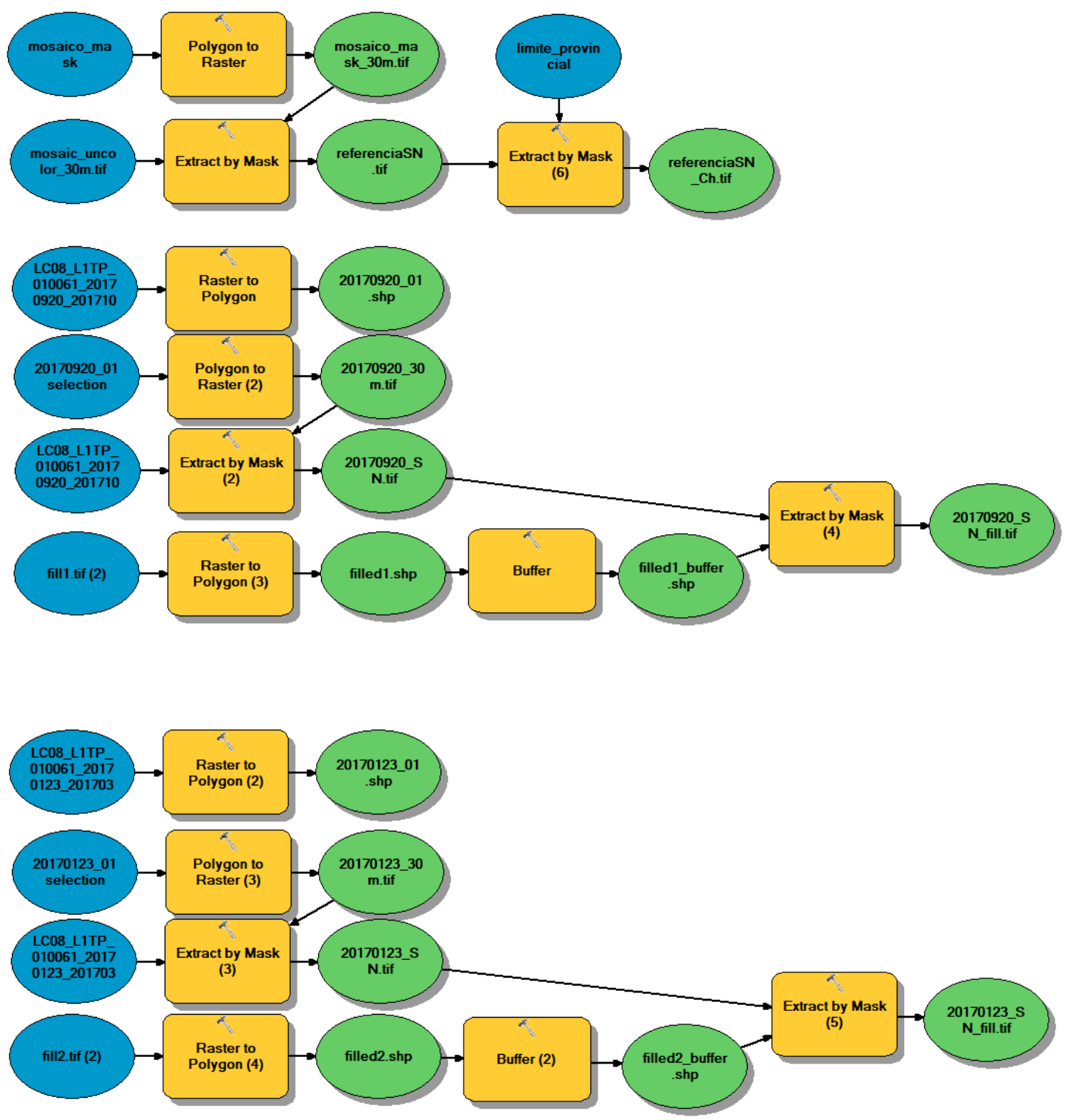

Figura 5. 10. Modelado cartográfico utilizado, en el mosaico de referencia y las imágenes de relleno. Aplicación ModelBuilder-ArcGis 10.2 

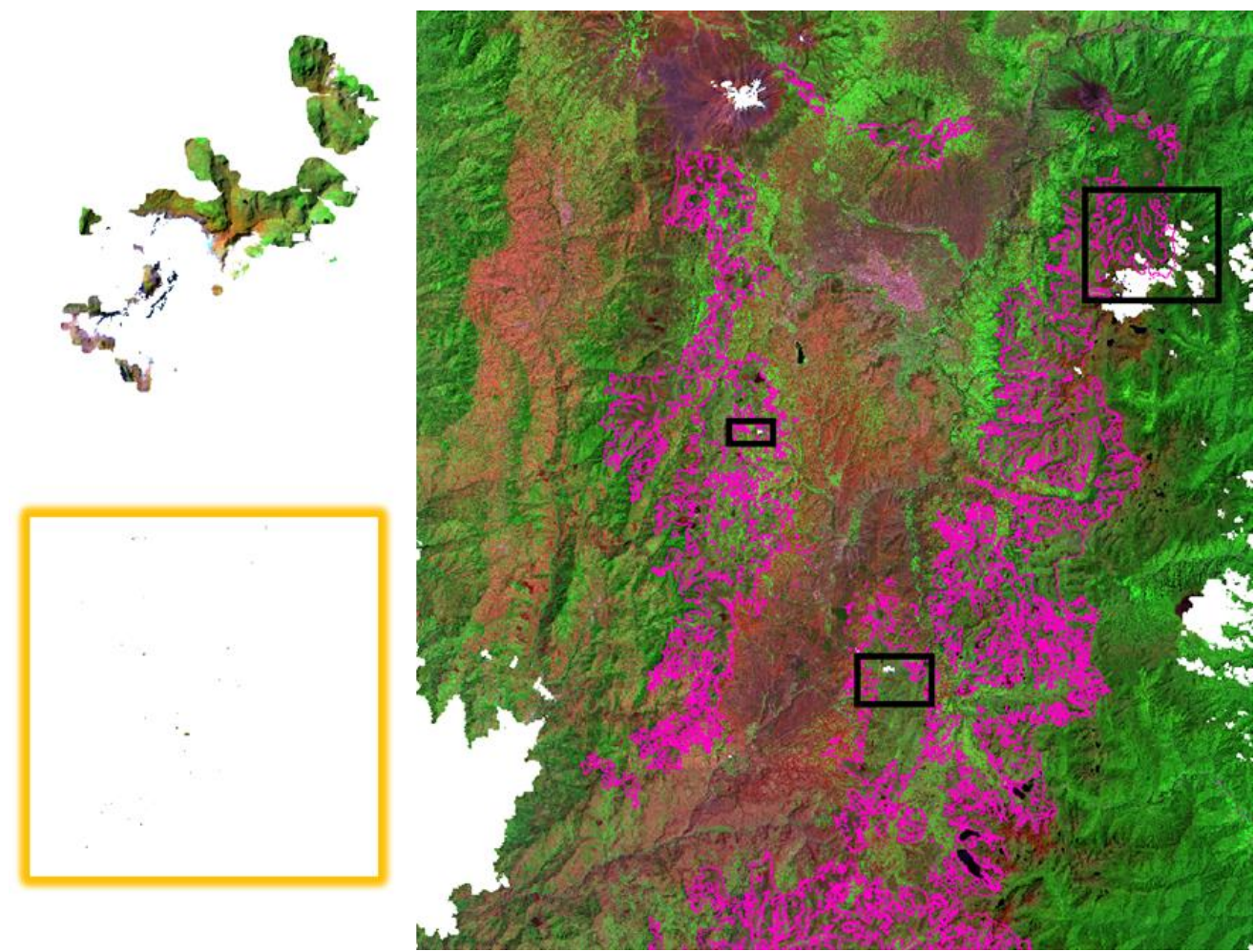

Figura 5. 11. A la izquierda pixeles de relleno. A la derecha, mosaico de referencia con vacíos de información por concepto de extracción por nubosidad.

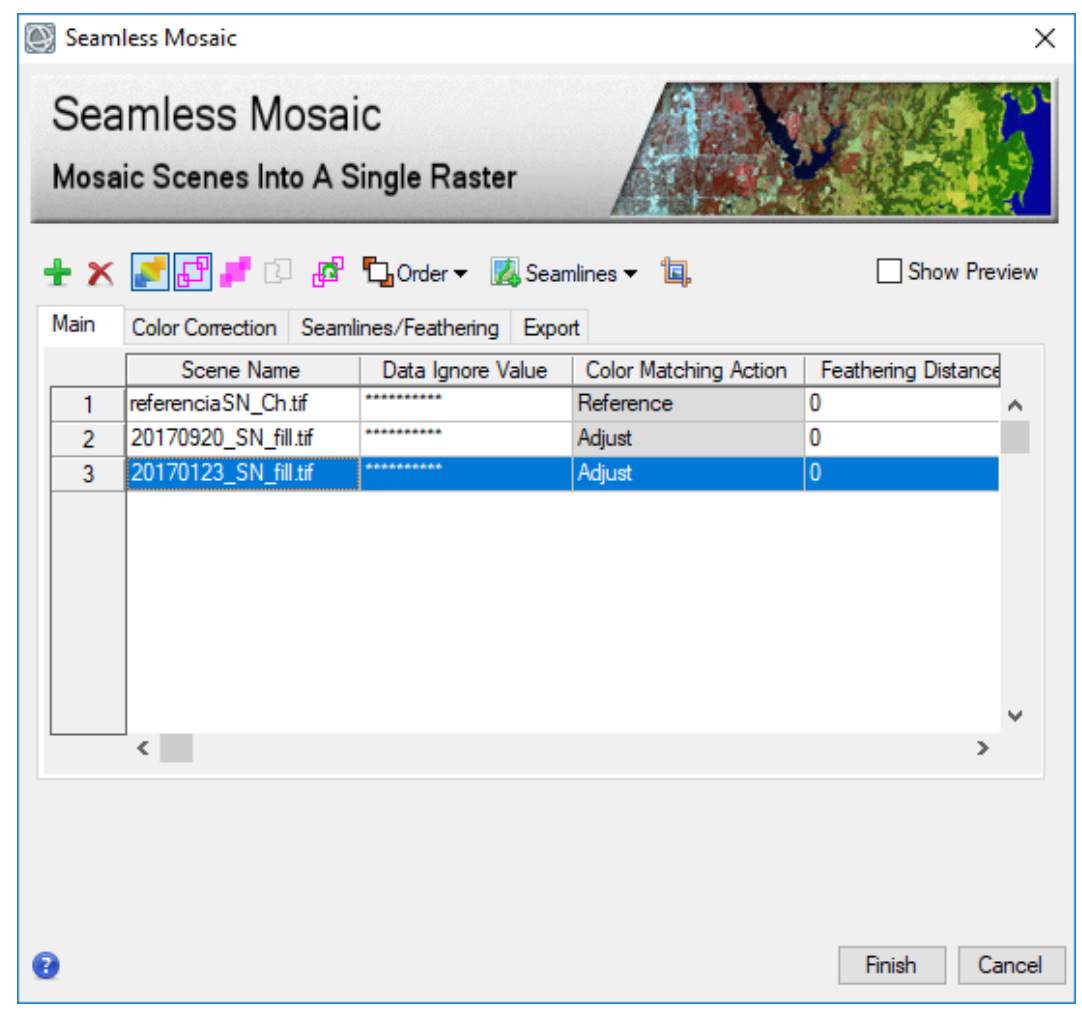

Figura 5. 12. Configuración del relleno. Mosaico de referencia es la imagen a rellenar y las imágenes para el relleno son de ajuste 

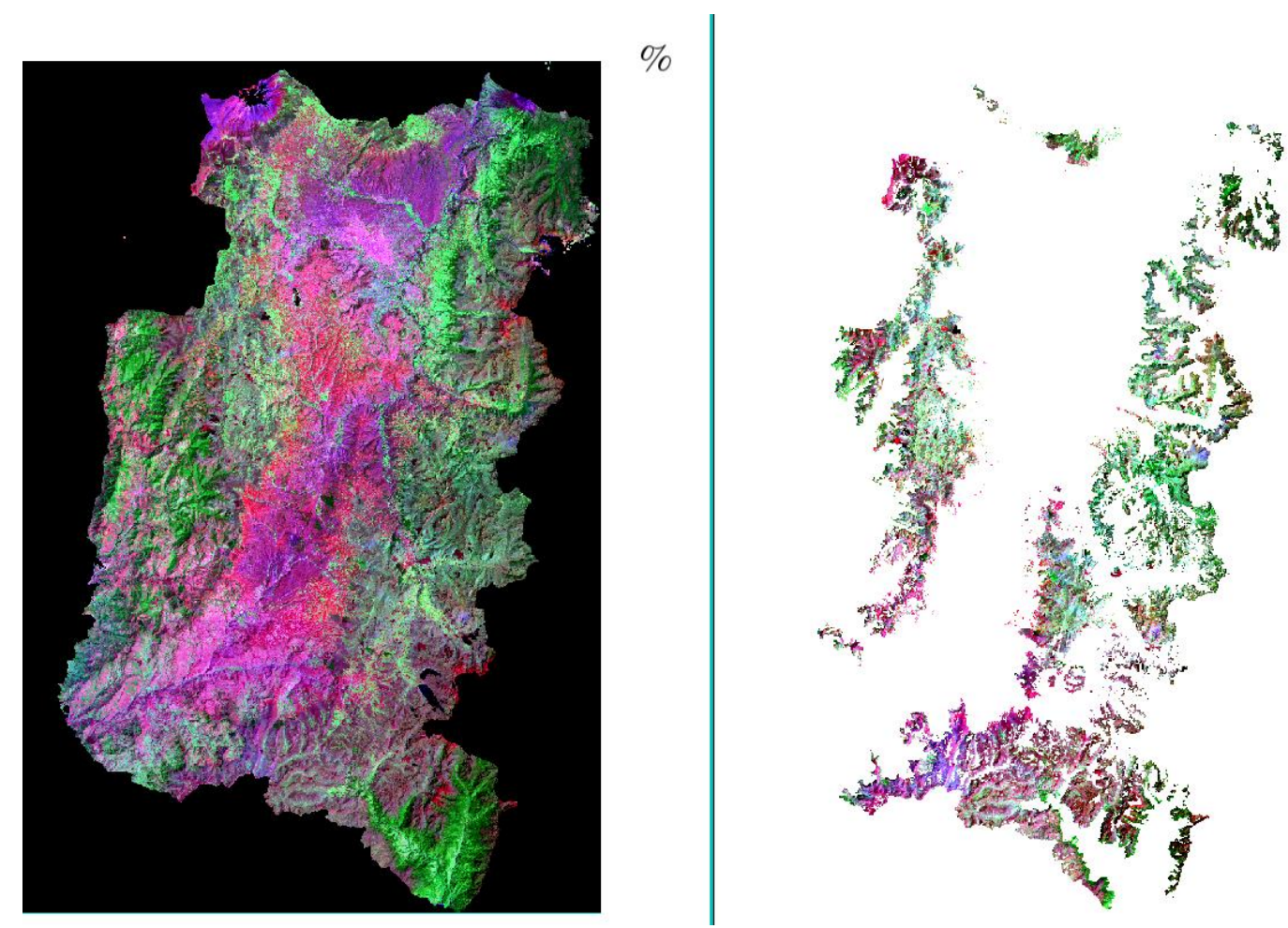

Figura 5. 13. Combinación falso color $(7,5,3)$. En el lado izquierdo, la imagen satelital corregida de la provincia de Chimborazo (el sector Oeste del cantón Cumandá no es considerado por encontrarse fuera de la zona del estudio); del lado derecho se presenta la imagen cortada con la zona objetivo del estudio, ecosistema Herbazal del Páramo de Chimborazo.

\subsubsection{CÁLCULO DE ÍNDICES ESPECTRALES}

\section{Sensor Operational Land Imager (OLI)}

Conforme lo expuesto en el capítulo anterior, se calcularon los índices espectrales que más adelante serán puestos en evaluación por su capacidad indicadora como variables que controlan el almacenamiento de COS. Se utilizó el álgebra de bandas a través de la herramienta Math Band, de ENVI, para generar los índices detallados en la Tabla 5.2 de acuerdo a su correspondiente banda de Landsat 8. El suelo y el medio ambiente se encuentran relacionados a la hora de comprender los procesos biológicos, químicos y físicos que rigen las funciones de los suelos (Minasny et al., 2014). Desde este punto de vista este estudio ha contemplado índices espectrales que realcen características superficiales como tipo de cubierta vegetal, tipos de suelo, humedad, y así evaluar su covariabilidad con el almacenaje de COS. Por ejemplo, el índice BI Bare Index (Chen et al., 2004), es capaz de identificar superficies de suelo desnudo, en ambientes de baja intervención antrópica; éste tipo de suelo podría aportar información relevante sobre la cantidad de COS bajo del mismo ver Figura 5.14. En el anexo B se presentan los mapas de todos los índices generados según Tabla 5.2. 


\begin{tabular}{|c|c|}
\hline $\begin{array}{l}\text { EXPRESIÓN MATEMÁTICA EN FUNCIÓN DEL } \\
\text { ESPECTRO ELECTROMAGNÉTICO }\end{array}$ & $\begin{array}{l}\text { EXPRESIÓN MATEMÁTICA EN FUNCIÓN DE } \\
\text { LAS BANDAS DE LANDSAT } 8\end{array}$ \\
\hline $\mathrm{NDVI}=\frac{\mathrm{NIR}-\mathrm{R}}{\mathrm{NIR}+\mathrm{R}}$ & $\mathrm{NDVI}=\frac{\mathrm{B} 5-\mathrm{B} 4}{\mathrm{~B} 5+\mathrm{B} 4}$ \\
\hline $\mathrm{SAVI}=\frac{\mathrm{NIR}-\mathrm{R}}{\mathrm{NIR}+\mathrm{R}+\mathrm{L}}(1+\mathrm{L}) \quad \mathrm{L}=0.15$ & $\mathrm{SAVI}=\frac{\mathrm{B} 5-\mathrm{B} 4}{\mathrm{~B} 5+\mathrm{B} 4+0.15}(1+0.15)$ \\
\hline $\mathrm{WDRVI}=\frac{\mathrm{aNIR}-\mathrm{R}}{\mathrm{aNIR}+\mathrm{R}}$ & $\mathrm{WDRVI}=\frac{0.05 \mathrm{~B} 5-\mathrm{B} 4}{0.05 \mathrm{~B} 5+\mathrm{B} 4}$ \\
\hline $\mathrm{EVI} 2=2.5 \frac{\mathrm{NIR}-\mathrm{R}}{\mathrm{NIR}+(2.4) \mathrm{R}+1}$ & $\mathrm{EVI} 2=2.5 \frac{\mathrm{B} 5-\mathrm{B} 4}{\mathrm{~B} 5+(2.4) \mathrm{B} 4+1}$ \\
\hline $\mathrm{NDWI}=\frac{\mathrm{G}-\mathrm{NIR}}{\mathrm{G}+\mathrm{NIR}}$ & $\mathrm{NDWI}=\frac{\mathrm{B} 3-\mathrm{B} 5}{\mathrm{~B} 3+\mathrm{B} 5}$ \\
\hline $\operatorname{VARI}_{G}=\frac{G-R}{G+R}$ & $\mathrm{VARI}_{\mathrm{G}}=\frac{\mathrm{B} 3-\mathrm{B} 4}{\mathrm{~B} 3+\mathrm{B} 4}$ \\
\hline $\mathrm{NDSI}=\frac{\mathrm{SWIR} 1-\mathrm{NIR}}{\mathrm{SWIR} 1+\mathrm{NIR}}$ & $\mathrm{NDSI}=\frac{\mathrm{B} 6-\mathrm{B} 5}{\mathrm{~B} 6+\mathrm{B} 5}$ \\
\hline $\mathrm{BI}=\frac{(\mathrm{SWIR} 1+\mathrm{R})-(\mathrm{NIR}+\mathrm{B})}{(\mathrm{SWIR} 1+\mathrm{R})+(\mathrm{NIR}+\mathrm{B})}$ & $\mathrm{BI}=\frac{(\mathrm{B} 6+\mathrm{B} 4)-(\mathrm{B} 5+\mathrm{B} 2)}{(\mathrm{B} 6+\mathrm{B} 4)-(\mathrm{B} 5+\mathrm{B} 2)}$ \\
\hline $\mathrm{NDMI}=\frac{\mathrm{NIR}-\mathrm{SWIR} 1}{\mathrm{NIR}+\mathrm{SWIR} 1}$ & $\mathrm{NDMI}=\frac{\mathrm{B} 5-\mathrm{B} 6}{\mathrm{~B} 5+\mathrm{B} 6}$ \\
\hline $\mathrm{NBR}=\frac{\mathrm{NIR}-\mathrm{SWIR} 2}{\mathrm{NIR}+\mathrm{SWIR} 2}$ & $\mathrm{NBR}=\frac{\mathrm{B} 5-\mathrm{B} 7}{\mathrm{~B} 5+\mathrm{B} 7}$ \\
\hline $\mathrm{NBR} 2=\frac{\mathrm{SWIR} 1-\text { SWIR2 }}{\text { SWIR1 }+ \text { SWIR2 }}$ & $\mathrm{NBR} 2=\frac{\mathrm{B} 6-\mathrm{B} 7}{\mathrm{~B} 6+\mathrm{B} 7}$ \\
\hline
\end{tabular}




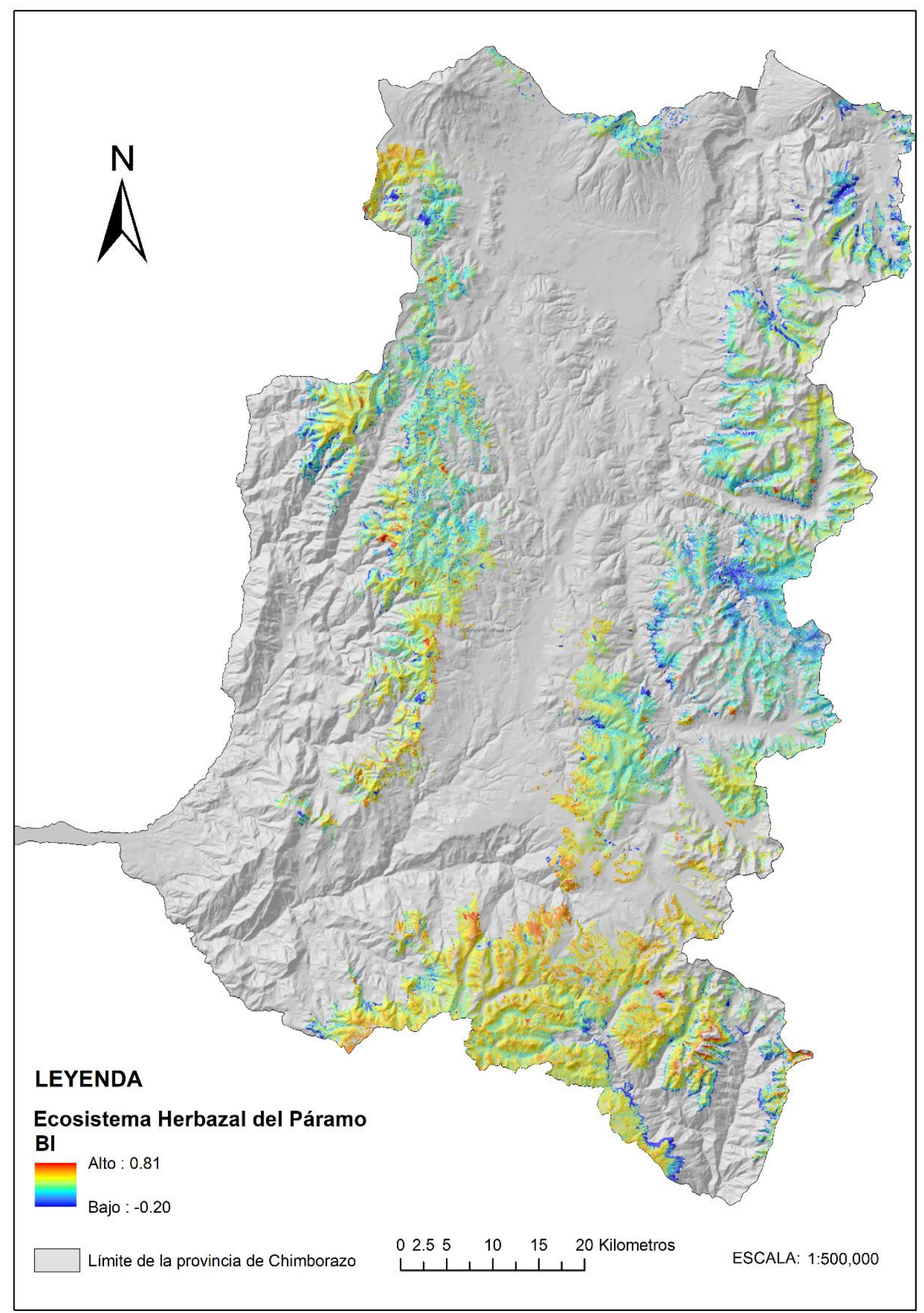

Figura 5. 14. Índice de suelo desnudo-BI 


\section{Sensor Thermal Infrared Sensor (TIRS)}

La temperatura del brillo de la superficie terrestre (T) TOA Brightnees Temperature, puede ser calculada mediante los datos del sensor TIRS. Al igual que con OLI, es posible convertir la radiancia a temperatura del brillo superficial, Ec: 5.2, (Survey, 2016). El cálculo de T se hizo mediante el software ENVI 5.1 (Harris Geoespacial Solutions, 2014), herramienta Math Band. El proceso es realizado en las bandas 10 y 11 correspondientes al sensor TIRS de Landsat 8; la temperatura resultante en grados Kelvin $\mathrm{T}\left({ }^{\circ} \mathrm{K}\right)$ es convertida a su valor correspondiente en grados Celsius $\mathrm{T}\left({ }^{\circ} \mathrm{C}\right)$ y la composición de las bandas se hizo con la herramienta Cell Statistics aplicado el valor medio. Así como en el caso de OLI, también se hizo el mosaico para unificar las escenas, ver Figura 5.15. Como resultado se obtiene el mapa de temperatura del brillo superficial $\mathrm{T}\left({ }^{\circ} \mathrm{C}\right)$, ver Figura 5.16, teniendo una media de T de $21^{\circ} \mathrm{C}$.

$$
T=\frac{\mathrm{K} 2}{\ln \left(\frac{K 1}{L_{\lambda}}\right)+1} \quad \quad E c: 5.2
$$

Donde:

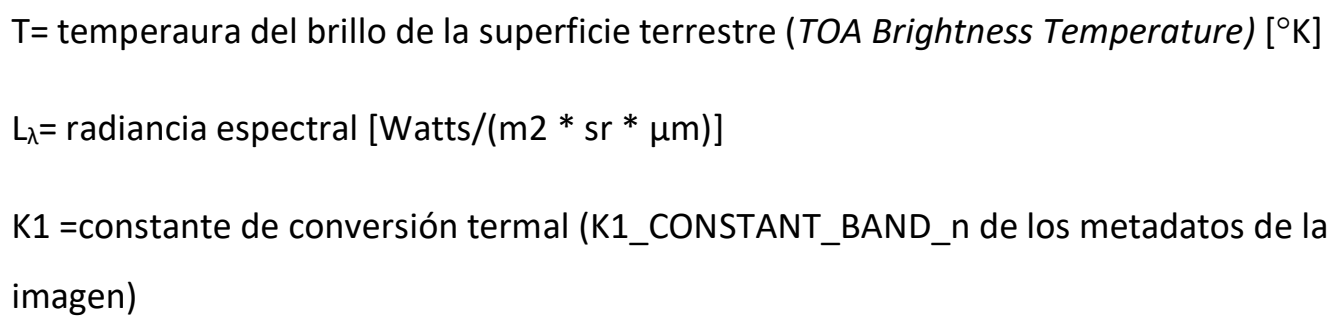

$\mathrm{T}=$ temperaura del brillo de la superficie terrestre (TOA Brightness Temperature) $\left[{ }^{\circ} \mathrm{K}\right]$

$L_{\lambda}=$ radiancia espectral $[$ Watts $/(m 2 * s r * \mu m)]$

K1 =constante de conversión termal (K1_CONSTANT_BAND_n de los metadatos de la imagen)

K2 =constante de conversión termal (K2_CONSTANT_BAND_n de los metadatos de la imagen)

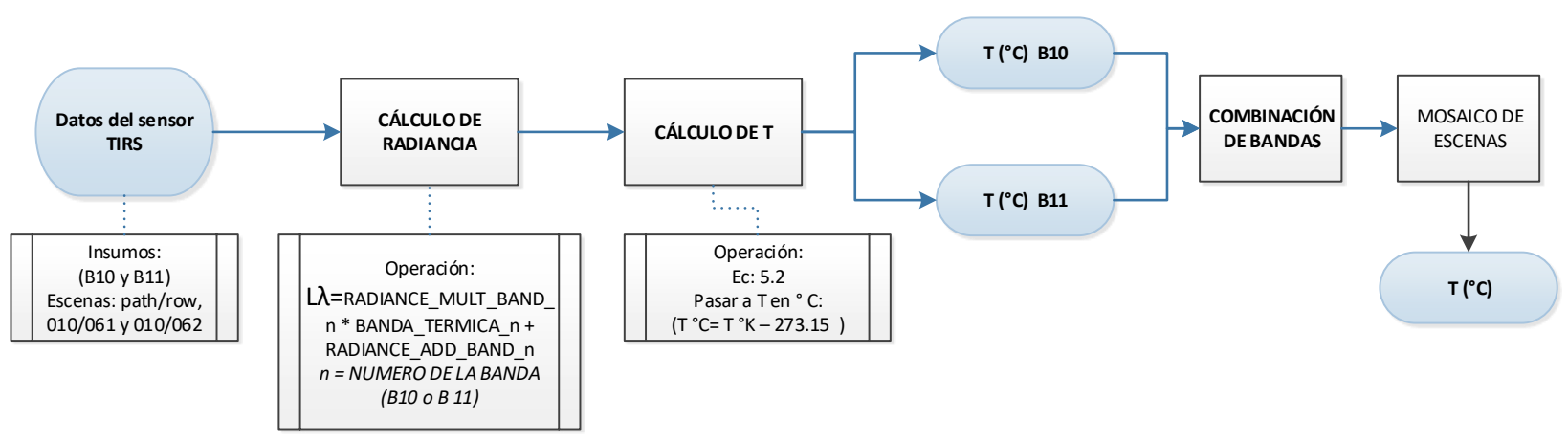

Figura 5. 15. Esquema procedimental del cálculo de T 


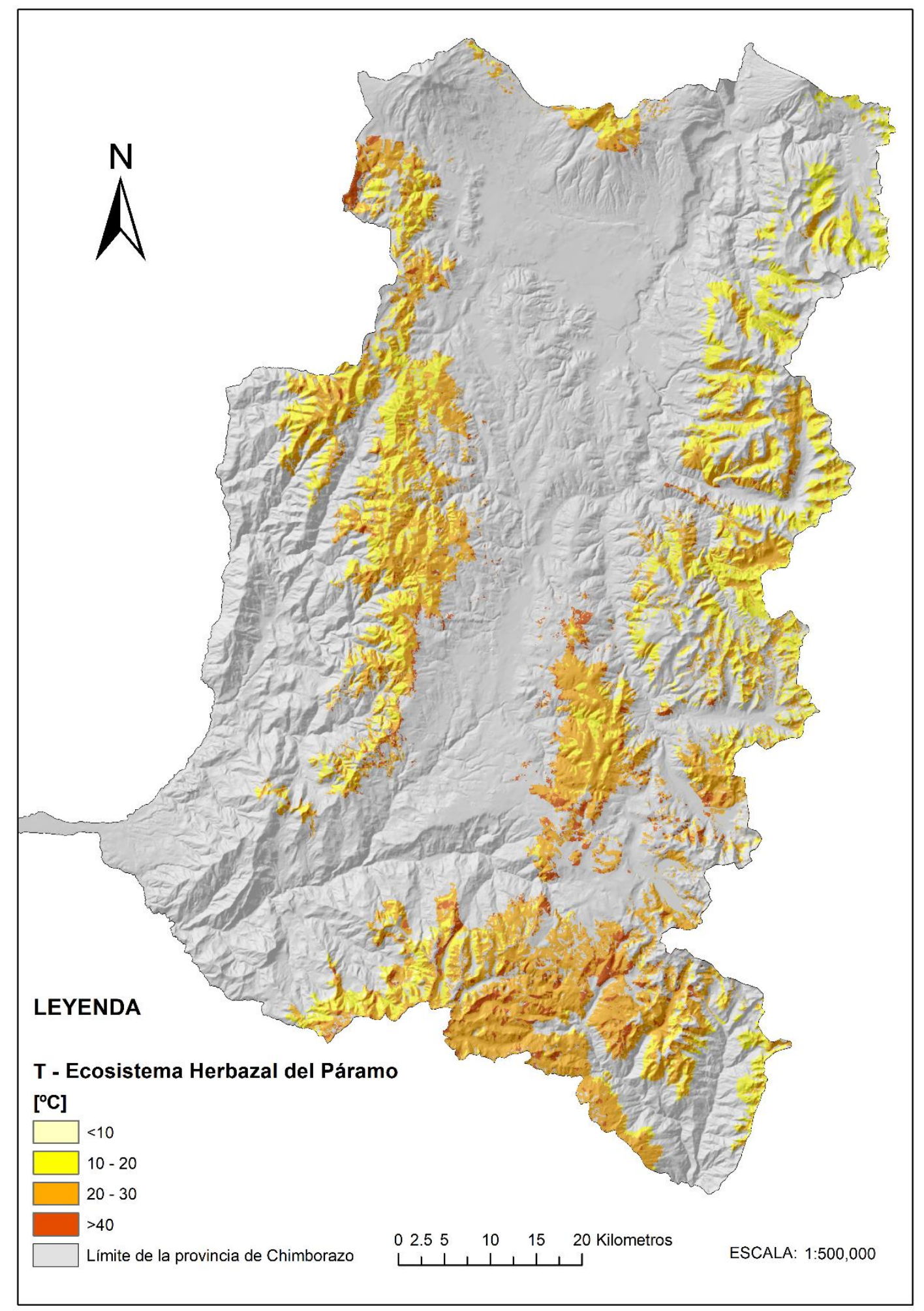

Figura 5. 16. Mapa de T en el Ecosistema Herbazal del Páramo 


\subsection{GENERACIÓN DE VARIABLES TOPOGRÁFICAS}

\section{Factor topográfico LS}

El Modelo Digital de Elevación (MDE) y el factor LS determinan la resolución espacial de los resultados del modelo de erosión del suelo e incorporan el potencial de erosión del suelo debido a la escorrentía superficial. El factor $L$ da el impacto de la longitud de la pendiente mientras que el factor S explica el efecto de la inclinación de la pendiente. El factor LS es adimensional, con valores iguales o mayores a 0 (Panagos et al., 2015) y es apropiado para modelar la erosión del paisaje abarcando topografías complejas (Desmet \& Govers, 1996). El procedimiento fue realizado en el software ArcGis 10.2 (ESRI, 2013), según el esquema procedimental expuesto en la Figura 5.17, los resultados se muestran en la Figura 5.18.

$$
\text { Factor } L S=L * S \quad E c: 5.3
$$

\section{Factor L}

$$
\begin{aligned}
& \beta=\frac{\frac{\sin \theta}{0.0896}}{3 \sin \theta^{0.8}+0.56} \quad \text { Ec: } 5.4 \\
& m=\frac{\beta}{\beta+1} \quad E c: 5.5 \\
& L=\frac{\left[A_{i, j}+D\right]^{(m+1)}-A_{i, j}{ }^{(m+1)}}{x^{m} D^{m+2}(22.13)^{m}} \quad E c: 5.6
\end{aligned}
$$

(Desmet \& Govers, 1996)

Donde:

$$
\begin{aligned}
& A=\text { área de acumulación }\left[\mathrm{m}^{2}\right] \\
& D=\text { longitud del lado del tamaño del pixel [m] } \\
& X=\text { coeficiente de forma } \\
& m=\text { entre } 0 \text { y } 1 \text { (Mccool et al., 1987) } \\
& \Theta=\text { ángulo de la pendiente } \\
& \beta=\text { tasa de erosión (por surcos a laminar) }
\end{aligned}
$$




\section{Factor S}

$$
\begin{array}{ll}
S=10.8 \sin \theta+0.03, & \text { si } \operatorname{tg} \theta<0.09 \quad \text { Ec: } 5.7 \\
S=16.8 \sin \theta-0.05, \quad & \text { si } \operatorname{tg} \theta \geq 0.09 \quad \text { Ec: } 5.8
\end{array}
$$

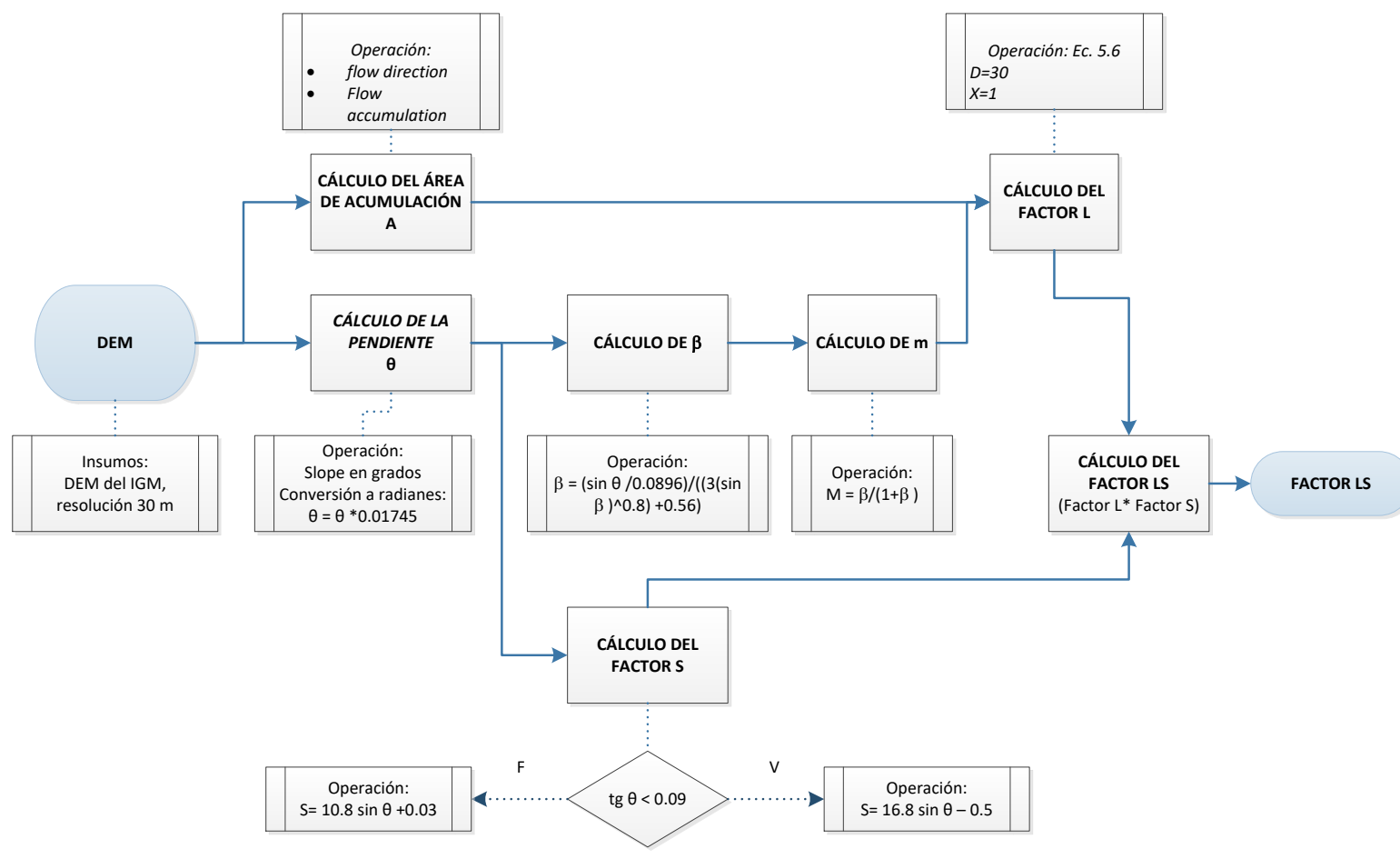

Figura 5. 17. Esquema procedimental del cálculo del Factor $L S$ 


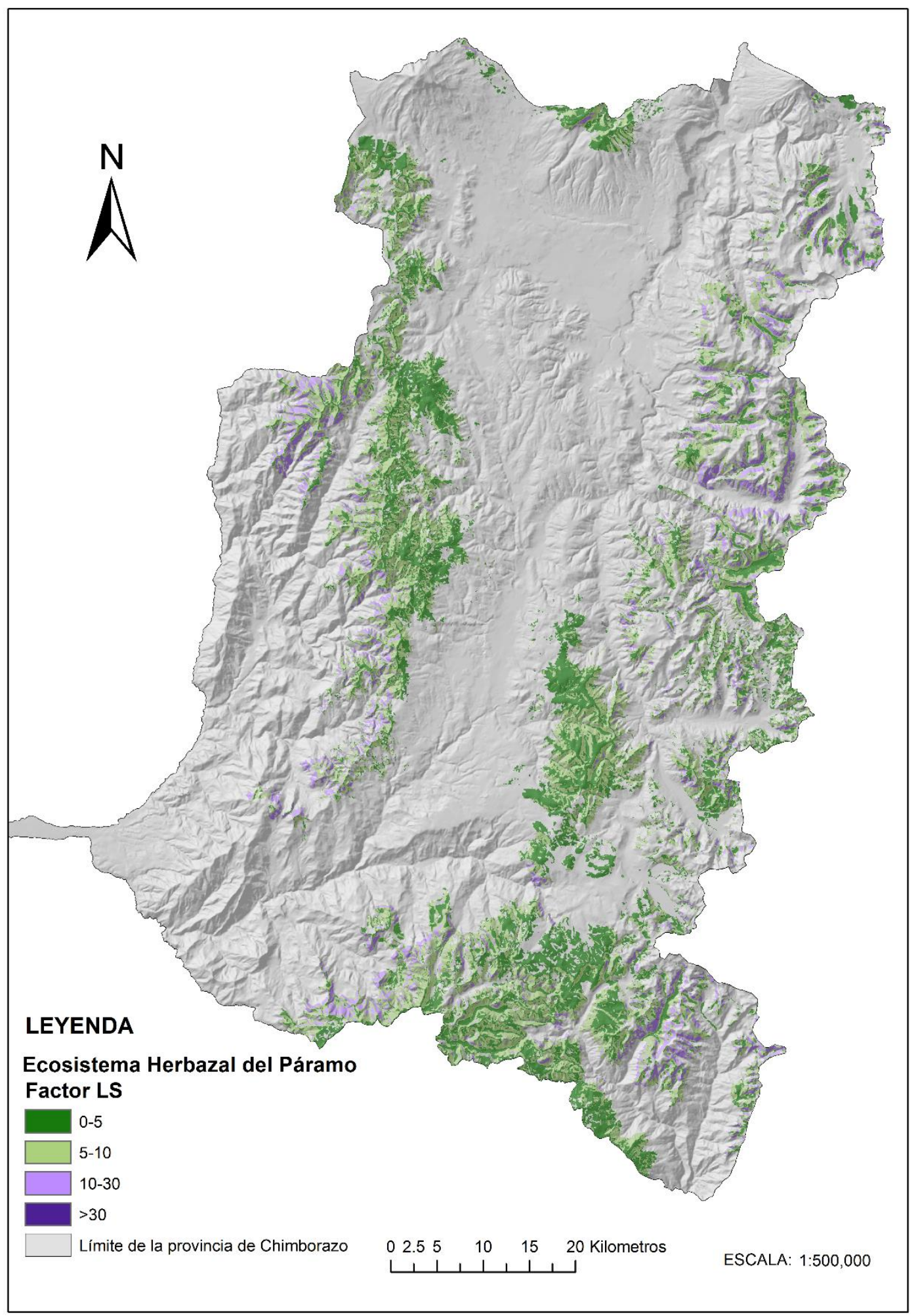

Figura 5. 18. Mapa del Factor LS del Ecosistema Herbazal del Páramo

\section{Pendiente y orientación}

La pendiente es la magnitud de la tasa máxima de cambio en el valor de z para cada celda de la superficie ráster y es calculada en grados, el rango de la pendiente está entre $0^{\circ}$ y $90^{\circ}$, obtenida a partir del MDE de $30 \mathrm{~m}$ de resolución, con la herramienta Slope de ArcGis. La 
orientación es calculada mediante la herramienta Aspect de ArcGis y resulta de la máxima tasa de cambio en z de cada celda de superficie ráster, medido desde el norte en dirección de las manecillas del reloj expresándose en grados de $0^{\circ}$ a $360^{\circ}$. Como resultado se obtienen las variables en datos ráster simple.

\subsection{ESTIMACIÓN DE SUPERFICIES MEDIANTE KRIGING}

\subsubsection{SUPERFICIES CLIMÁTICAS}

La cartografía base no cuenta con superficies climáticas de temperatura y precipitación; se disponen de isoyetas e isotermas del año 2011 pero éstas resultan muy antiguas para el estudio considerando que la información de COS y demás variables son del año 2016. En este caso la disposición de información del año 2016 no fue completa, por lo que se utilizaron datos del 2015. Por tal motivo, la estimación de las superficies climáticas tanto de temperatura como precipitación, se hizo a través un análisis geoestadístico con el método kriging con el fin de realizar la interpolación de mediciones generadas en las estaciones meteorológicas ubicadas dentro y en los alrededores de la provincia de Chimborazo, ver Figura 5.19. Las estaciones meteorológicas pertenecen al Instituto Nacional de Meteorología e Hidrología del Ecuador (INAMHI), y 3 estaciones de la UNACH ubicadas al Sureste de la provincia de Chimborazo. En el Anexo $C$ se detallan las estaciones utilizadas mediante su código de identificación a nivel nacional.

Ya que los archivos del INAMHI corresponden a datos alfanuméricos en formato txt (text file) y las coordenadas de ubicación de las estaciones es recibida en coordenadas geográficas GCS (Geographic Coordinate System), se hizo una conversión de formato de entrada de datos a vectorial de estructura shapefile de puntos. También se proyectó al sistema de coordenadas planas utilizada en el estudio (WGS_1984_UTM_Zone_17S). Las superficies climáticas son estimadas mediante el módulo de ArcGis 10.2 Geoestatistical Analyst, se realizó un Krigeado ordinario con ajuste del semivariograma analizando la continuidad y variabilidad de los datos, tanto de temperatura como de precipitación. Como resultado se obtienen las superficies estimadas de temperatura y precipitación en formato ráster de la zona de estudio. Para el uso a posteriori se reclasificó a las superficies en rangos de $2^{\circ}$ y para el caso de la precipitación en rangos de $250 \mathrm{~mm}$, ver Figura 5.20 . 


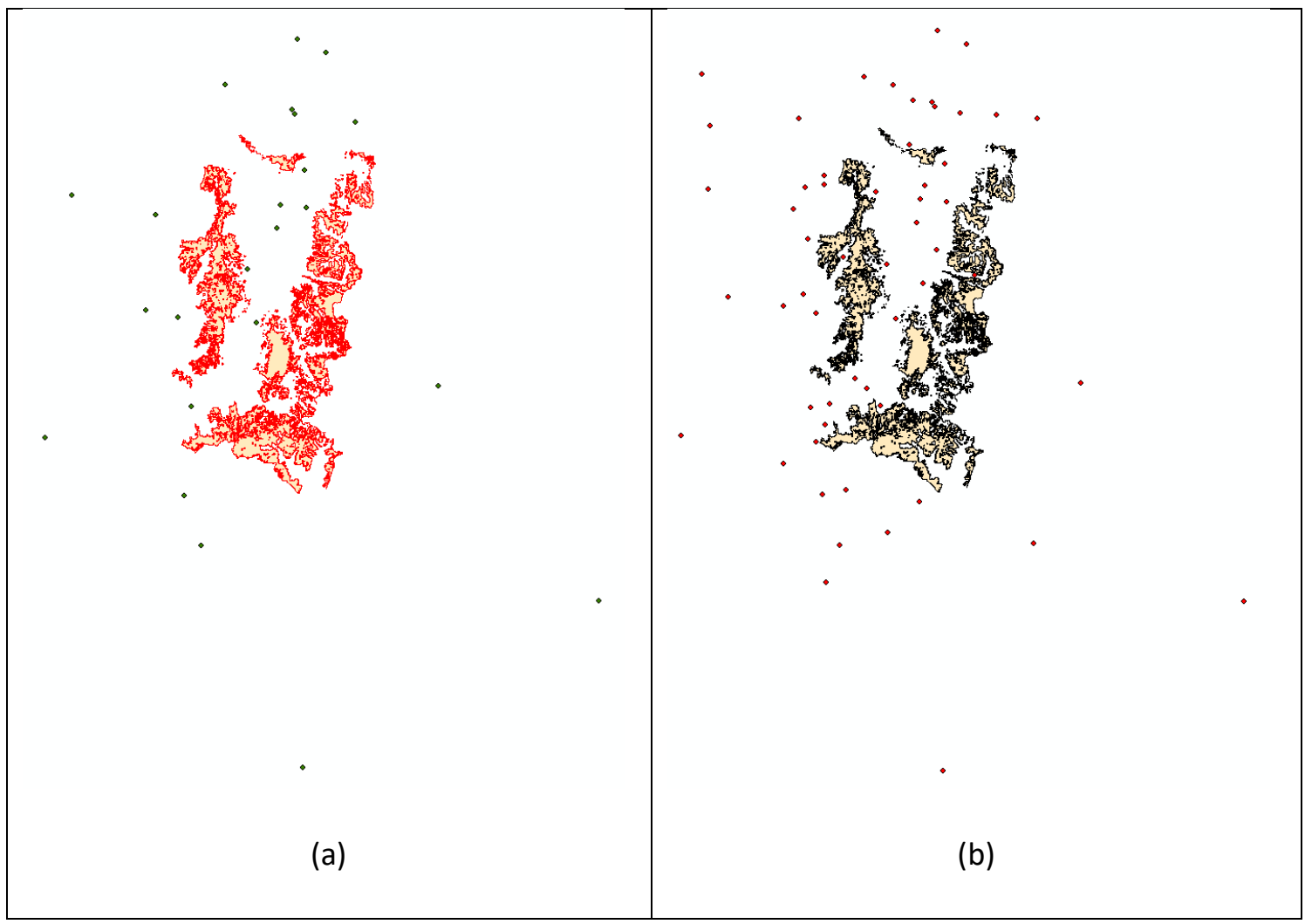

Figura 5. 19. (a) Ubicación de las estaciones meteorológicas con datos de temperatura respecto al ecosistema de estudio. (b) Ubicación de las estaciones con mediciones pluviométricas respecto al ecosistema de estudio.

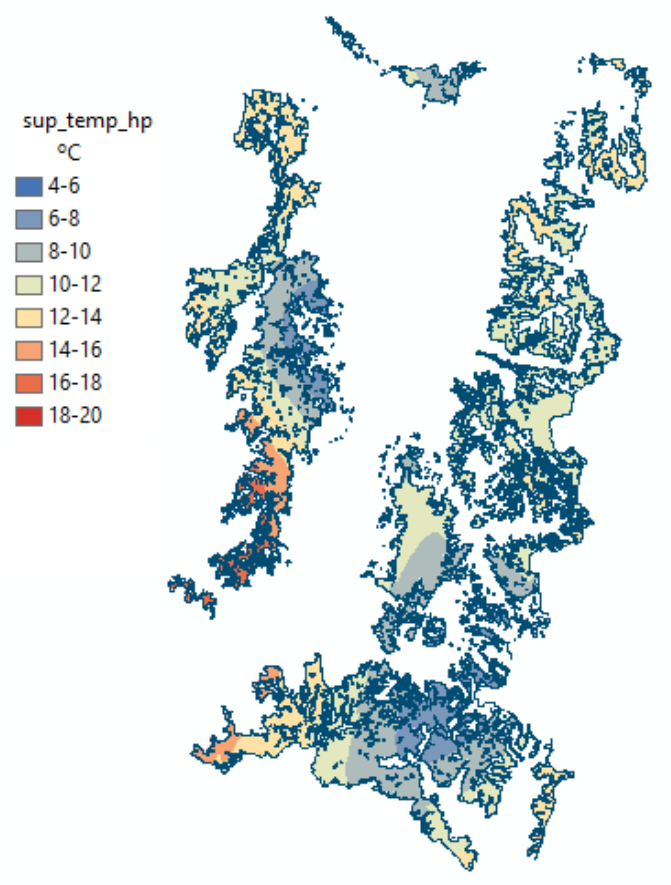

(a)

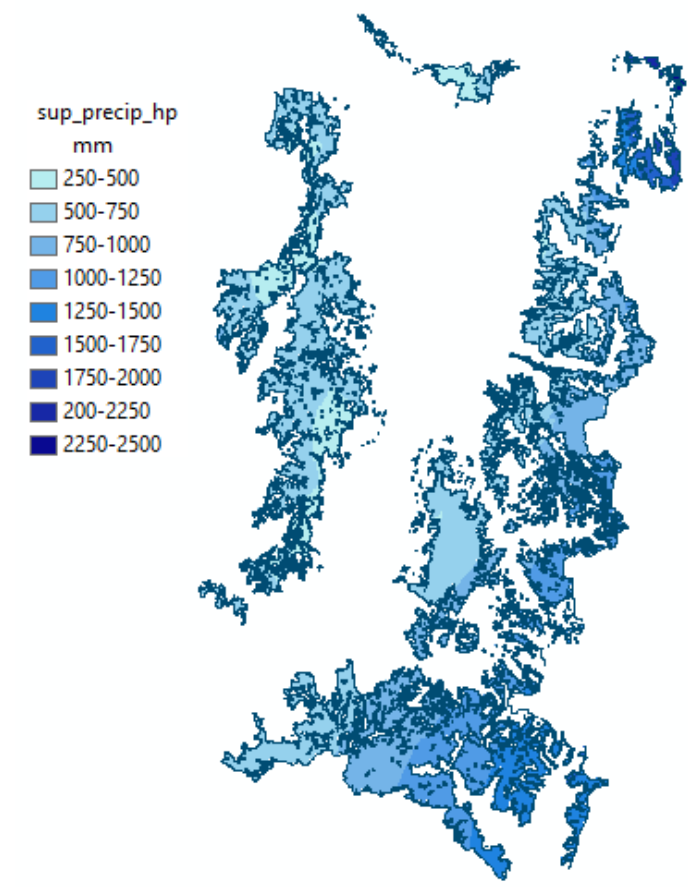

(b)

Figura 5. 20. (a) Superficie de temperatura en el Ecosistema Herbazal del Páramo. (b) Superficie de precipitación en el Ecosistema Herbazal del Páramo. 


\subsubsection{ESTIMACIÓN DE DISTRIBUCIÓN DE pH}

La superficie de $\mathrm{pH}$ se obtuvo mediante los valores in situ por mediciones de la variable en el horizonte superficial ( $30 \mathrm{~cm}$ bajo suelo), distribuidos en la zona de estudio. Se utilizó el módulo de ArcGis 10.2 Geoestatistical Analyst y se aplicó kriging ordinario con ajuste del semivariograma, al igual que las superficies climáticas. Como resultado se obtuvo el mapa de distribución de la variable pH en formato ráster, ver Figura 5.21.

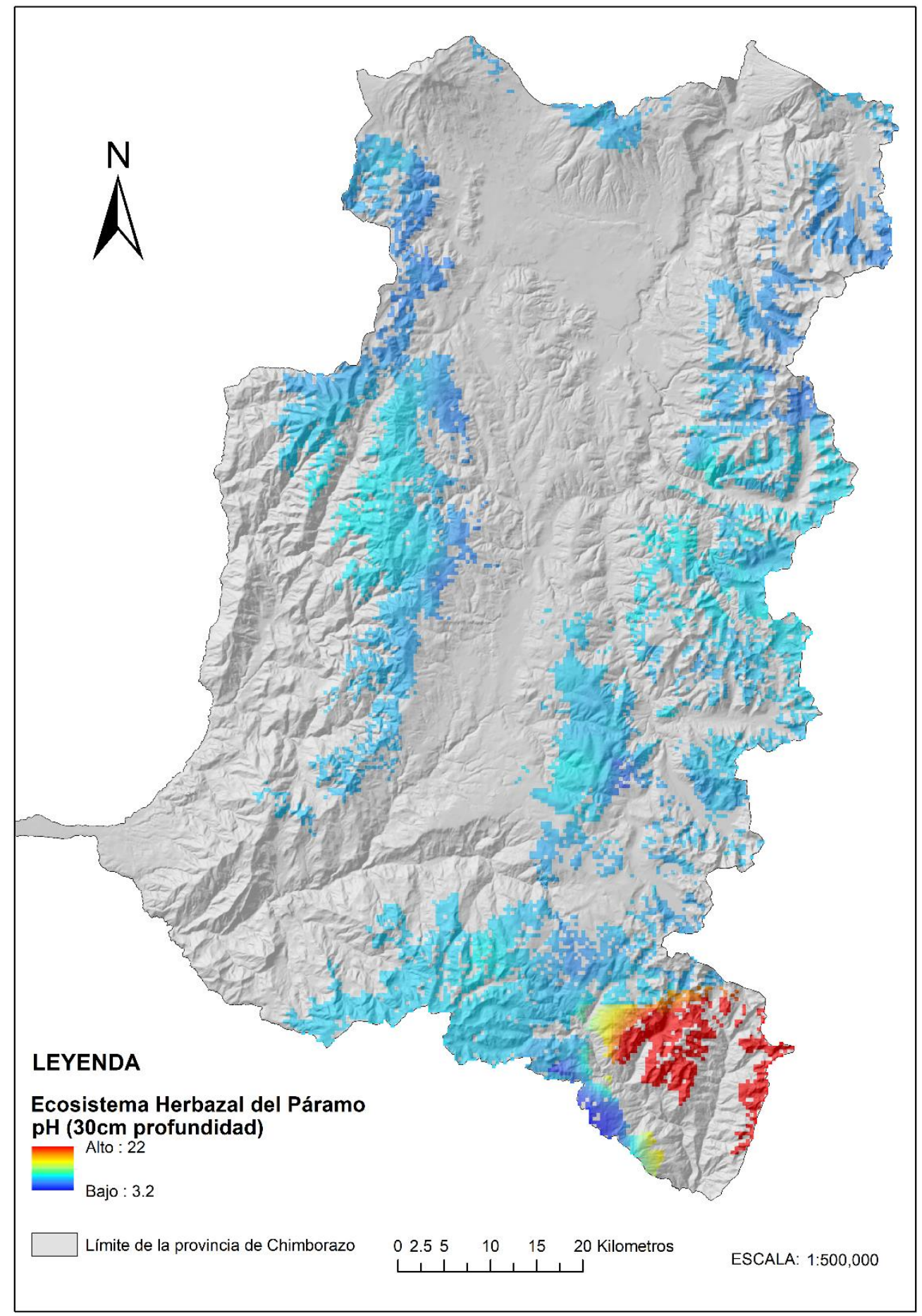

Figura 5. 21. Mapa de pH en el Ecosistema Herbazal del Páramo. 


\subsection{ENTRENAMIENTO DEL ALGORITMO DE AUTOAPRENDIZAJE PARA PREDICCIÓN DE COS}

\subsubsection{TRATAMIENTO DE INFORMACIÓN IN SITU}

La información recibida del muestreo in situ cuenta con 501 puntos de muestreo realizados en los meses mayo, junio, agosto y septiembre, del año 2016. Los datos obtenidos son archivos alfanuméricos con coordenadas planas de proyección UTM Datum WGS84 zona 17S. Se hizo una conversión de esta entrada de datos alfanumérica a vectorial de estructura shapefile, tipo puntos, mediante el software ArcGis 10.2 (ESRI, 2013), con el fin de tener información geográfica.

\subsubsection{GENERACIÓN DEL ARCHIVO PARA CALIBRACIÓN DEL ALGORITMO CON RANDOM FOREST}

A partir de la información geográfica in situ con los datos de COS de las muestras, se hace una extracción de los valores obtenidos de los índices multiespectrales, variables topográficas, superficies climáticas, estimación de pH, geología, taxonomía del suelo (a partir de la cartografía base del Ecuador provista por el IGM se obtienen archivos vectoriales de estructura shapefile, tipo polígono, correspondientes a geología y taxonomía del suelo) y también la variable altura a partir del MDE.

Como resultado se tienen 501 puntos de muestreo de $\operatorname{COS}$ asociados a los valores correspondientes de las 21 variables a ser evaluadas, por su capacidad indicadora en el almacenamiento de COS, y mediante la calibración del algoritmo de autoaprendizaje Random Forest (RF) con el software Salford Predictive Modeler (SMP) 8.2 (Salford Systems a Minitab company, 2018), ver Figura 5.22. La distribución de los puntos de entrenamiento se observa en la Figura 5.23. 


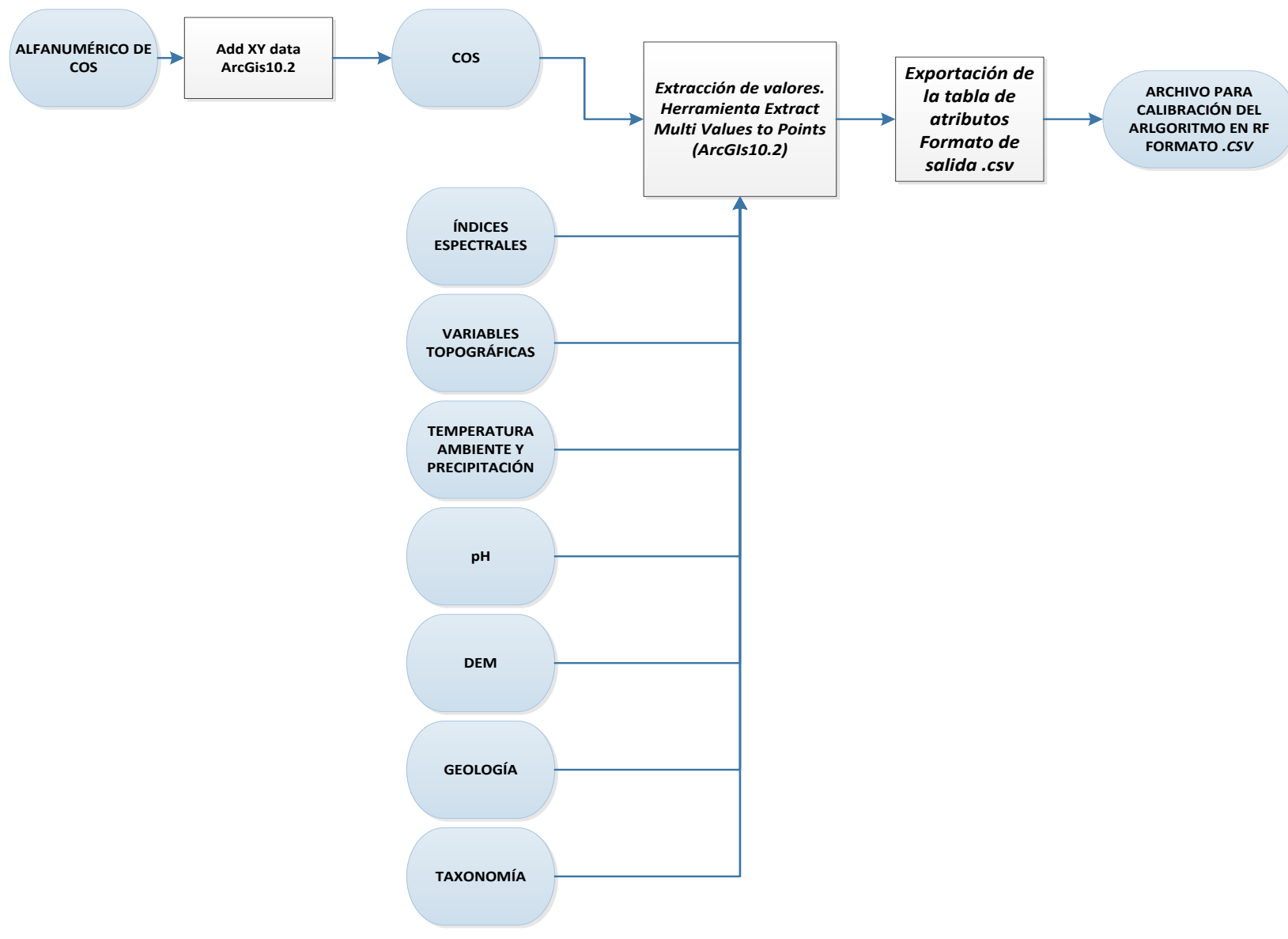

Figura 5. 22. Diagrama procedimental de la generación del archivo de calibración para el algoritmo RF

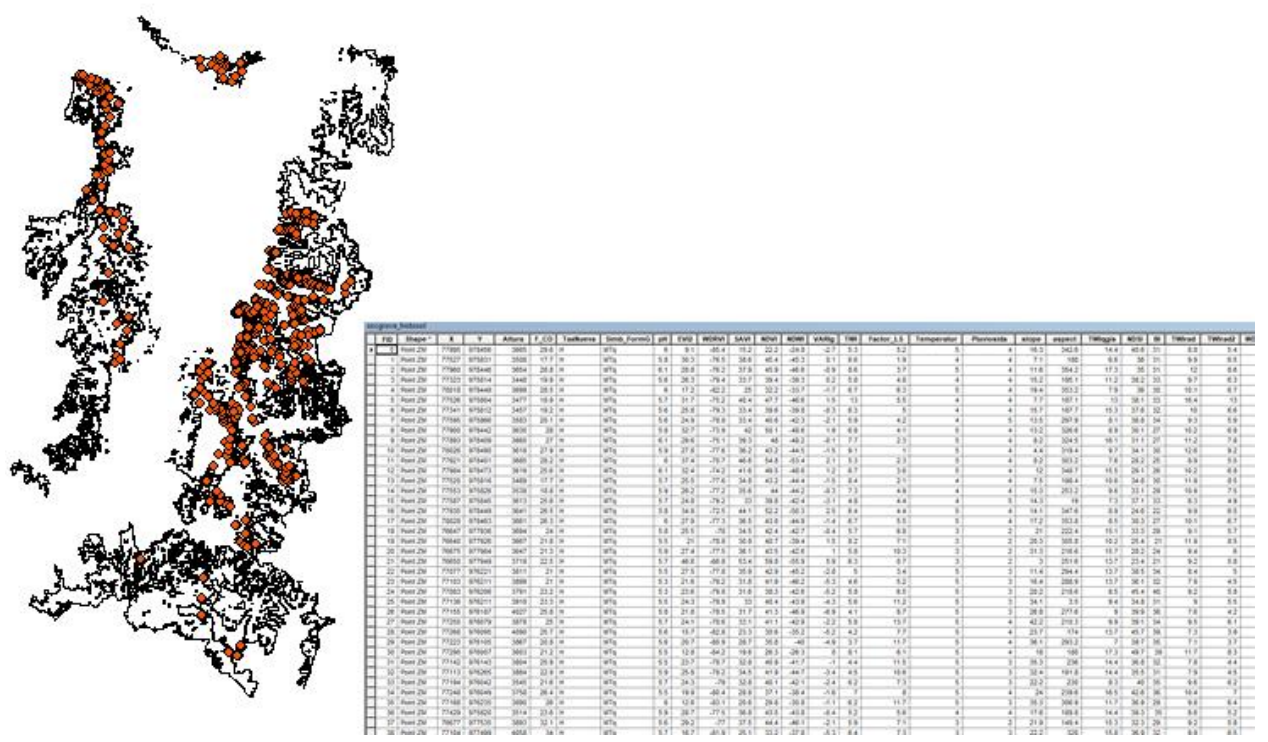

Figura 5. 23. Distribución de puntos de entrenamiento del algoritmo RF y captura del archivo .csv generado para el entrenamiento

\subsubsection{CALIBRACIÓN DEL ALGORITMO DE AUTOAPRENDIZAJE}

Como se enunció en el apartado 5.4.2, se calibra el algoritmo de autoaprendizaje Random Forest (RF), para ello, se utiliza el software propietario Salford Predictive Modeler (SMP) 8.2 de 
Salford Systems and Minitab Company (Salford Systems a Minitab company, 2018). A partir del archivo de entrenamiento en formato .csv, se configura el "target" que hace referencia al valor de COS conocido (variable dependiente - Y), también el "predictor" que corresponde a las variables que van a ser analizadas por su capacidad indicadora para la predicción de COS (variables independientes - X). El "Target Type" corresponde a la operación a realizar; ya que nuestro objetivo es realizar una regresión múltiple con el fin de predecir el valor de COS, se configuró una regression que resulta ser una predicción cuantitativa, ver Figura 5.24. El mecanismo de validación del algoritmo es el tipo Out of bag data used for testing que permite obtener un conjunto de las muestras de entrada que son escogidas en forma aleatoria para la validación, ver Figura 5.25. Finalmente, se configuraron 500 árboles de decisión y el número de predictores usados en los Split fue de 4, ver Figura 5.26.

Se evalúan en este estudio un total de 21 variables como posibles predictores en los ensayos para calibrar el algoritmo que constituirá el modelo de predicción de COS, incluyendo variables espectrales (EVI2, WDRVI, SAVI, NDVI, NDWI, VARI ${ }_{G}, N D S I, B I, N D M I, N B R, N B R 2$, temperatura de superficie terrestre), variables topográficas (Altura, Factor LS, pendiente y orientación), variables climáticas (temperatura y precipitación), pH del suelo y variables correspondientes a cartografía base del suelo del Ecuador (formación geológica y taxonomía del suelo). El uso de las variables fue en forma conjunta y así también a través de subgrupos combinados, con el fin de descartar variables no útiles. Como resultado de la calibración del algoritmo se obtiene un archivo con extensión .grv, proporcionado por el software SMP 8.2 -algoritmo Random Forest. Este archivo denominado grove es el modelo que deberá ser utilizado para la predicción de coS. 


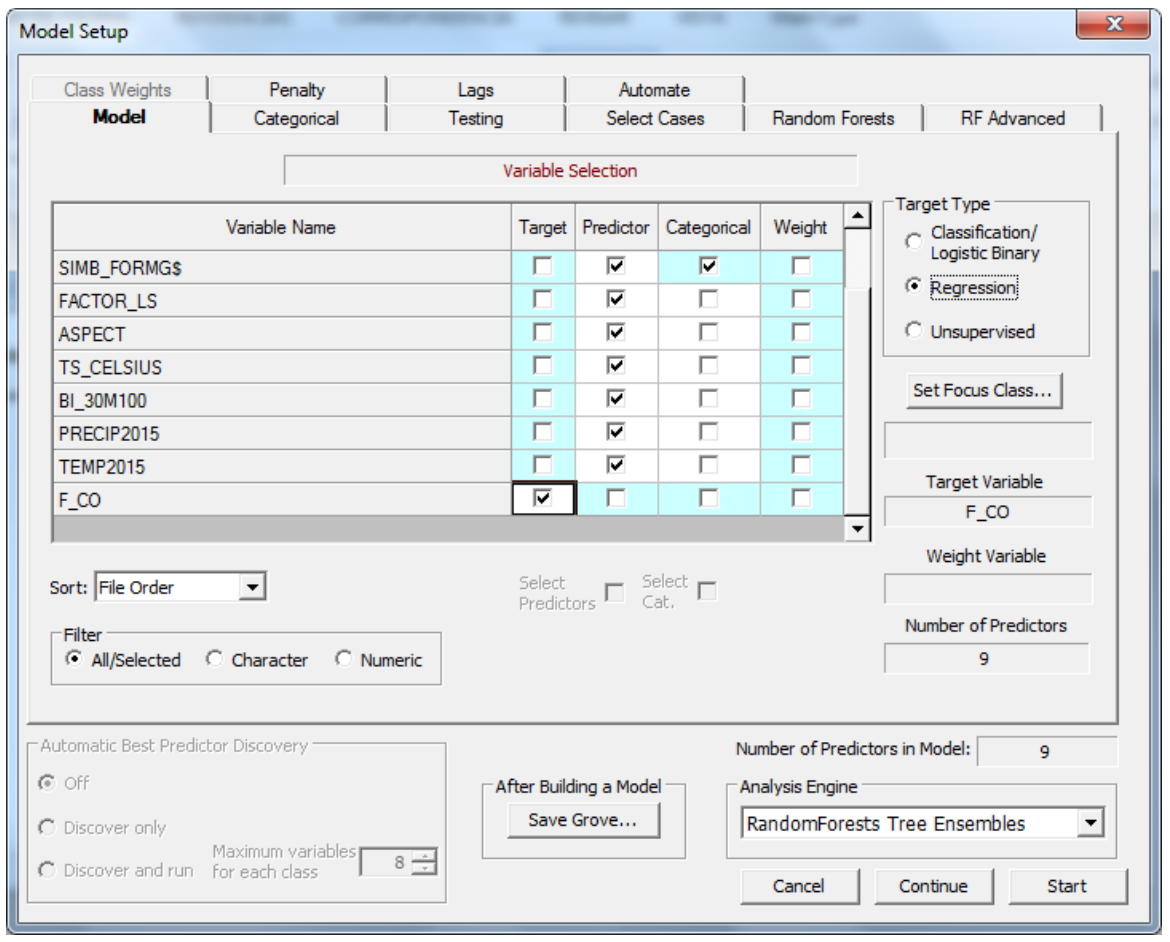

Figura 5. 24. Configuración del modelo RF

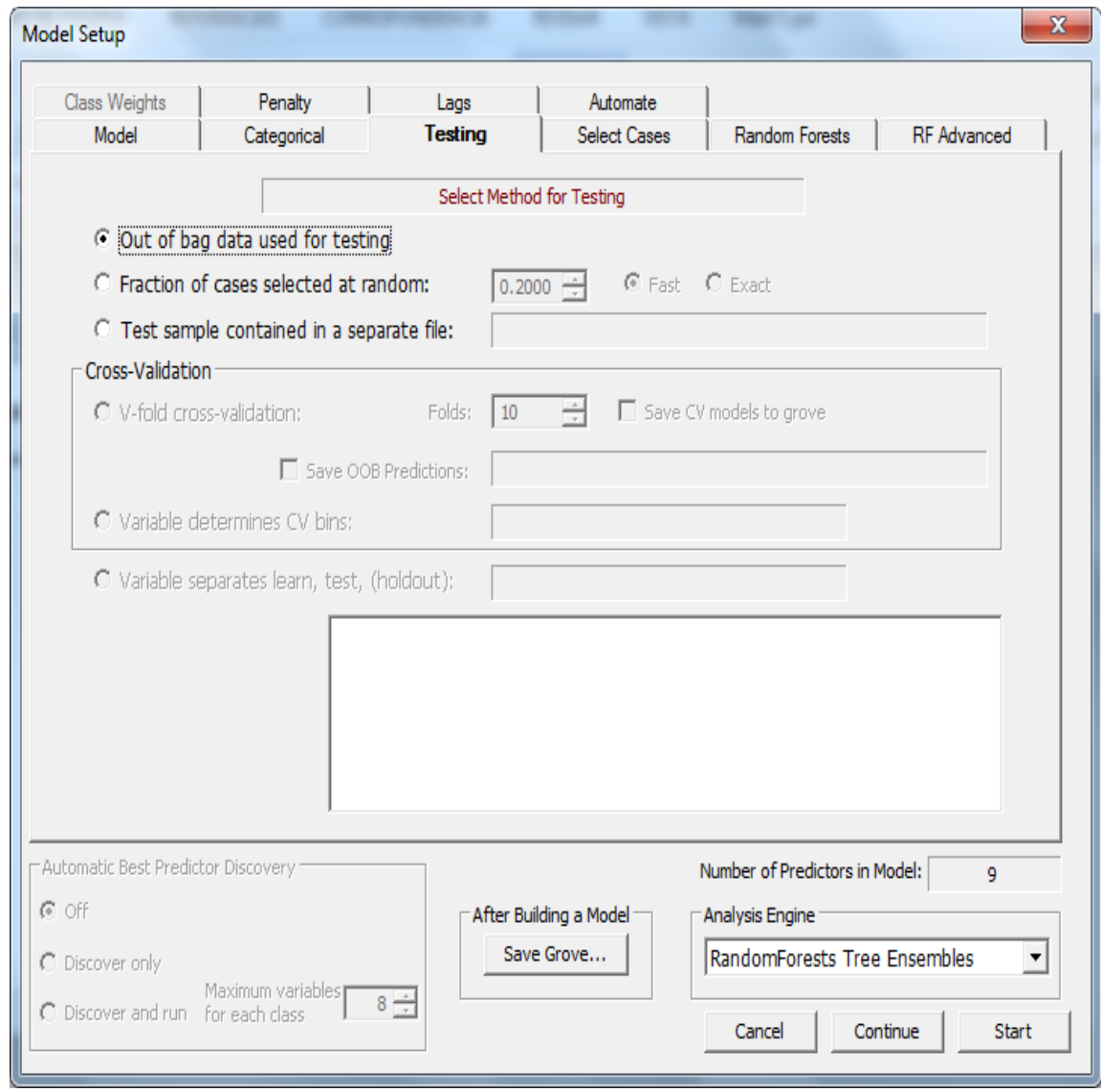

Figura 5. 25. Configuración de características de testeo para validación del modelo RF 


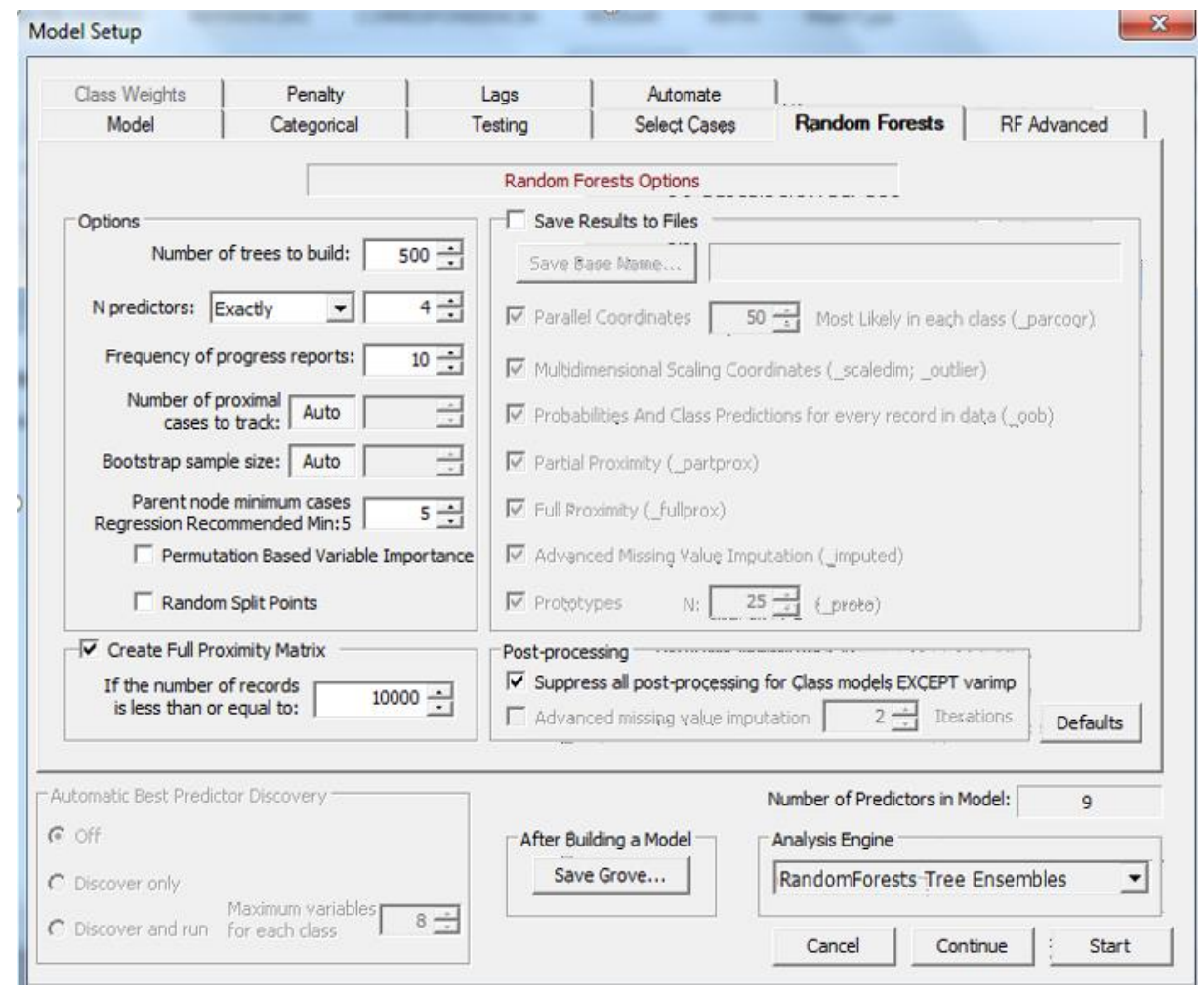

Figura 5. 26. Configuración de parámetros del modelo RF

\subsection{OBTENCIÓN DE LA PREDICCIÓN DEL COS CON EL MODELO GENERADO (ALGORITMO RANDOM FOREST CALIBRADO)}

El software SMP usado a través del algoritmo RF permite usar el modelo generado con la calibración previa del algoritmo; de esta manera se aplica el modelo a un conjunto de puntos de interés con las mismas variables que las que intervienen en el modelo generado, a través del procedimiento score, (ver Figura 5.27). La manera de realizar el score es introduciendo un archivo alfanumérico que contiene todas y cada una de las variables predictivas descubiertas a través del modelo excepto la variable COS ya que ésta es la variable que será predicha (target variable) en todos los puntos de interés en donde el COS no es conocido.

Se predicen un total de 1,686,503 registros, que corresponden a todos los pixeles de $30 \mathrm{~m}$ x 30 m que conforman la imagen Landsat 8 en la zona de estudio, identificados de manera puntual a través de una transformación de la estructura de datos ráster a vectorial. Estos 1,686,503 puntos con coordenadas de posición $(X, Y))$ son utilizados como referencia espacial para la extracción de la información proveniente de las variables de capacidad predictiva halladas tras calibrar el modelo. 


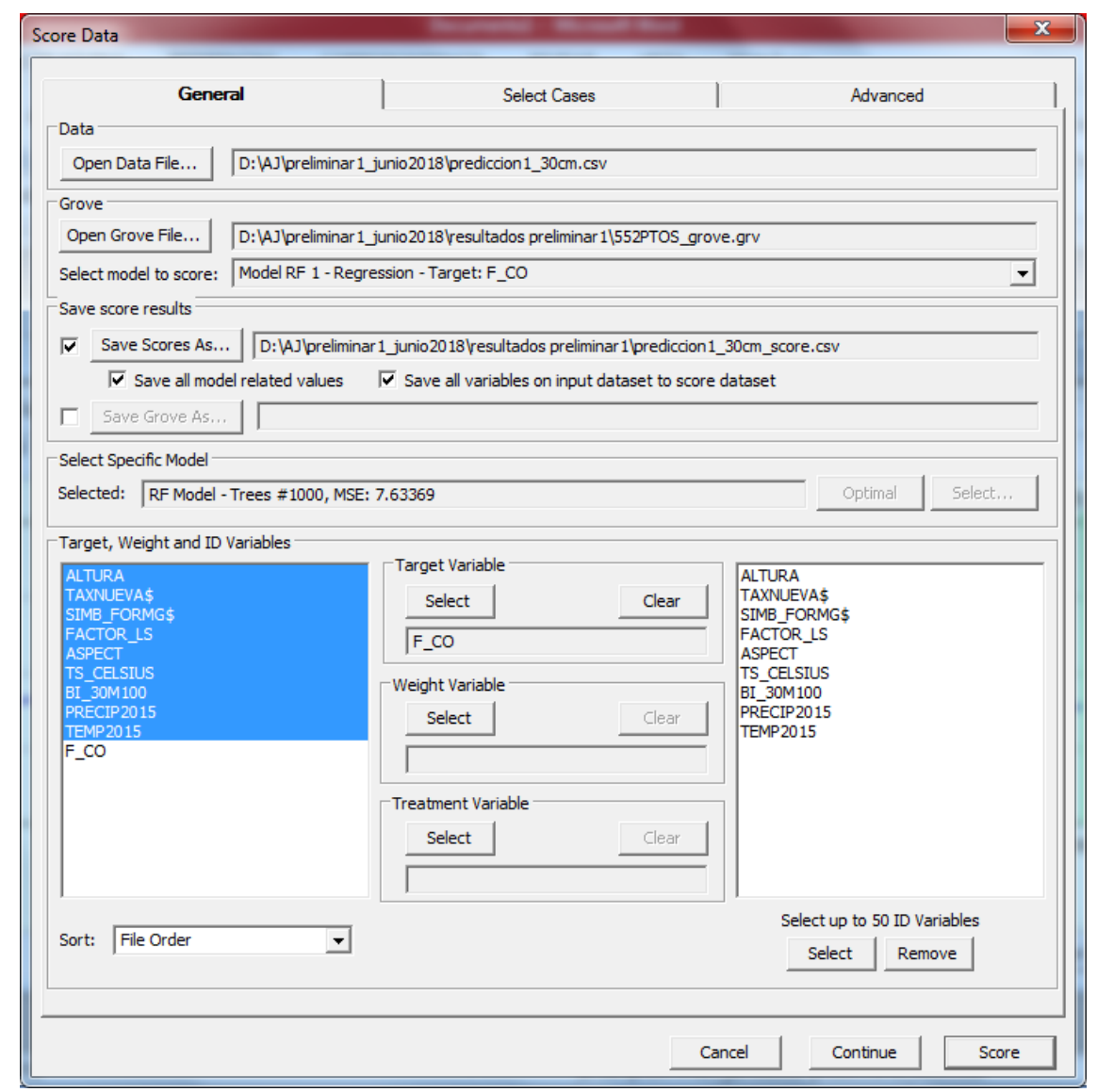

Figura 5. 27. Configuración de parámetros para la predicción

Como resultado se obtiene un archivo alfanumérico con la información resultante de la predicción de COS respecto la combinación en valor de las variables predictivas dispuesto en el archivo de entrada del proceso de predicción (score). El resultado es llevado a un SIG mediante el software ArcGis 10.2 a través de su posición asociada, para la correspondiente evaluación de los resultados obtenidos y mapeo de los mismos.

\subsection{VALIDACIÓN DE RESULTADOS POR MUESTREO DE CAMPO}

La validación de los resultados se realiza por muestreo de campo, con el fin de constatar la precisión obtenida en el modelo. Para tal fin, se usan 29 puntos de validación ubicados dentro de la zona de estudio, mediante un muestreo aleatorio simple - M.A.S. (Galmés, 2011), Ec: 5.9.

$$
n=\frac{Z^{2} p q N}{d^{2}(N-1)+Z^{2} p q} \quad E c: 5.9
$$

En dónde:

$\mathrm{n}=$ cantidad de muestras de suelo a evaluar. 
$\mathrm{N}=$ población representada por las unidades de muestreo utilizadas en el estudio, es decir, los puntos con información de COS utilizados en la obtención del modelo de predicción resultante. $p=$ probabilidad de éxito, el valor de $p$ en este caso es de 0.95 .

$q=$ probabilidad de error, el valor de q es de 0.05

Z= Valor correspondiente a la distribución t-Student con n-1 grados de libertad, es un valor constante relacionado a los intervalos de confianza sobre el cual se basa la precisión. Para el intervalo de confianza del 95\% usado en este estudio se tiene un valor de $Z$ de 1.96 basado en (Galmés, 2011) para M.A.S.

d= error de la precisión para el intervalo de confianza, el valor de d es de 0.05 .

Por restricciones de accesibilidad y económicas, se realiza el muestreo de validación al $45 \%$ del tamaño muestral $(n)$ encontrado, las muestras a evaluarse son identificadas por un mecanismo de elección al azar, teniendo como resultado la extracción de 29 muestras aleatorias simples.

\section{ANÁLISIS DE RESULTADOS Y DISCUSIÓN}

De al totalidad de las 21 variables usadas como posibles predictores, la Tabla 6.1 muestra los resultados más relevantes a los cuales denominaremos ensayos puesto que son previos a la obtención del modelo de predicción de COS. Los ensayos constituyen multiples pruebas de calibración del algoritmo de predicción; el objetivo es encontrar a los predictores descartando las variables no útiles al mismo tiempo que el coeficiente de determinación $R^{2}$ (rango 0 - 1 ) aumenta.

El ensayo $A$ emplea 13 predictores sin embargo el valor de $R^{2}$ es inferior al de los otros ensayos. Calibraciones distintas en el algoritmo modificando como por ejemplo la cantidad de árboles de decisión y eliminando las variables de menor relevancia permiten mejorar los resultados como es el caso de los ensayos B y C. Es necesario indicar que las variables son descartadas por la información limitada que proporcionan en la calibración del modelo de regresión. Así, el algoritmo ordena las variables evaluadas según su importancia relativa con lo cual el usuario puede ubicar y elegir el descarte de una o más variables.

En el ensayo $\mathrm{C}$, se incorpora la variable $\mathrm{pH}$ del suelo, dicha variable está relacionada a la cuantificación de COS ya que la MOS afecta la reacción del suelo (pH) (Martínez et al., 2008), aun así, ya que el obtener valores de $\mathrm{pH}$ implica muestrear in situ; con el fin de prescindir de dicha variable especialmente para aplicaciones de interés extendido del modelo se buscó 
encontrar la mejor alternativa de calibración. De esta manera, se logró obtener un excelente modelo de predicción de COS con un $\mathrm{R}^{2}$ de 0.82 y con un error cuadrático medio (RMSE) de 1.72 (ensayo D) usando para tal fin 500 nodos árbol.

La Figura 6.1, indica la importancia relativa de las variables predictivas según su aporte en el rendimiento del modelo, en orden descendente se tiene: Formación Geológica > Taxonomía $>$ Precipitación > Altura > Orientación > Factor LS > Índice $\mathrm{BI}>$ Temperatura $>$ Temperatura Superficial - TOA Brightnees Temperature. Como resultado, el modelo generado con el ensayo D (grove.grv), fue utilizado para la predicción del contenido de COS en el perfil $0-30 \mathrm{~cm}$, del área de estudio (ver Figura 6.2). La Figura 6.3 muestra el resultado de la predicción de COS en las unidades de $\mathrm{Mg} / \mathrm{ha}$ por considerase unidades más estandarizadas en el marco mundial para la representación de COS (FAO, 2017a).

Tabla 6. 1. Ensayos para la presentación del modelo de COS

\begin{tabular}{|c|c|c|c|c|}
\hline Ensayo & $\begin{array}{l}\text { Número de } \\
\text { predictores }\end{array}$ & Variables con fines de predicción usadas ${ }^{a}$ & $\begin{array}{l}\text { RMSE } \\
\text { (ODB) }\end{array}$ & $\begin{array}{l}\mathbf{R}^{2} \\
\text { (ODB) }\end{array}$ \\
\hline A & 13 & $\begin{array}{l}\text { FG, Temp, Pre, Tx, Alt, VARI }, \text { Asp, Slp, NDVI, } \\
\text { NDWI, FLS, SAVI, EVI2 }\end{array}$ & 4.27 & 0.70 \\
\hline B & 8 & FG, Temp, Pre, Tx, Alt, VariG, Asp, Slp & 3.88 & 0.75 \\
\hline C & 10 & Tx, FG, pH, Pre, Temp, Alt, BI, T, Asp, FLS & 2.69 & 0.88 \\
\hline D & 9 & FG, Tx, , Pre, Alt, Asp, FLS, BI, Temp, T & 1.72 & 0.82 \\
\hline
\end{tabular}

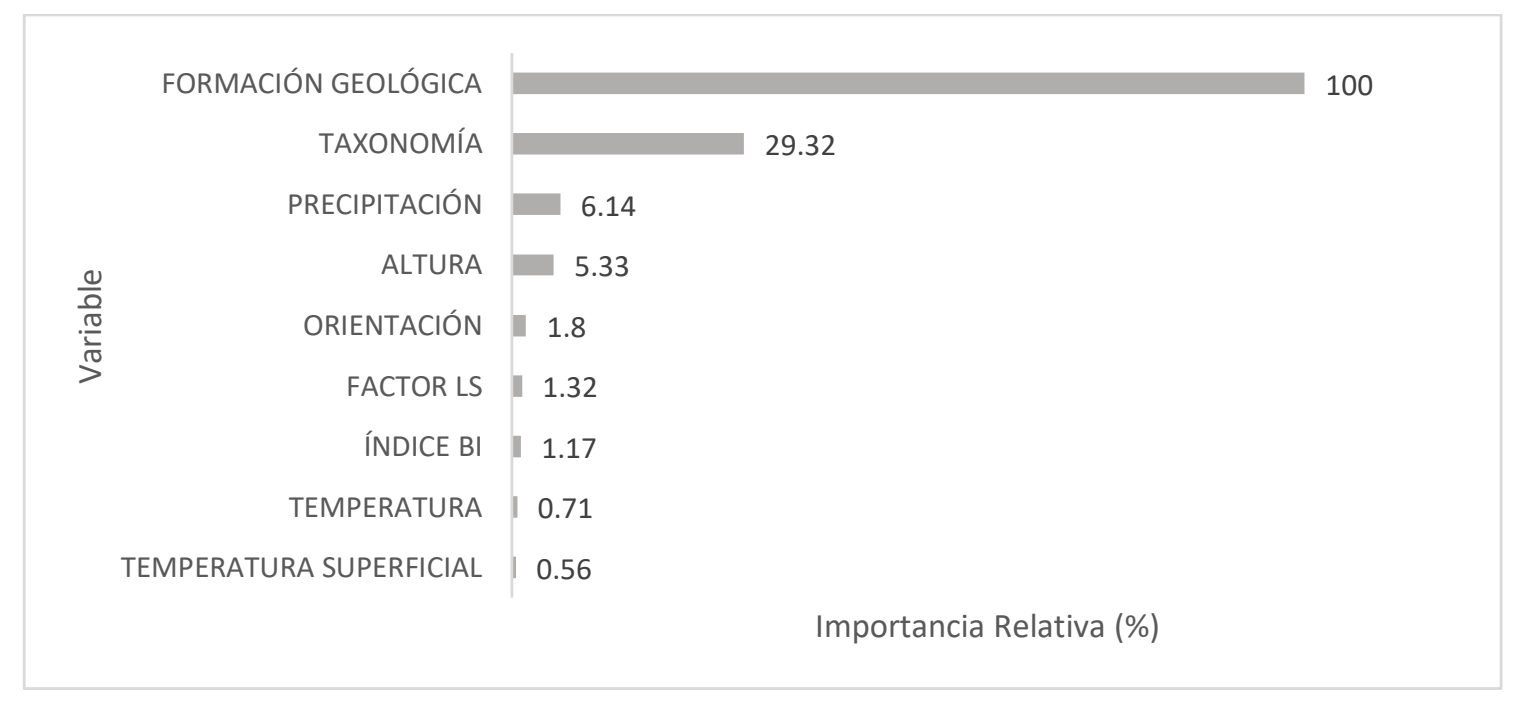

Figura 6. 1. Importancia de las variables de predicción 
PREDICCION DE COS EN EL ECOSISTEMA HERBAZAL DEL PARAMO

DE LA PROVINCIA DE CHIMBORAZO, ECUADOR
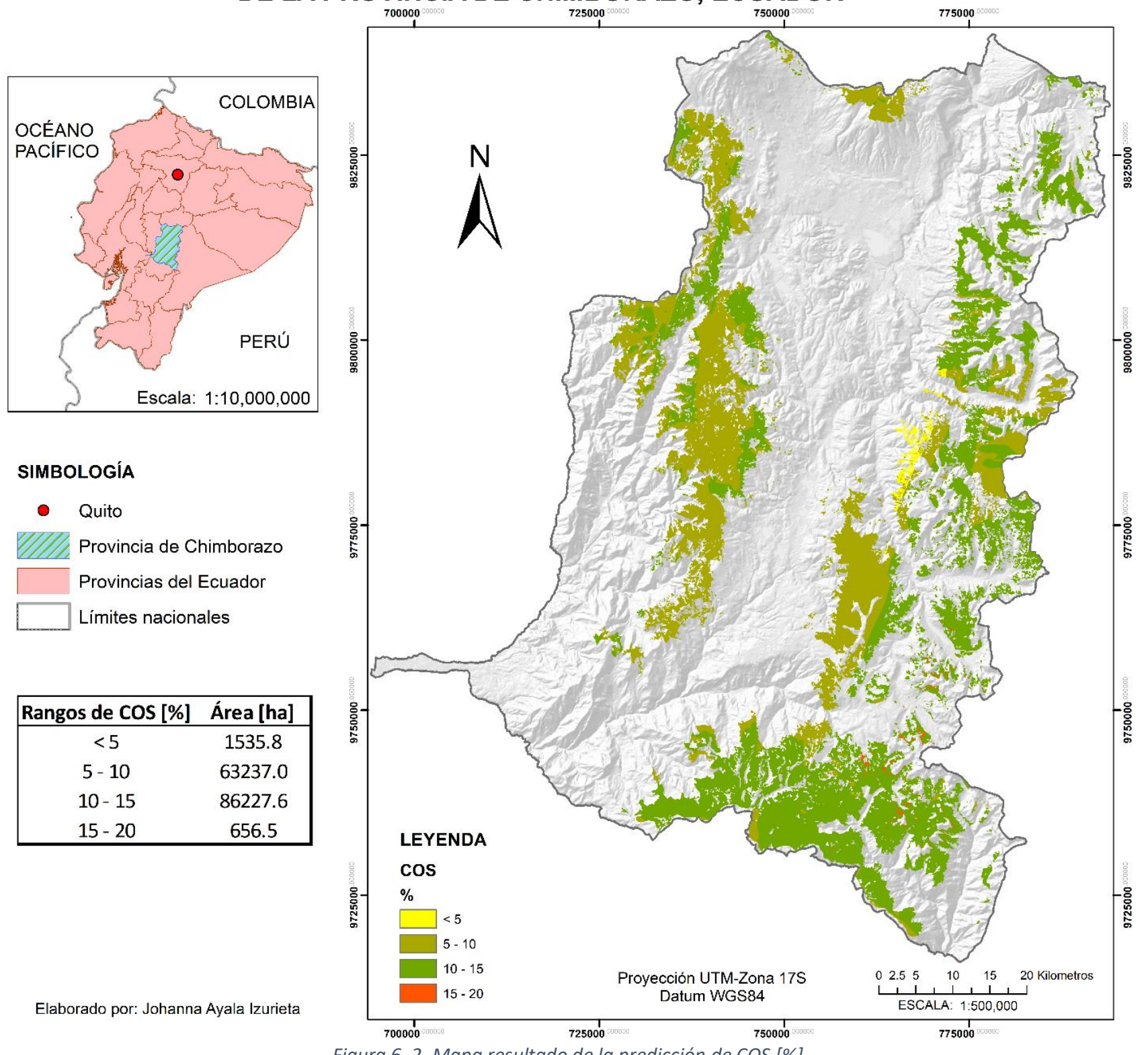

SIMBOLogía

- Quito

VIVl/ Provincia de Chimborazo

Provincias del Ecuador

Límites nacionales

\begin{tabular}{|cc|}
\hline Rangos de COS [\%] & Área [ha] \\
\hline$<5$ & 1535.8 \\
$5-10$ & 63237.0 \\
$10-15$ & 86227.6 \\
$15-20$ & 656.5 \\
\hline
\end{tabular}

Elaborado por: Johanna Ayala Izurieta

Figura 6. 2. Mapa resultado de la predicción de cos [\%] 
PREDICCION DE COS EN EL ECOSISTEMA HERBAZAL DEL PÁRAMO

DE LA PROVINCIA DE CHIMBORAZO, ECUADOR

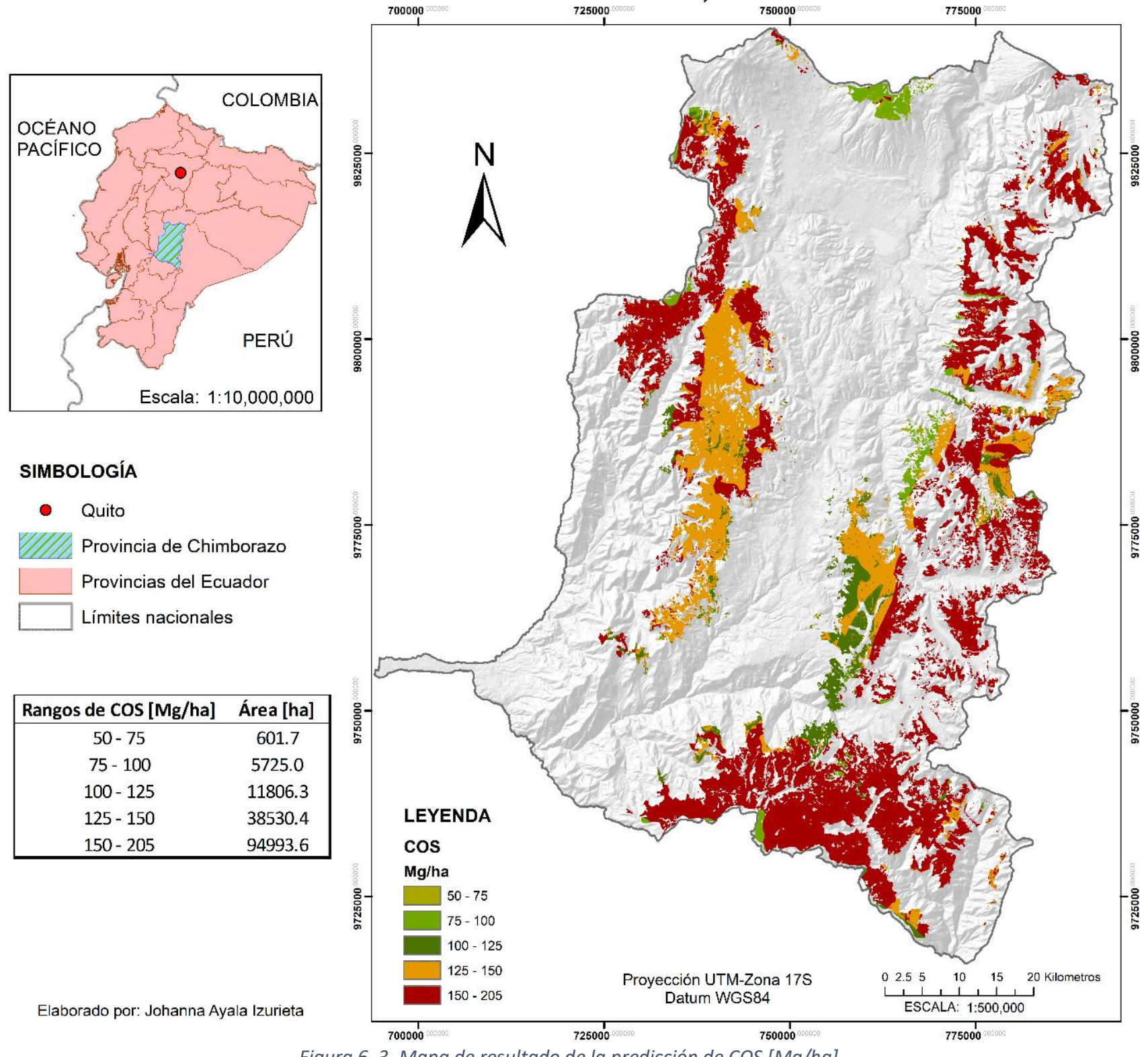

Figura 6. 3. Mapa de resultado de la predicción de $\cos [\mathrm{Mg} / \mathrm{ha}]$ 
De los 9 predictores encontrados, la formación geológica, taxonomía, precipitación y altura fueron las variables que aportan mayor información en el modelo de predicción de COS, esto concuerda con (Lal, 2004) en su análisis sobre los procesos que afectan la dinámica del COS considera que la textura y estructura del suelo, la precipitación, la temperatura, tienen mucha incidencia; del mismo modo variables como la altura, encontrada como predictor de COS apoyan la teoría en que los sitios sin intervención antrópica suelen ser más dependientes de variables más locales (Tan et al., 2004). En fin, se pudo encontrar que las variables que forman parte del modelo de predicción de COS hallado mantienen una relación físico-químico con la dinámica de secuestro de carbono (FAO, 2017b; Stockmann et al., 2013), en donde, la composición, características de los suelos y su cubierta, así como el entorno climático juegan un papel muy importante, ahora es posible conocer el grado de importancia en torno a la cantidad de secuestro de cOS.

Los resultados muestran que el mayor porcentaje del área de estudio, equivalente al $57 \%$ tiene altas concentraciones de COS entre los 150-205 Mg/ha (ver Figura 6.3). Estudios distintos de reservas de $\operatorname{COS}$ en entornos tropicales y templados, han encontrado niveles de $\operatorname{COS}$ que están entre los 50-60 Mg/ha (Andriulo et al., 2012); el contenido de SOC presente en los suelos es mayor en latitudes más altas, disminuye en las latitudes medias y aumenta en los trópicos (Batjes, 1999), lo cual queda evidenciado con el presente estudio, así como la importancia de conocer las reservas de COS en los ecosistemas de mayor relevancia por la capacidad de almacenamiento de COS, así es el caso del ecosistema páramo.

La importancia de conocer las reservas de COS a nivel mundial hace que la FAO inicie un programa con el fin de reunir toda la información existente a nivel mundial GSOC (FAO, 2018), resultados como el del presente estudio y los resultados que serán conocidos tras extender el modelo generado en todo el ecosistema herbazal del páramo del Ecuador, constituirá información geográfica de gran interés y que podrá ponerse a disposición del proyecto GSOC con el fin de colaborar en el avance del objetivo del programa.

La zona alto andina es un gran desafío por la dinámica cambiante del suelo a la hora de determinar predictores y evitar posibles errores en la información para la calibración del modelo. Usar Random Forest al ser robusto ante una posible inclusión de predictores con información limitada o información con cierto nivel de ruido (Ließ et al., 2016), minimiza el error en la predicción. 


\subsection{RESULTADOS DEL MUESTREO DE VALIDACIÓN}

La figura 6.4 muestra la distribución de los 29 puntos de validación ubicados en la zona de estudio.

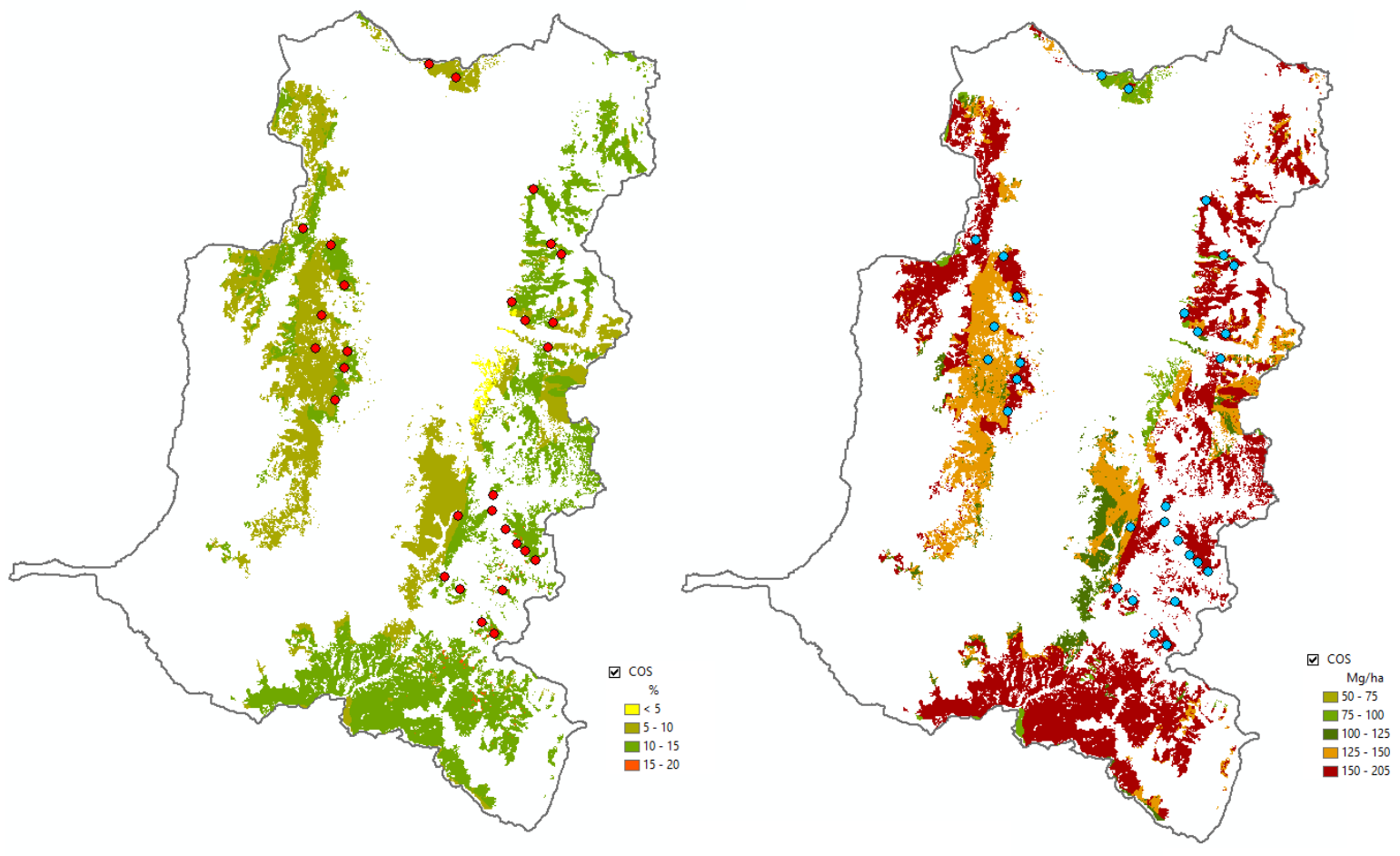

Figura 6. 4. Ubicación de puntos de validación en la zona de estudio

Luego de comparar los resultados de la predicción con los resultados de los muestreos de COS en los 29 puntos de validación, ver Figuras 6.5 y 6.7; la mediana del error absoluto porcentual obtenido de los resultados provenientes del muestreo de COS para la validación y el encontrado mediante el algoritmo de predicción está por debajo del $10 \%$ para el COS expresado en [\%] y del $11.5 \%$ en los resultados de $\operatorname{COS}$ en $\left[\mathrm{Mg} / \mathrm{ha}\right.$ ]. El modelo generado alcanzó un $\mathrm{R}^{2}$ de 0.82 en su calibración y prueba, mientras que, en la validación a través del error medio, se alcanza un $\mathrm{R}^{2}$ de 0.85 , con lo cual el modelo de predicción de COS y su precisión son verificados. La distribución del error para cada una de las muestras se observa en Figura 6.6 y Figura 6.8. 


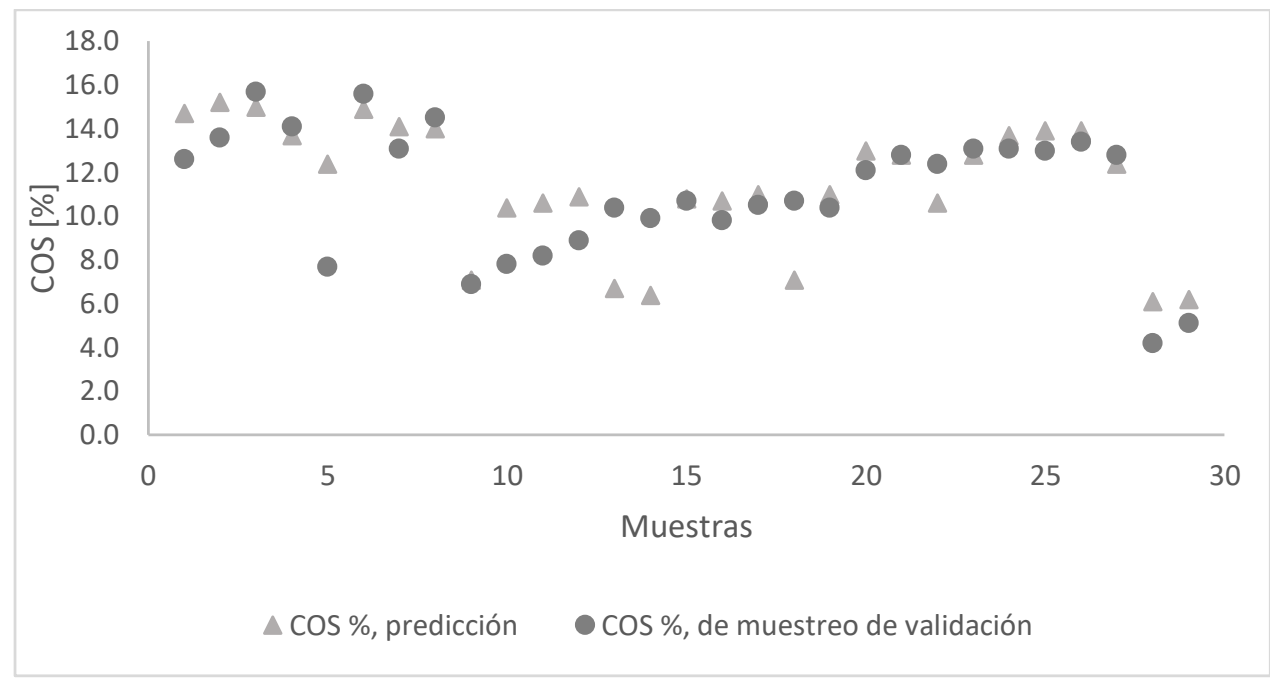

Figura 6. 5. Valores de COS en los puntos de validación vs COS predicho, unidades [\%]
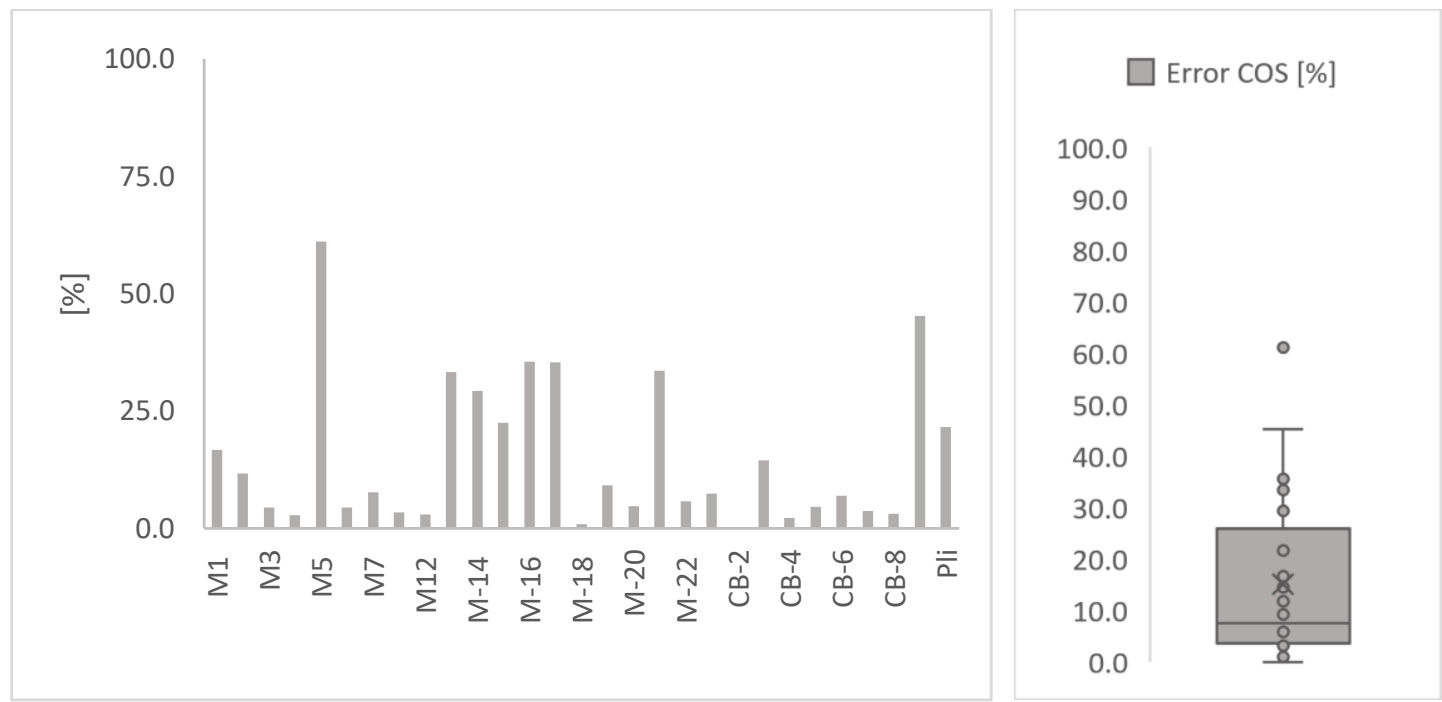

Figura 6. 6. Gráficas de error de coS [\%] en función de las muestras de validación

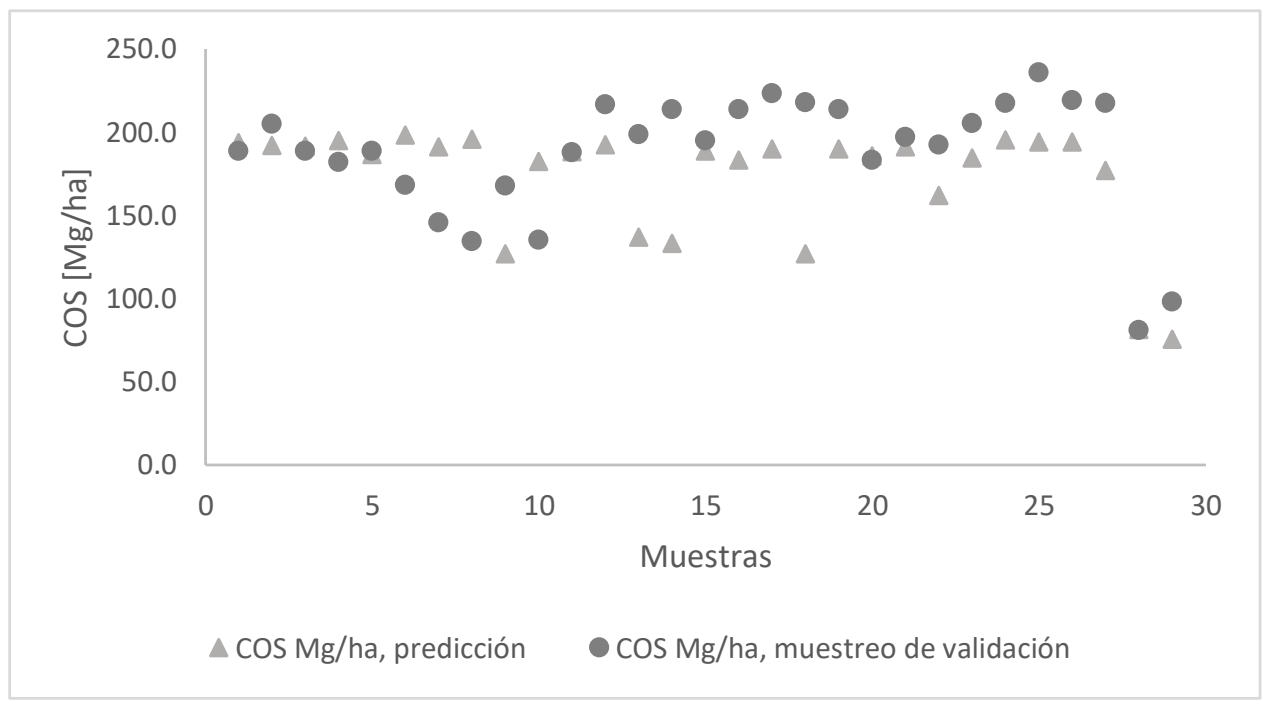

Figura 6. 7. Valores de COS de puntos de validación vs COS predicho, unidades [Mg/ha] 


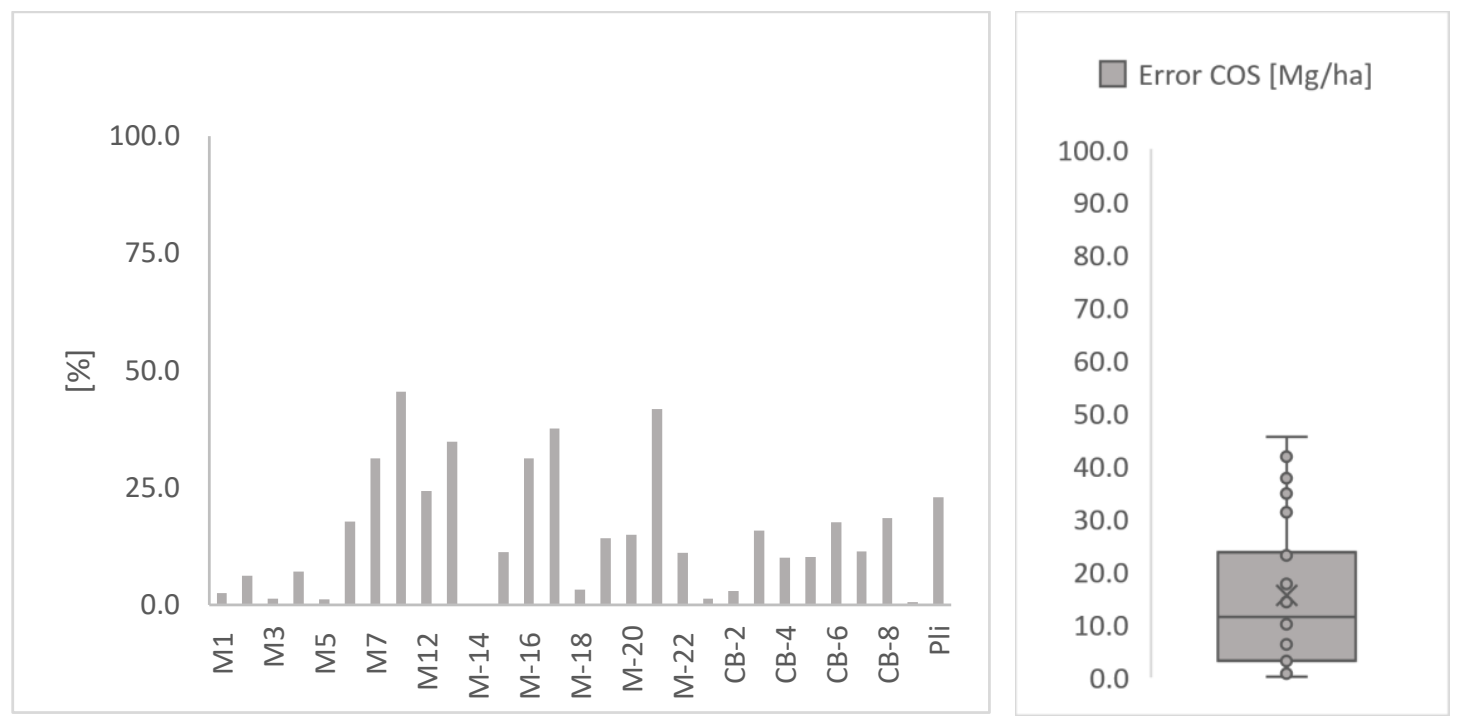

Figura 6. 8. Gráficas de error de $\operatorname{COS}[\mathrm{Mg} / \mathrm{ha}]$ en función de las muestras de validación

\section{CONCLUSIONES}

En esta investigación se calibró un modelo de predicción de carbono orgánico del suelo con un nivel de precisión del $82 \%$. Muy difícil de lograr en zonas complejas desde el punto de vista climático, variabilidad topográfica, diversidad geológica, entre otros. Para tal fin, Random Forest como algoritmo de aprendizaje automático permitió detectar las 9 variables ambientales con información valiosa en la dinámica del secuestro del COS. La aplicabilidad de este tipo de algoritmos reduce grandes costes económicos, que conllevan levantar la información en zonas con dificultades de acceso o de gran extensión. También pueden ser utilizados como una nueva alternativa metodológica con presupuestos limitados.

Se encontró que las variables: formación geológica, taxonomía del suelo, precipitación, altura, orientación, factor LS, índice BI, temperatura y temperatura superficial - TOA Brightnees Temperature; tienen gran relevancia en la cuantificación de COS. Las variables encontradas en conjunto con el modelo logrado con RF reducen la necesidad de muestreos intensivos en campo. Estas variables se pueden obtener con la metodología desarrollada en el presente estudio.

La predicción de carbono orgánico del suelo (COS) es influenciada principalmente por la formación geológica y la taxonomía del suelo, seguidas de la precipitación y altura. La complejidad topográfica del terreno de estudio, así como, la heterogeneidad geológica en el área de estudio, hacen que, información adicional con menor importancia relativa sea relevante en el incremento de la precisión del modelo. Así es el caso de las variables obtenidas a través de los sensores remotos OLI y TIRS, así como la variable meteorológica temperatura. 
A través del modelo de predicción y SIG se logró mapear de manera digital el COS en la capa superficial $(0-30 \mathrm{~cm})$ del ecosistema Herbazal del Páramo de toda la provincia de Chimborazo Ecuador, descubriendo en él las elevadas reservas de COS. Más del 50\% del área de estudio tiene concentraciones de COS entre los 150-205 Mg/ha. De esta manera, los resultados ubican al HP como un ecosistema de relevancia en las reservas de COS a nivel nacional y mundial.

El uso de imágenes Landsat 8 en este estudio de gran extensión superficial con distribución irregular y dispersa del ecosistema HP fue un reto. Las condiciones climáticas extremas por la presencia de clima frío-húmedo a lo largo del año, así como el elevado gradiente altitudinal de las zonas de páramo, provocan en las imágenes satelitales, escenas con gran porcentaje de nubosidad en pequeñas y grandes áreas. Por tal motivo, el tiempo dedicado en la selección de imágenes, el tratamiento y detección de zonas nubosas, así como el relleno es un proceso laborioso, minucioso, crítico y de gran importancia en éstos entornos; en donde, muchas de las veces el uso de imágenes satelitales ópticas no resulta viable. Aun así, la metodología empleada en el procesamiento de imágenes y generación de información geográfica fue útil y fue posible lograr información valiosa para el modelo. Futuras líneas de investigación en estos entornos podrían considerar alternativas en donde la influencia atmosférica pueda ser minimizada tal es el caso de los sensores RADAR- Radio Detection And Ranging, mismos que trabajan con microondas.

La metodología propuesta es un gran aporte a la comunidad científica, especialmente a los grupos de investigación en escenarios de tal complejidad como son las zonas alto andinas. Los resultados de la cuantificación y mapeo del COS en el HP son de vital importancia para el objetivo mundial de conocer las reservas de COS. Así mismo, los resultados hicieron evidente la gran capacidad de secuestro de carbono que tiene el ecosistema estudiado debido la composición del suelo, las condiciones físico-químicas del suelo y las de su entorno.

Se ha desarrollado una alternativa de cuantificación de COS, el modelo puede ser extendido sin necesidad de muestreo in situ. Así mismo, los resultados obtenidos mediante el mapeo digital de $\cos$ y el descubrimiento de las elevadas reservas de COS, existentes en el ecosistema de estudio, representan un gran aporte en la caracterización de los suelos del territorio nacional. Con lo cual podrá ser posible establecer normativas provinciales y nacionales que eviten la degradación del suelo en este tipo de ecosistemas, por la importancia que estos tienen, en la estabilización de las estructuras del suelo y regulación hídrica. También por su aporte en la 
mitigación del cambio climático, por su participación en el proceso de reducción de las concentraciones de $\mathrm{CO}_{2}$ de la atmósfera.

\section{RECOMENDACIÓN}

El proyecto SOCEPE da inicio tras la reunión con un representante de la Organización de las Naciones Unidas para la Educación, la Ciencia y la Cultura (UNESCO) (UNESCO, 2019), en donde se estudia la mitigación y adaptabilidad al cambio climático. Se evidenció la necesidad de crear un programa científico con 5 líneas de trabajo o proyectos: "Soil Organic Carbon Sequestration in Ecuadorian Paramo Ecosystems", "Vulnerability assessment of the social-ecological system", "Development of ecosystem-based adaptations strategies", "Cost-benefits analyses from carbon sequestration through conservation to the various options of adaptations", "Simulations of the future scenarios (and how they can be perceived by actors)".

Dentro del proyecto SOCEPE, en el área de SIG y teledetección, se encuentra enmarcada la presente investigación dentro de la componente 3 (Validación y Diseño del mapa digital de carbono orgánico del suelo en el páramo). Los resultados de la investigación entregados serán usados como estudio base en la componente 4 (Diseño del modelo digital para mapeo del carbono en toda el área del corredor interandino del Ecuador). Paralelamente el área ambiental del proyecto SOCEPE, lleva permanentemente actividades de socialización y capacitación con las comunidades. Las comunidades son los actores que viven dentro del área de estudio y que sin el consentimiento de ellos no es posible el acceso y mucho menos realizar muestreos. También dentro de la socialización, la Universidad Nacional de Chimborazo (UNACH) genera reportes continuos al Ministerio del Ambiente del Ecuador (MAE), como parte de los requerimientos que permiten a la universidad obtener y mantener el permiso de investigación en áreas protegidas.

Sin embargo, con la finalidad de elevar los resultados obtenidos en pro de la conservación del ecosistema Herbazal del Páramo, se recomienda aplicar inteligencia territorial mediante la elaboración de agendas científicas con mesas de trabajo permanentes (Bozzano \& Canevari, 2018). En las que se incluyen a los actores involucrados: científicos, políticos e instituciones, comunitarios y empresarios como ejes de participación y acción. Con estas mesas de trabajo se espera activar y generar un intercambio de ideas, que se orienten a la construcción del conocimiento en el marco de la mitigación y adaptabilidad al cambio climático global. Así mismo, de manera conjunta es posible realizar acuerdos que constituyan las bases para las regulaciones y normativas necesarias. 
Así, dentro de la componente socialización del proyecto SOCEPE. Se recomienda la agenda de investigación operacionalizada mediante la mesa de trabajo permanente con la temática "Preservación y mantenimiento del ecosistema Páramo". Los actores involucrados constituyen: el área ambiental del proyecto SOCEPE e investigadores asociados, los presidentes de las juntas parroquiales de la provincia de Chimborazo, los representantes de las comunidades y representantes del MAE.

Considerando la constitución de la República del Ecuador bajo el Art. 406 (“El Estado regulará la conservación, manejo y uso sustentable, recuperación, y limitaciones de dominio de los ecosistemas frágiles y amenazados; entre otros, los páramos, humedales, bosques nublados, bosques tropicales secos y húmedos y manglares, ecosistemas marinos y marinoscosteros.") (República del Ecuador, 2008), se tiene al ecosistema páramo dentro del Marco normativo del Ecuador relacionado con las áreas protegidas. Aun así, es necesario contar con un instrumento legal específico para el páramo. Es decir, una "Ley sobre conservación y uso de páramos" o bien un "Reglamento sobre conservación y uso de páramos" (Hofstede et al., 2011).

En este contexto, se contempla que las mesas de trabajo deben ser periódicas y deben regular las actividades antrópicas que contribuyen a la pérdida del ecosistema y la degradación de los suelos. También se contemple encontrar las acciones preventivas, correctivas, así como sus consecuencias a corto, mediano y largo plazo. Como resultado de las mesas de trabajo se puede tener en corto plazo convenios y acuerdos a nivel de actores. Esto sería un adelanto positivo que evidencia una aplicación favorable de la investigación, que repercute en la conservación del ecosistema.

Los instrumentos técnicos, científicos y socio ambientales -productos de la mesa de trabajo y la investigación- serán socializados y llevados a la siguiente instancia en el MAE con el objetivo de estructurar el proyecto de ley para su presentación y aprobación, enmarcado en el contexto del uso soberano de la inteligencia territorial (Bozzano et al., 2012).

Ahora bien, el ecosistema páramo en América Latina tiene una superficie aproximada de 1,6663,03 ha. Se distribuye de manera ininterrumpida desde la cordillera de Mérida en Venezuela hasta la depresión de Huancabamba en el norte del Perú, también se ubica en los páramos centroamericanos de Costa Rica, Panamá y la Sierra Nevada de Santa Marta en Colombia (Hofstede et al., 2014). En tal virtud, se considera investigar la posibilidad de replicabilidad del presente estudio en entornos similares, favoreciendo el conocimiento y la ciencia integral, de todos y para todos (Boaventura, 2009). El estudio puede ser replicado 
fuera del territorio nacional, incrementando el alcance y proyección del proyecto SOCEPE en los próximos años. Del mismo modo, se pueden establecer vínculos con otros proyectos, pudiendo llegar también a organizaciones internacionales y a los ministerios del ambiente de los países correspondientes. Se considera también, el evaluar la implementación de una agenda científica participativa que abra la puerta a una política de estado. En este sentido se contempla usar el método Territorii por su adaptabilidad en todas las líneas de interés territorial (Ferrari \& Bozzano, 2016). 


\section{NOMENCLATURA}

A

árboles de decisión: Es un método usado en RF como modelo de predicción. Se denominan árboles ya que poseen una estructura nodo rama, resultado de una partición recursiva bajo la cual se obtiene un árbol de regresión en el caso del estudio, el árbol es usado para obtener las predicciones de COS en base a las variables independientes consideradas., $25,50,55$

B

barrenación: Insertar el instrumento barreno (especie de pala metálica) en el suelo para obtener el porcentaje de muestra requerida, 18

bootstrap: Muestra aleatoria basada en los registros de los datos de entrenamiento del algoritmo Random Forest de SMP. Se usan para generar un algoritmo de autoaprendizaje y finalmente lograr un modelo de predicción de COS del suelo., 26

C

COS: Carbono Orgánico del Suelo, 27

D

DEM: Modelo Digital de Elevación, 19, 29, 31, $41,44,49$

E

ENMASCARAMIENTO: DElimitación de las zonas en la imagen bajo determinada regla., 33

EP: Ecosistema de Páramo, 10

EPE: Ecosistema de Páramo en el Ecuador, 10, $12,13,14,17$

$\boldsymbol{F}$

ferralíticos: Suelo rico en hierro y aluminio, debido al lavado de otros cationes como consecuencia de un largo período de condiciones climáticas húmedas., 21

G

geosistemas: Conjunto de entidades bióticas (biósfera), abióticas (litósfera, atmósfera e hidrósfera) y antrópicas (sociedad), entre las cuales se producen permanentes interrelaciones que originan cambios cualitativos y cuantitativos que caracterizan finalmente la estructura terrestre., 2, 21, 62 GEOTIFF: Es un estándar de metadatos de dominio público que permite que información georreferenciada sea encajada en un archivo de imagen de formato TIFF., 29

grove: Archivo generado en el software SMP, algoritmo Random Forest con extensión .grv, constituye el modelo de predicción generado con el software al concluir el entrenameinto del algoritmo de autoaprendizaje., 51, 55

H

helio-sincrónica: Es una órbita geocéntrica que combina altitud e inclinación para lograr que un objeto en esa órbita pase sobre una determinada latitud terrestre a un mismo tiempo solar local. Es retrógrada es decir el satélite orbita en forma opuesta al giro direccional de la Tierra., 24

HsSn02: Ecosistema de páramo tipo Herbazal del Páramo codificado según el Ministerio del Ambiente del Ecuador, 14, 15, 17, 27

I

IGM: El Instituto Geográfico Militar del Ecuador gestiona, aprueba y controla todas las actividades encaminadas a la elaboración de la cartografía oficial y del archivo de datos geográficos y cartográficos del país, elabora especies valoradas y documentos de seguridad como único organismo autorizado y difunde las ciencias geoespaciales, 29, 30, 49, 67

INAMHI: Instituto Nacional de Meteorología e Hidrología del Ecuador, 14, 44, 45, 46

INFOPLAN: es una herramienta que consolida información estadística y geográfica de las instituciones públicas y la pone a disposición de la ciudadanía a traves del sitio www.sni.gob.ec. Se dispone información estadística y geográfica elaborada por fuentes oficiales, 19 
KRIGING: Usado en el Krigeado, es un método geoestadistico para la estimación de puntos. Utiliza un modelo de variograma para la obtención de los ponderadores que se darán a cada punto de referencias usados en la estimación. Esta técnica de interpolación se basa en la premisa de que la variación espacial continúa con el mismo patrón. Utilizado en el estudio para la estimación de superficies climáticas y de $\mathrm{pH} ., 44$

M

mineralización: Referente a un proceso biológico que ocurre mediante la conversión de la materia orgánica a un estado inorgánico, a través de la acción de microorganismos., 10, 24

MO: Matería orgánica presente en las muestras de suelo, 18, 24

MODELO: Referente al algoritmo final de predicción entrenado y calibrado, mismo que es usado para la predicción de COS en el área de estudio., 52

$\boldsymbol{P}$

$\mathrm{pH}$ : Potencial de hidrogeno unidad de medida que sirve para establecer el nivel de acidez o alcalinidad de una sustancia., 17, 28, 48, 49, 55

píxeles: De pixel, es la menor unidad homogénea en color que forma parte de una imagen digital., 31, 32, 33 radiancia: Es el flujo radiante, es la magnitud que detecta el sensor en la plataforma del satélite. Cuando la radiancia se refiere a una porción., 30, 31, 40; Es el flujo radiante, es la magnitud que detecta el sensor en la plataforma del satélite. Cuando la radiancia se refiere a una porción. concreta del espectro electromagnético se le denomina radiancia espectral, 30

$S$

score: Procedimeinto en el softeiware Random Forest para realizar la predicción de una variable utilizando un modelo previamente entrenado grove., 52, 53

SIG: Sistemas de Información Geográfica, 11, $12,13,53$

SOCEPE: Soil Organic Carbon Evaluation and Sequestration in Ecuadorian Páramo Ecosystems. Es un proyecto que estudia el almacenaje de COS en el ecosistema de páramo en el Ecuador, 11, 12, 14, 17, 18

V

variables predictivas: Son variables que proporcionan información suficiente para la predicción de la variable de interés (COS), estas variables estarían controlando la dinámica de distribución y almacenaje del cos en la zona de estudio., 13, 25, 52, 53, 55 


\section{BIBLIOGRAFÍA}

Africano, K., Cely, G., \& Serrano, P. (2016). Potencial de captura de CO 2 asociado al componente edáfico en páramos Guantiva-La Rusia, departamento de Boyacá, Colombia. Perspectiva Goegrafica, 21(1), 91-110.

Aguilar Arias, H., Mora Zamora, R., \& Vargas Bolaños, C. (2014). Metodología Para La Corrección Atmosférica De Imágenes Aster, Rapideye, Spot 2 Y Landsat 8 Con El Módulo Flaash Del Software Envi. Revista Geográfica de América Central, 53, 39-59. https://doi.org/10.15359/rgac.2-53.2

Andriulo, A., Galantini, J., Studdert, G., Sasal, M., Wilson, M., Basanta, M., ... Restovich, S. (2012). Existencias de carbono orgánico edáfico bajo diferentes usos y tipos de suelo. Xix Congreso Latinoamericano De La Ciencia Del Suelo, (January), 5.

Arbelo, C., Rodríguez, A., Sánchez, J., Notario, J., Recalata, L., Mora, J., ... Armas, C. (2008). CARACTERIZACIÓN EN ENTORNO SIG DE LOS SUELOS DEL PARQUE NACIONAL DEL TEIDE. DINÁMICA DE NUTRIENTES Y CARBONO EN LOS SUELOS. In Proyectos de investigación en parques nacionales 2005-2008 (pp. 43-72).

Ayala, J. E., Márquez, C. O., García, V. J., Recalde, C. G., Rodríguez, M.-V., \& Damián, D. A. (2017). Land cover classification in an ecuadorian mountain geosystem using a random forest classifier, spectral vegetation indices, and ancillary geographic data. Geosciences (Switzerland), 7(2). https://doi.org/10.3390/geosciences7020034

Bannari, A., Morin, D., Bonn, F., \& Huete, A. R. (1995). A review of vegetation indices. Remote Sensing Reviews, 13(1), 95-120. https://doi.org/10.1080/02757259509532298

Batjes, N. H. (1999). Management options for reducing CO2 - concentrations in the atmosphere by increasing carbon sequestration in the soil. Options, (952282), 126.

Beltrán, K., Salgado, S., Cuesta, F., León-Yánez, S., Romoleroux, K., Ortiz, E., ... Velástegui, A. (2009). Distribución espacial, sistemas ecológicos y caracterización florística de los páramos en el Ecuador. EcoCiencia, 72-150.

Blanco, A., Alonso, F., \& Gomariz, F. (2014). Elaboración de un mapa de carbono orgánico del suelo en la Región de Murcia. In XVI Congreso de Tecnologías de la Información Geográfica (p. 9).

Boaventura, D. S. S. (2009). Una epistemología del Sur La reinvención del conocimiento y la 
emancipación social. México: CLACSO y Siglo XXI.

Bozzano, H., \& Canevari, T. (2018). Estrategias para la Gestión Integral del Territorio.

Bozzano, H., Girardot, J. ., Cirio, G., Barrionuevo, C. ., \& Gliemmo, F. (2012). Intelligencia Territorial: teoría, métodos e iniciativas en Europa y América Latina.

Breiman, L. (2001). Random Forests. Machine Learning, 45(1), 5-32. https://doi.org/10.1023/A:1010933404324

Breiman, L., Friedman, J., Olshen, R., \& Stone, C. (2017). Classification and Regression Trees (19 October). https://doi.org/10.1201/9781315139470

Chartin, C., Stevens, A., Goidts, E., Krüger, I., Carnol, M., \& van Wesemael, B. (2017). Mapping Soil Organic Carbon stocks and estimating uncertainties at the regional scale following a legacy sampling strategy (Southern Belgium, Wallonia). Geoderma Regional, 9, 73-86. https://doi.org/10.1016/j.geodrs.2016.12.006

Chen, W., Liu, L., Zhang, C., Wang, J., Wang, J., \& Pan, Y. (2004). Monitoring the seasonal bare soil areas in Beijing using multi-temporal TM images, (October), 1-5. https://doi.org/10.1109/IGARSS.2004.1370429

Chuvieco, E. (1995). Fundamentos De Teledeteccion Espacial (Segunda. E). Madrid. https://doi.org/23.304-1995

Chuvieco, E. (2008). Teledeteccion ambiental.pdf (Tercera ed). Barcelona.

CONAE. (2016). Índices Espectrales derivados de imágenes satelitales Landsat 8 Sensor OLI. Guia de Usuario CONAE.

Desmet, J., \& Govers, G. (1996). A GIS procedure for automatically calculating the USLE LS factor on topographically complex landscape units. Journal of Soil and Water Conservation, 51(5).

Exelis Visual Information Solutions. (2013). ENVI tutorial.

FAO. (2017a). Mapa de Carbono Orgánico del Suelo.

FAO. (2017b). Soil Organic Carbon: the hidden pptencial. Rome, Italy. https://doi.org/10.1038/nrg2350

FAO. (2018). Food and Agriculture Organization of the United Nations.

Farley, K. A., Bremer, L. L., Harden, C. P., \& Hartsig, J. (2012). Changes in carbon storage under alternative land uses in biodiverse Andean grasslands: Implications for payment for 
ecosystem services. Conservation Letters, 6(1), 21-27. https://doi.org/10.1111/j.1755263X.2012.00267.x

Farley, K. A., Kelly, E. F., \& Hofstede, R. G. M. (2004). Soil Organic Carbon and Water Retention after Conversion of Grasslands to Pine Plantations in the Ecuadorian Andes. Ecosystems, 7(7), 729-739. https://doi.org/10.1007/s10021-004-0047-5

Ferrari, M. P., \& Bozzano, H. (2016). APPLICATION OF TERRITORII METHOD IN TWO SPONTANEOUS SETTLEMENTS OF PUERTO MADRYN , ARGENTINA. Geography Papers, 62. https://doi.org/dx.doi.org/10.6018/geografia/2016/260061

Galmés, M. (2011). Métodos de muestreo. In Taller Regional sobre el uso de Muestreo en las Encuestas Agrícolas. Montevideo.

González, M., Jurado, E., González, S., Aguirre, Ó., Jiménez, J., \& Navar, J. (2003). Cambio climático mundial: origen y consecuencias. Ciencia Uanl, 3, 377-385.

Herrán, C. (2012). El cambio climático y sus consecuencias para Amércia Latina. Revista de La Bolsa de Comercio de Rosario, 6-10.

Hofstede, R. (2004). Health state of Páramos : an effort to correlate science and practice. Lyonia, 6(December), 61-73.

Hofstede, R., Josse, C., Lasso, S., Medina, G., Ochoa, N., \& Ortiz, D. (2011). Páramo. Paisaje habitado, manejado e institucionalizado. (EcoCiencia, Abya-Yala, \& ECOBONA, Eds.).

Hofstede, R., Calles, J., López, V., Polanco, R., Torres, F., Ulloa, J., ... Cerra, M. (2014). Los páramos Andinos ¿Qué Sabemos? Estado de conocimiento sobre el impacto del cambio climático en el ecosistema páramo. UICN, Quito, Ecuador.

IGM. (2016). Geoportal IGM. Retrieved from http://www.igm.gob.ec/index.php/en/servicios

Lal, R. (2004). Soil carbon sequestration impacts on global change and food security. Science 304: 1623-1627., 304(June), 1623-1627.

Li, S., \& Chen, X. (2014). A NEW BARE-SOIL INDEX FOR RAPID MAPPING DEVELOPING AREAS USING LANDSAT 8 DATA. In The International Archives of the Photogrammetry, Remote Sensing and Spatial Information Sciences (Vol. XL, pp. 14-16). Suzhou-China. https://doi.org/10.5194/isprsarchives-XL-4-139-2014

Ließ, M., Schmidt, J., \& Glaser, B. (2016). Improving the spatial prediction of soil organic carbon stocks in a complex tropical mountain landscape by methodological specifications in 
machine learning approaches. PLOS ONE, 11(4), 1-22. https://doi.org/10.1371/journal.pone.0153673

López, M. J., \& Caselles, V. (1991). Mapping burns and natural reforestation using thematic Mapper data Mapping Burns and Natural Reforestation Using Thematic Mapper Data. Geocarto International, 6(1), 31-37. https://doi.org/http://dx.doi.org/10.1080/10106049109354290

MAE. (2012). Sistema de clasificación de los ecosistemas del Ecuador continental. Subsecretaría de Patrimonio Natural (a), 143. https://doi.org/10.1017/CBO9781107415324.004

MAE. (2013). Sistema de Clasificación de Ecosistemas del Ecuador Continental.

Martínez, E., Fuentes, J. P., \& Acevedo, E. (2008). Carbono orgánico y propiedades del suelo. Revista de La Ciencia Del Suelo y Nutrición Vegetal, 8(1), 68-96. https://doi.org/10.4067/S0718-27912008000100006

Mccool, D., Brown, L. ., Foster, G. ., Mutchler, C. ., \& Meyer, L. . (1987). Revised Slope Length Factor for the Universal Soil Loss Equation. https://doi.org/10.13031/2013.30576

Mcknight, J. Y. (2015). Linking soil moisture and carbon-cycle processes in two understudied terrestrial ecosystems: Ecuadorian páramo grasslands and constructed agricultural wetlands. University of Tennessee, Knoxville.

Mena, P., Josse, C., \& Medina, G. (2000). Los suelos de los Páramos del Ecuador. Los Suelos Del Páramo, 1-75. https://doi.org/ISSN 1390-1222

Minasny, B., McBratney, A. B., Malone, B. P., Lacoste, M., \& Walter, C. (2014). Soil Carbon. Progress in Soil Science. Springer International Publishing Switzerland 2014, (December). https://doi.org/10.1007/978-3-319-04084-4

Moreno, J., Yerovi, F., Herrera, M., Yánez, D., \& José, E. (2018). The Soils of Ecuador. https://doi.org/10.1007/978-3-319-25319-0_3

Panagos, P., Borrelli, P., \& Meusburger, K. (2015). A New European Slope Length and Steepness Factor (LS-Factor) for Modeling Soil Erosion by Water. Geosciences, 5(2), 117-126. https://doi.org/10.3390/geosciences5020117

Ramifehiarivo, N., Brossard, M., Grinand, C., Andriamananjara, A., Razafimbelo, T., Rasolohery, A., ... Razakamanarivo, H. (2017). Mapping soil organic carbon on a national scale: Towards an improved and updated map of Madagascar. Geoderma Regional, 9, 29-38. 
https://doi.org/10.1016/j.geodrs.2016.12.002

República del Ecuador. Constitucion de la República del Ecuador 2008 (2008). Ecuador.

Rouse, J. W., Hass, R. H., Schell, J. A., \& Deering, D. W. (1974). Monitoring vegetation systems in the great plains with ERTS. Third Earth Resources Technology Satellite (ERTS) Symposium, 1, 309-317. https://doi.org/citeulike-article-id:12009708

SALFOR SYSTEMS A MINITAB. (2017). Improve Your Regression Models. In Improve Your Regression Models.

Segura, M., Sánchez, P., Ortiz, C., \& Gutiérrez, M. de. C. (2005). Organic Carbon of Mexican Soils. TERRA Latinoamericana, 23(1), 21-28. https://doi.org/ISSN: 2395-8030

SNI ECUADOR - INFOPLAN. (2011). INFOPLAN. Retrieved from http://sni.gob.ec/inicio

Stockmann, U., Adams, M. A., Crawford, J. W., Field, D. J., Henakaarchchi, N., Jenkins, M., ... Zimmermann, M. (2013). The knowns, known unknowns and unknowns of sequestration of soil organic carbon. Agriculture, Ecosystems and Environment, 164(2013), 80-99. https://doi.org/10.1016/j.agee.2012.10.001

Survey, U. S. G. (2016). Landsat 8 (L8) Data Users Handbook. America (Vol. 2). https://doi.org/http://www.webcitation.org/6mu9r7riR

Tan, Z. X., Lal, R., Smeck, N. E., \& Calhoun, F. G. (2004). Relationships between surface soil organic carbon pool and site variables. Geoderma, 121(3-4), 187-195. https://doi.org/10.1016/j.geoderma.2003.11.003

UNACH. (2016). Proyectos de Investigacion. Retrieved from http://investigacion.unach.edu.ec/proyectos.php

UNESCO. (2019). Organización de las Naciones Unidas para la Educación, la Ciencia y la Cultura. Retrieved from https://es.unesco.org

USDA, \& NRCS. (2014). Claves para la Taxonomía de Suelos.

USGS-USA. (2018). USGS Landsat Missions-USGS EROS GCP Library. Retrieved from https://landsat.usgs.gov/landsat-8-ground-control-point-search

USGS, U. (2017). USGS GloVis. Retrieved from https://glovis.usgs.gov

Van Bemmelen, J. M. (1891). Über Die Bestimmung Des Wassers, Des Humus, Des Schwefels, Der in Den Colloïdalen Silikaten Gebundenen Kieselsäure, Des Mangans U. S. W. Im 
Ackerboden. Die Landwirthschaftlichen Versuchs-Stationen, 37, 279-290.

Vico, G., \& Porporato, A. (2009). Probabilistic description of topographic slope and aspect. Journal de Geophysical Research, 114(February), 1-13. https://doi.org/10.1029/2008JF001038

Zhang, G., LIU, F., \& Song, X. (2017). Recent progress and future prospect of digital soil mapping : A review. Journal of Integrative Agriculture, 16(0). https://doi.org/10.1016/S20953119(17)61762-3 
ANEXOS

Anexo A

TABLA DE DATOS DE UBICACIÓN DE PUNTOS DE MUESTREO RECIBIDA DEL PROYECTO SOCEPE PARA EL MAPEO DIGITAL DE COS vs GEOLOGÍA Y TAXONOMÍA DEL SUELO

\begin{tabular}{|c|c|c|c|c|c|c|c|}
\hline $\begin{array}{l}\text { ID } \\
\text { LABORATOR } \\
\text { IO }\end{array}$ & $\mathrm{X}$ & $\mathrm{Y}$ & $\begin{array}{l}\text { FORMACIÓN } \\
\text { GEOLOGICA/ } \\
\text { TAXONÓMICA }\end{array}$ & $\begin{array}{l}\text { TAXONOMÍ } \\
\text { A }\end{array}$ & GEOLOGÍA & $\begin{array}{l}\text { SIM_TAX } \\
\text { ONOMÍA }\end{array}$ & $\begin{array}{l}\text { SIMB_FOR } \\
\text { MACIÓN } \\
\text { GEOLÓGICA }\end{array}$ \\
\hline 317 & 777130 & 9805444 & Edg & Entisol & Depósito Glacial & E & dg \\
\hline 318 & 777283 & 9805507 & Edg & Entisol & Depósito Glacial & $E$ & $\mathrm{dg}$ \\
\hline 319 & 777416 & 9805602 & Edg & Entisol & Depósito Glacial & $E$ & $\mathrm{dg}$ \\
\hline 320 & 777511 & 9805764 & Edg & Entisol & Depósito Glacial & $\mathrm{E}$ & $\mathrm{dg}$ \\
\hline 321 & 777641 & 9805676 & Edg & Entisol & Depósito Glacial & E & $\mathrm{dg}$ \\
\hline 322 & 777762 & 9805764 & Edg & Entisol & Depósito Glacial & $E$ & $\mathrm{dg}$ \\
\hline 323 & 777871 & 9805838 & Edg & Entisol & Depósito Glacial & $E$ & $\mathrm{dg}$ \\
\hline 324 & 778048 & 9805851 & Edg & Entisol & Depósito Glacial & E & $\mathrm{dg}$ \\
\hline 325 & 778217 & 9805772 & Edg & Entisol & Depósito Glacial & E & $\mathrm{dg}$ \\
\hline 326 & 778421 & 9805700 & Edg & Entisol & Depósito Glacial & $E$ & $\mathrm{dg}$ \\
\hline 297 & 777800 & 9805644 & EJAa & Entisol & Unidad Alao & $\mathrm{E}$ & $\mathrm{JAa}$ \\
\hline 298 & 778009 & 9805659 & EJAa & Entisol & Unidad Alao & E & JAa \\
\hline 299 & 778318 & 9805568 & EJAa & Entisol & Unidad Alao & E & $\mathrm{JAa}$ \\
\hline 300 & 778591 & 9805545 & EJAa & Entisol & Unidad Alao & E & $\mathrm{JAa}$ \\
\hline 301 & 777980 & 9805053 & EJAa & Entisol & Unidad Alao & $E$ & $\mathrm{JAa}$ \\
\hline 302 & 778146 & 9805024 & EJAa & Entisol & Unidad Alao & E & $\mathrm{JAa}$ \\
\hline 303 & 778394 & 9805081 & EJAa & Entisol & Unidad Alao & $\mathrm{E}$ & $\mathrm{JAa}$ \\
\hline 304 & 778575 & 9805164 & EJAa & Entisol & Unidad Alao & $\mathrm{E}$ & $\mathrm{JAa}$ \\
\hline 305 & 778722 & 9805235 & EJAa & Entisol & Unidad Alao & $E$ & $\mathrm{JAa}$ \\
\hline 306 & 778901 & 9805251 & EJAa & Entisol & Unidad Alao & E & $\mathrm{JAa}$ \\
\hline 73 & 771394 & 9792908 & EJAp & Entisol & Unidad Pelpetec & $\mathrm{E}$ & JAp \\
\hline 74 & 771181 & 9792399 & EJAp & Entisol & Unidad Pelpetec & $E$ & JAp \\
\hline 75 & 771428 & 9792717 & EJAp & Entisol & Unidad Pelpetec & $E$ & JAp \\
\hline 76 & 772547 & 9791913 & EJAp & Entisol & Unidad Pelpetec & E & JAp \\
\hline 77 & 772140 & 9791569 & EJAp & Entisol & Unidad Pelpetec & $E$ & JAp \\
\hline 78 & 772298 & 9791366 & EJAp & Entisol & Unidad Pelpetec & $\mathrm{E}$ & JAp \\
\hline 79 & 772656 & 9791138 & EJAp & Entisol & Unidad Pelpetec & $\mathrm{E}$ & JAp \\
\hline 80 & 771189 & 9792520 & EJAp & Entisol & Unidad Pelpetec & $E$ & JAp \\
\hline 81 & 768863 & 9784578 & EJAp & Entisol & Unidad Pelpetec & $E$ & JAp \\
\hline 82 & 768993 & 9785139 & EJAp & Entisol & Unidad Pelpetec & $E$ & JAp \\
\hline 83 & 769353 & 9785611 & EJAp & Entisol & Unidad Pelpetec & $E$ & JAp \\
\hline 84 & 769267 & 9785353 & EJAp & Entisol & Unidad Pelpetec & $E$ & JAp \\
\hline 85 & 767279 & 9781280 & EJAp & Entisol & Unidad Pelpetec & E & JAp \\
\hline 86 & 766959 & 9780959 & EJAp & Entisol & Unidad Pelpetec & $\mathrm{E}$ & JAp \\
\hline
\end{tabular}




\begin{tabular}{|c|c|c|c|c|c|c|c|}
\hline 87 & 766607 & 9780302 & EJAp & Entisol & Unidad Pelpetec & $\mathrm{E}$ & JAp \\
\hline 88 & 766398 & 9779869 & EJAp & Entisol & Unidad Pelpetec & $\mathrm{E}$ & JAp \\
\hline 89 & 766138 & 9779289 & EJAp & Entisol & Unidad Pelpetec & $\mathrm{E}$ & JAp \\
\hline 90 & 766307 & 9779634 & EJAp & Entisol & Unidad Pelpetec & $\mathrm{E}$ & JAp \\
\hline 127 & 765094 & 9779073 & EJGc & Entisol & Unidad Cebadas & $\mathrm{E}$ & JGc \\
\hline 128 & 764793 & 9779485 & EJGc & Entisol & Unidad Cebadas & $\mathrm{E}$ & $J G c$ \\
\hline 129 & 765512 & 9779658 & EJGc & Entisol & Unidad Cebadas & $\mathrm{E}$ & $J G c$ \\
\hline 130 & 766169 & 9780236 & EJGc & Entisol & Unidad Cebadas & $\mathrm{E}$ & $J G c$ \\
\hline 131 & 765898 & 9780555 & EJGc & Entisol & Unidad Cebadas & $\mathrm{E}$ & $J G c$ \\
\hline 132 & 765373 & 9781444 & EJGc & Entisol & Unidad Cebadas & $\mathrm{E}$ & JGc \\
\hline 133 & 765569 & 9781853 & EJGc & Entisol & Unidad Cebadas & $\mathrm{E}$ & JGc \\
\hline 134 & 765975 & 9782551 & EJGc & Entisol & Unidad Cebadas & $\mathrm{E}$ & $J G c$ \\
\hline 135 & 766763 & 9782130 & EJGc & Entisol & Unidad Cebadas & $\mathrm{E}$ & $J G c$ \\
\hline 136 & 766980 & 9782991 & EJGc & Entisol & Unidad Cebadas & $\mathrm{E}$ & $J G c$ \\
\hline 137 & 765873 & 9783244 & EJGc & Entisol & Unidad Cebadas & $\mathrm{E}$ & $J G c$ \\
\hline 138 & 767628 & 9787685 & EJGc & Entisol & Unidad Cebadas & $\mathrm{E}$ & $J G c$ \\
\hline 139 & 768168 & 9788014 & EJGc & Entisol & Unidad Cebadas & $\mathrm{E}$ & $\mathrm{JGc}$ \\
\hline 140 & 769659 & 9789893 & EJGc & Entisol & Unidad Cebadas & $\mathrm{E}$ & JGc \\
\hline 141 & 769294 & 9789728 & EJGc & Entisol & Unidad Cebadas & $\mathrm{E}$ & $J G c$ \\
\hline 142 & 770961 & 9792557 & EJGc & Entisol & Unidad Cebadas & $\mathrm{E}$ & JGc \\
\hline 143 & 770225 & 9792946 & EJGc & Entisol & Unidad Cebadas & $\mathrm{E}$ & JGc \\
\hline 144 & 769106 & 9793140 & EJGc & Entisol & Unidad Cebadas & $\mathrm{E}$ & JGc \\
\hline 19 & 766475 & 9779361 & EMTq & Entisol & Formación Tarqui & $\mathrm{E}$ & MTq \\
\hline 20 & 766408 & 9779264 & EMTq & Entisol & Formación Tarqui & $\mathrm{E}$ & MTq \\
\hline 21 & 766759 & 9779843 & EMTq & Entisol & Formación Tarqui & $\mathrm{E}$ & MTq \\
\hline 22 & 766507 & 9779493 & EMTq & Entisol & Formación Tarqui & $\mathrm{E}$ & MTq \\
\hline 23 & 770779 & 9762210 & EMTq & Entisol & Formación Tarqui & $\mathrm{E}$ & $\mathrm{MTq}$ \\
\hline 24 & 771038 & 9762119 & EMTq & Entisol & Formación Tarqui & $\mathrm{E}$ & $\mathrm{MTq}$ \\
\hline 25 & 770834 & 9762067 & EMTq & Entisol & Formación Tarqui & $\mathrm{E}$ & MTq \\
\hline 26 & 771369 & 9762113 & EMTq & Entisol & Formación Tarqui & $E$ & MTq \\
\hline 27 & 771555 & 9761873 & EMTq & Entisol & Formación Tarqui & $E$ & MTq \\
\hline 28 & 772500 & 9760794 & EMTq & Entisol & Formación Tarqui & $\mathrm{E}$ & $\mathrm{MTq}$ \\
\hline 29 & 772686 & 9760958 & EMTq & Entisol & Formación Tarqui & $\mathrm{E}$ & MTq \\
\hline 30 & 772237 & 9761059 & EMTq & Entisol & Formación Tarqui & $\mathrm{E}$ & MTq \\
\hline 31 & 772906 & 9760070 & EMTq & Entisol & Formación Tarqui & $\mathrm{E}$ & MTq \\
\hline 32 & 771428 & 9761439 & EMTq & Entisol & Formación Tarqui & $\mathrm{E}$ & MTq \\
\hline 33 & 771135 & 9762659 & EMTq & Entisol & Formación Tarqui & $\mathrm{E}$ & MTq \\
\hline 34 & 771947 & 9760425 & EMTq & Entisol & Formación Tarqui & $\mathrm{E}$ & MTq \\
\hline 35 & 772480 & 9760491 & EMTq & Entisol & Formación Tarqui & $\mathrm{E}$ & MTq \\
\hline 36 & 771683 & 9762356 & EMTq & Entisol & Formación Tarqui & $\mathrm{E}$ & MTq \\
\hline 307 & 776783 & 9805808 & EPA & Entisol & Volcánicos del Altar & $E$ & PA \\
\hline 308 & 777016 & 9805781 & EPA & Entisol & Volcánicos del Altar & $\mathrm{E}$ & PA \\
\hline 309 & 777201 & 9805866 & EPA & Entisol & Volcánicos del Altar & $E$ & PA \\
\hline 310 & 777424 & 9805972 & EPA & Entisol & Volcánicos del Altar & $\mathrm{E}$ & PA \\
\hline 311 & 777874 & 9806062 & EPA & Entisol & Volcánicos del Altar & $\mathrm{E}$ & PA \\
\hline 312 & 779272 & 9805433 & EPA & Entisol & Volcánicos del Altar & $\mathrm{E}$ & PA \\
\hline 313 & 779350 & 9805152 & EPA & Entisol & Volcánicos del Altar & $\mathrm{E}$ & PA \\
\hline 314 & 777251 & 9804378 & EPA & Entisol & Volcánicos del Altar & $\mathrm{E}$ & PA \\
\hline 315 & 779061 & 9803900 & EPA & Entisol & Volcánicos del Altar & $\mathrm{E}$ & PA \\
\hline 316 & 777740 & 9804402 & EPA & Entisol & Volcánicos del Altar & $\mathrm{E}$ & PA \\
\hline
\end{tabular}




\begin{tabular}{|c|c|c|c|c|c|c|c|}
\hline 437 & 737102 & 9829907 & EPC3 & Entisol & $\begin{array}{l}\text { Piroclásticos del } \\
\text { Chimborazo }\end{array}$ & $\mathrm{E}$ & PC3 \\
\hline 438 & 737568 & 9830088 & EPC3 & Entisol & $\begin{array}{l}\text { Piroclásticos del } \\
\text { Chimborazo }\end{array}$ & E & PC3 \\
\hline & & & & & Piroclásticos del & & \\
\hline 439 & 737466 & 9830387 & EPC3 & Entisol & $\begin{array}{l}\text { Chimborazo } \\
\text { Piroclásticos del }\end{array}$ & $\mathrm{E}$ & PC3 \\
\hline 440 & 737810 & 9830553 & EPC3 & Entisol & $\begin{array}{l}\text { Chimborazo } \\
\text { Piroclásticos del }\end{array}$ & $E$ & PC3 \\
\hline 441 & 738830 & 9830556 & EPC3 & Entisol & $\begin{array}{l}\text { Chimborazo } \\
\text { Piroclásticos del }\end{array}$ & E & PC3 \\
\hline 442 & 737616 & 9830818 & EPC3 & Entisol & $\begin{array}{l}\text { Chimborazo } \\
\text { Piroclásticos del }\end{array}$ & $E$ & PC3 \\
\hline 443 & 737124 & 9830802 & EPC3 & Entisol & $\begin{array}{l}\text { Chimborazo } \\
\text { Piroclásticos del }\end{array}$ & $E$ & PC3 \\
\hline 444 & 736616 & 9830644 & EPC3 & Entisol & $\begin{array}{l}\text { Chimborazo } \\
\text { Piroclásticos del }\end{array}$ & $\mathrm{E}$ & PC3 \\
\hline 445 & 736822 & 9831116 & EPC3 & Entisol & $\begin{array}{l}\text { Chimborazo } \\
\text { Piroclásticos del }\end{array}$ & $E$ & PC3 \\
\hline 446 & 737481 & 9831096 & EPC3 & Entisol & Chimborazo & $E$ & PC3 \\
\hline 237 & 777489 & 9793552 & $\mathrm{HJAa}$ & Histosol & Unidad Alao & $\mathrm{H}$ & JAa \\
\hline 238 & 777767 & 9793750 & HJAa & Histosol & Unidad Alao & $\mathrm{H}$ & JAa \\
\hline 239 & 778038 & 9793922 & $\mathrm{HJAa}$ & Histosol & Unidad Alao & $\mathrm{H}$ & JAa \\
\hline 240 & 778204 & 9794180 & $\mathrm{HJAa}$ & Histosol & Unidad Alao & $\mathrm{H}$ & JAa \\
\hline 241 & 777807 & 9794140 & $\mathrm{HJAa}$ & Histosol & Unidad Alao & $\mathrm{H}$ & JAa \\
\hline 242 & 777193 & 9804736 & HJAa & Histosol & Unidad Alao & $\mathrm{H}$ & JAa \\
\hline 243 & 777498 & 9804806 & HJAa & Histosol & Unidad Alao & $\mathrm{H}$ & JAa \\
\hline 244 & 777796 & 9804952 & HJAa & Histosol & Unidad Alao & $\mathrm{H}$ & JAa \\
\hline 245 & 778279 & 9804736 & HJAa & Histosol & Unidad Alao & $\mathrm{H}$ & JAa \\
\hline 246 & 778856 & 9804774 & HJAa & Histosol & Unidad Alao & $\mathrm{H}$ & JAa \\
\hline 1 & 779956 & 9784563 & HMTq & Histosol & Formación Tarqui & $\mathrm{H}$ & MTq \\
\hline 2 & 775272 & 9758314 & HMTq & Histosol & Formación Tarqui & $\mathrm{H}$ & MTq \\
\hline 3 & 779607 & 9784462 & HMTq & Histosol & Formación Tarqui & $\mathrm{H}$ & MTq \\
\hline 4 & 773238 & 9758142 & HMTq & Histosol & Formación Tarqui & $\mathrm{H}$ & MTq \\
\hline 5 & 780181 & 9784499 & HMTq & Histosol & Formación Tarqui & $\mathrm{H}$ & MTq \\
\hline 6 & 775260 & 9758041 & HMTq & Histosol & Formación Tarqui & $\mathrm{H}$ & MTq \\
\hline 7 & 773417 & 9758121 & HMTq & Histosol & Formación Tarqui & $\mathrm{H}$ & MTq \\
\hline 8 & 775957 & 9758663 & HMTq & Histosol & Formación Tarqui & $\mathrm{H}$ & MTq \\
\hline 9 & 779005 & 9784423 & HMTq & Histosol & Formación Tarqui & $\mathrm{H}$ & MTq \\
\hline 10 & 778936 & 9784091 & HMTq & Histosol & Formación Tarqui & $\mathrm{H}$ & MTq \\
\hline 11 & 780265 & 9784903 & HMTq & Histosol & Formación Tarqui & $\mathrm{H}$ & MTq \\
\hline 12 & 779213 & 9784019 & HMTq & Histosol & Formación Tarqui & $\mathrm{H}$ & $\mathrm{MTq}$ \\
\hline 13 & 779840 & 9784733 & HMTq & Histosol & Formación Tarqui & $\mathrm{H}$ & $\mathrm{MTq}$ \\
\hline 14 & 775206 & 9758160 & HMTq & Histosol & Formación Tarqui & $\mathrm{H}$ & $\mathrm{MTq}$ \\
\hline 15 & 775530 & 9758263 & HMTq & Histosol & Formación Tarqui & H & $\mathrm{MTq}$ \\
\hline 16 & 775870 & 9758453 & HMTq & Histosol & Formación Tarqui & $\mathrm{H}$ & $\mathrm{MTq}$ \\
\hline 17 & 779350 & 9784493 & HMTq & Histosol & Formación Tarqui & $\mathrm{H}$ & $\mathrm{MTq}$ \\
\hline 18 & 780282 & 9784631 & HMTq & Histosol & Formación Tarqui & $\mathrm{H}$ & $\mathrm{MTq}$ \\
\hline 277 & 775529 & 9805130 & HPA & Histosol & Volcánicos del Altar & $\mathrm{H}$ & PA \\
\hline 278 & 775781 & 9805119 & HPA & Histosol & Volcánicos del Altar & $\mathrm{H}$ & PA \\
\hline 279 & 776126 & 9805035 & HPA & Histosol & Volcánicos del Altar & $\mathrm{H}$ & PA \\
\hline 280 & 776305 & 9804749 & HPA & Histosol & Volcánicos del Altar & $\mathrm{H}$ & PA \\
\hline 281 & 776656 & 9804583 & HPA & Histosol & Volcánicos del Altar & $\mathrm{H}$ & PA \\
\hline 282 & 777106 & 9804509 & HPA & Histosol & Volcánicos del Altar & $\mathrm{H}$ & PA \\
\hline 283 & 777662 & 9804588 & HPA & Histosol & Volcánicos del Altar & $\mathrm{H}$ & PA \\
\hline 284 & 778347 & 9804204 & HPA & Histosol & Volcánicos del Altar & $\mathrm{H}$ & PA \\
\hline 285 & 778823 & 9804035 & HPA & Histosol & Volcánicos del Altar & $\mathrm{H}$ & PA \\
\hline 286 & 779374 & 9804903 & HPA & Histosol & Volcánicos del Altar & $\mathrm{H}$ & PA \\
\hline
\end{tabular}




\begin{tabular}{|c|c|c|c|c|c|c|c|}
\hline 457 & 763498 & 9832431 & IDa & Inceptisol & Depósito Aluvial & I & $\mathrm{Da}$ \\
\hline 458 & 763131 & 9833267 & IDa & Inceptisol & Depósito Aluvial & I & $\mathrm{Da}$ \\
\hline 459 & 763197 & 9832682 & IDa & Inceptisol & Depósito Aluvial & I & $\mathrm{Da}$ \\
\hline 460 & 762476 & 9832666 & IDa & Inceptisol & Depósito Aluvial & 1 & $\mathrm{Da}$ \\
\hline 461 & 762526 & 9833386 & IDa & Inceptisol & Depósito Aluvial & I & $\mathrm{Da}$ \\
\hline 462 & 762157 & 9833118 & IDa & Inceptisol & Depósito Aluvial & I & $\mathrm{Da}$ \\
\hline 463 & 761487 & 9833202 & IDa & Inceptisol & Depósito Aluvial & I & $\mathrm{Da}$ \\
\hline 464 & 761554 & 9833695 & IDa & Inceptisol & Depósito Aluvial & I & $\mathrm{Da}$ \\
\hline 465 & 762157 & 9833705 & IDa & Inceptisol & Depósito Aluvial & I & $\mathrm{Da}$ \\
\hline 466 & 762294 & 9834243 & IDa & Inceptisol & Depósito Aluvial & I & $\mathrm{Da}$ \\
\hline 199 & 778203 & 9783748 & Idg & Inceptisol & Depósito Glacial & 1 & dg \\
\hline 200 & 778103 & 9782124 & Idg & Inceptisol & Depósito Glacial & I & $\mathrm{dg}$ \\
\hline 201 & 777270 & 9782094 & Idg & Inceptisol & Depósito Glacial & 1 & $\mathrm{dg}$ \\
\hline 202 & 776378 & 9782214 & Idg & Inceptisol & Depósito Glacial & I & $\mathrm{dg}$ \\
\hline 203 & 775804 & 9782078 & Idg & Inceptisol & Depósito Glacial & 1 & $\mathrm{dg}$ \\
\hline 204 & 775981 & 9784237 & Idg & Inceptisol & Depósito Glacial & I & $\mathrm{dg}$ \\
\hline 205 & 770415 & 9778001 & Idg & Inceptisol & Depósito Glacial & 1 & $\mathrm{dg}$ \\
\hline 206 & 770297 & 9778447 & Idg & Inceptisol & Depósito Glacial & I & $\mathrm{dg}$ \\
\hline 207 & 768179 & 9779683 & Idg & Inceptisol & Depósito Glacial & I & $\mathrm{dg}$ \\
\hline 208 & 771569 & 9781382 & Idg & Inceptisol & Depósito Glacial & I & $\mathrm{dg}$ \\
\hline 209 & 771484 & 9780788 & Idg & Inceptisol & Depósito Glacial & 1 & $\mathrm{dg}$ \\
\hline 210 & 777479 & 9786700 & Idg & Inceptisol & Depósito Glacial & 1 & $\mathrm{dg}$ \\
\hline 211 & 777137 & 9786987 & Idg & Inceptisol & Depósito Glacial & 1 & $\mathrm{dg}$ \\
\hline 212 & 776854 & 9787621 & Idg & Inceptisol & Depósito Glacial & 1 & $\mathrm{dg}$ \\
\hline 213 & 776783 & 9787929 & Idg & Inceptisol & Depósito Glacial & 1 & $\mathrm{dg}$ \\
\hline 214 & 776675 & 9788158 & Idg & Inceptisol & Depósito Glacial & 1 & dg \\
\hline 215 & 776987 & 9788541 & Idg & Inceptisol & Depósito Glacial & 1 & $\mathrm{dg}$ \\
\hline 216 & 776990 & 9783928 & Idg & Inceptisol & Depósito Glacial & 1 & $\mathrm{dg}$ \\
\hline 327 & 774940 & 9802211 & Idg & Inceptisol & Depósito Glacial & 1 & $\mathrm{dg}$ \\
\hline 328 & 775152 & 9802072 & Idg & Inceptisol & Depósito Glacial & I & $\mathrm{dg}$ \\
\hline 329 & 775469 & 9801867 & Idg & Inceptisol & Depósito Glacial & I & $\mathrm{dg}$ \\
\hline 330 & 775807 & 9801788 & Idg & Inceptisol & Depósito Glacial & I & dg \\
\hline 331 & 776118 & 9801662 & Idg & Inceptisol & Depósito Glacial & I & $\mathrm{dg}$ \\
\hline 332 & 774629 & 9802793 & Idg & Inceptisol & Depósito Glacial & I & $\mathrm{dg}$ \\
\hline 333 & 774934 & 9802945 & Idg & Inceptisol & Depósito Glacial & 1 & $\mathrm{dg}$ \\
\hline 334 & 774987 & 9803210 & Idg & Inceptisol & Depósito Glacial & I & dg \\
\hline 335 & 775199 & 9803095 & Idg & Inceptisol & Depósito Glacial & I & $\mathrm{dg}$ \\
\hline 336 & 775699 & 9803256 & Idg & Inceptisol & Depósito Glacial & I & $\mathrm{dg}$ \\
\hline 163 & 773605 & 9757329 & IG & Inceptisol & Rocas Intrusivas & 1 & G \\
\hline 164 & 774502 & 9757493 & IG & Inceptisol & Rocas Intrusivas & 1 & G \\
\hline 165 & 774013 & 9757777 & IG & Inceptisol & Rocas Intrusivas & I & G \\
\hline 166 & 773793 & 9758278 & IG & Inceptisol & Rocas Intrusivas & 1 & G \\
\hline 167 & 774066 & 9758946 & IG & Inceptisol & Rocas Intrusivas & I & G \\
\hline 168 & 774180 & 9759754 & IG & Inceptisol & Rocas Intrusivas & I & G \\
\hline 169 & 774721 & 9760161 & IG & Inceptisol & Rocas Intrusivas & I & G \\
\hline 170 & 771111 & 9763629 & IG & Inceptisol & Rocas Intrusivas & I & G \\
\hline 171 & 771958 & 9762130 & IG & Inceptisol & Rocas Intrusivas & I & G \\
\hline 172 & 774254 & 9763220 & IG & Inceptisol & Rocas Intrusivas & I & G \\
\hline 173 & 775216 & 9783266 & IG & Inceptisol & Rocas Intrusivas & I & G \\
\hline 174 & 775533 & 9785846 & IG & Inceptisol & Rocas Intrusivas & 1 & G \\
\hline
\end{tabular}




\begin{tabular}{|c|c|c|c|c|c|c|c|}
\hline 175 & 776142 & 9789180 & IG & Inceptisol & Rocas Intrusivas & 1 & G \\
\hline 176 & 776353 & 9790212 & IG & Inceptisol & Rocas Intrusivas & 1 & G \\
\hline 177 & 775440 & 9787619 & IG & Inceptisol & Rocas Intrusivas & 1 & G \\
\hline 178 & 770905 & 9775214 & IG & Inceptisol & Rocas Intrusivas & 1 & G \\
\hline 179 & 772337 & 9774427 & IG & Inceptisol & Rocas Intrusivas & 1 & G \\
\hline 180 & 777165 & 9775415 & IG & Inceptisol & Rocas Intrusivas & 1 & G \\
\hline 247 & 777289 & 9793205 & IG & Inceptisol & Rocas Intrusivas & 1 & G \\
\hline 248 & 776938 & 9793213 & IG & Inceptisol & Rocas Intrusivas & 1 & G \\
\hline 249 & 776650 & 9793373 & IG & Inceptisol & Rocas Intrusivas & 1 & G \\
\hline 250 & 776469 & 9793551 & IG & Inceptisol & Rocas Intrusivas & 1 & G \\
\hline 251 & 775268 & 9794623 & IG & Inceptisol & Rocas Intrusivas & 1 & G \\
\hline 252 & 775502 & 9794793 & IG & Inceptisol & Rocas Intrusivas & 1 & G \\
\hline 253 & 775768 & 9794932 & IG & Inceptisol & Rocas Intrusivas & 1 & G \\
\hline 254 & 776086 & 9794865 & IG & Inceptisol & Rocas Intrusivas & 1 & G \\
\hline 255 & 776159 & 9794607 & IG & Inceptisol & Rocas Intrusivas & 1 & G \\
\hline 256 & 776206 & 9794326 & IG & Inceptisol & Rocas Intrusivas & 1 & G \\
\hline 181 & 775183 & 9775532 & IJAa & Inceptisol & Unidad Alao & 1 & JAa \\
\hline 182 & 774964 & 9776138 & IJAa & Inceptisol & Unidad Alao & 1 & JAa \\
\hline 183 & 774951 & 9776722 & IJAa & Inceptisol & Unidad Alao & 1 & JAa \\
\hline 184 & 775910 & 9777201 & IJAa & Inceptisol & Unidad Alao & 1 & JAa \\
\hline 185 & 775251 & 9777941 & IJAa & Inceptisol & Unidad Alao & 1 & $\mathrm{JAa}$ \\
\hline 186 & 775601 & 9778770 & IJAa & Inceptisol & Unidad Alao & 1 & $\mathrm{JAa}$ \\
\hline 187 & 778540 & 9779067 & IJAa & Inceptisol & Unidad Alao & 1 & $\mathrm{JAa}$ \\
\hline 188 & 777771 & 9779892 & IJAa & Inceptisol & Unidad Alao & 1 & $\mathrm{JAa}$ \\
\hline 189 & 775356 & 9781736 & IJAa & Inceptisol & Unidad Alao & 1 & $\mathrm{JAa}$ \\
\hline 190 & 775785 & 9782965 & IJAa & Inceptisol & Unidad Alao & 1 & $\mathrm{JAa}$ \\
\hline 191 & 776919 & 9781588 & IJAa & Inceptisol & Unidad Alao & 1 & $\mathrm{JAa}$ \\
\hline 192 & 777497 & 9790259 & IJAa & Inceptisol & Unidad Alao & 1 & JAa \\
\hline 193 & 778922 & 9790773 & IJAa & Inceptisol & Unidad Alao & 1 & $\mathrm{JAa}$ \\
\hline 194 & 784800 & 9791592 & IJAa & Inceptisol & Unidad Alao & 1 & JAa \\
\hline 195 & 785009 & 9792848 & IJAa & Inceptisol & Unidad Alao & 1 & JAa \\
\hline 196 & 785792 & 9793529 & IJAa & Inceptisol & Unidad Alao & 1 & $\mathrm{JAa}$ \\
\hline 197 & 780725 & 9790322 & IJAa & Inceptisol & Unidad Alao & 1 & $\mathrm{JAa}$ \\
\hline 198 & 776620 & 9788846 & IJAa & Inceptisol & Unidad Alao & 1 & $\mathrm{JAa}$ \\
\hline 257 & 777723 & 9793183 & IJAa & Inceptisol & Unidad Alao & 1 & $\mathrm{JAa}$ \\
\hline 258 & 778193 & 9793151 & IJAa & Inceptisol & Unidad Alao & 1 & JAa \\
\hline 259 & 778650 & 9793317 & IJAa & Inceptisol & Unidad Alao & 1 & JAa \\
\hline 260 & 778974 & 9792770 & IJAa & Inceptisol & Unidad Alao & 1 & JAa \\
\hline 261 & 779406 & 9792910 & IJAa & Inceptisol & Unidad Alao & 1 & JAa \\
\hline 262 & 779946 & 9792561 & IJAa & Inceptisol & Unidad Alao & 1 & $\mathrm{JAa}$ \\
\hline 263 & 780390 & 9792675 & IJAa & Inceptisol & Unidad Alao & 1 & JAa \\
\hline 264 & 781083 & 9792288 & IJAa & Inceptisol & Unidad Alao & 1 & JAa \\
\hline 265 & 781540 & 9792078 & IJAa & Inceptisol & Unidad Alao & 1 & JAa \\
\hline 266 & 781996 & 9791963 & IJAa & Inceptisol & Unidad Alao & 1 & JAa \\
\hline 91 & 767959 & 9768430 & IJAm & Inceptisol & Unidad Manguazo & 1 & Jam \\
\hline 92 & 768374 & 9768125 & IJAm & Inceptisol & Unidad Manguazo & 1 & Jam \\
\hline 93 & 767993 & 9768732 & IJAm & Inceptisol & Unidad Manguazo & 1 & Jam \\
\hline 94 & 766894 & 9772718 & IJAm & Inceptisol & Unidad Manguazo & 1 & Jam \\
\hline 95 & 767704 & 9771038 & IJAm & Inceptisol & Unidad Manguazo & 1 & Jam \\
\hline 96 & 767734 & 9770858 & IJAm & Inceptisol & Unidad Manguazo & 1 & Jam \\
\hline
\end{tabular}




\begin{tabular}{|c|c|c|c|c|c|c|c|}
\hline 97 & 768449 & 9780737 & IJAm & Inceptisol & Unidad Manguazo & 1 & Jam \\
\hline 98 & 769624 & 9781208 & IJAm & Inceptisol & Unidad Manguazo & 1 & Jam \\
\hline 99 & 772984 & 9780343 & IJAm & Inceptisol & Unidad Manguazo & I & Jam \\
\hline 100 & 773004 & 9779803 & IJAm & Inceptisol & Unidad Manguazo & 1 & Jam \\
\hline 101 & 773171 & 9778608 & IJAm & Inceptisol & Unidad Manguazo & I & Jam \\
\hline 102 & 775718 & 9789012 & IJAm & Inceptisol & Unidad Manguazo & I & Jam \\
\hline 103 & 775710 & 9789190 & IJAm & Inceptisol & Unidad Manguazo & I & Jam \\
\hline 104 & 774425 & 9790780 & IJAm & Inceptisol & Unidad Manguazo & I & Jam \\
\hline 105 & 770213 & 9782971 & IJAm & Inceptisol & Unidad Manguazo & I & Jam \\
\hline 106 & 771202 & 9785145 & IJAm & Inceptisol & Unidad Manguazo & I & Jam \\
\hline 107 & 771413 & 9783306 & IJAm & Inceptisol & Unidad Manguazo & I & Jam \\
\hline 108 & 773732 & 9785687 & IJAm & Inceptisol & Unidad Manguazo & I & Jam \\
\hline 217 & 773521 & 9793370 & IJAm & Inceptisol & Unidad Manguazo & 1 & Jam \\
\hline 218 & 773768 & 9793220 & IJAm & Inceptisol & Unidad Manguazo & 1 & Jam \\
\hline 219 & 774011 & 9793161 & IJAm & Inceptisol & Unidad Manguazo & I & Jam \\
\hline 220 & 774375 & 9793104 & IJAm & Inceptisol & Unidad Manguazo & 1 & Jam \\
\hline 221 & 774791 & 9793101 & IJAm & Inceptisol & Unidad Manguazo & 1 & Jam \\
\hline 222 & 773938 & 9793706 & IJAm & Inceptisol & Unidad Manguazo & I & Jam \\
\hline 223 & 774216 & 9794067 & IJAm & Inceptisol & Unidad Manguazo & I & Jam \\
\hline 224 & 774444 & 9794255 & IJAm & Inceptisol & Unidad Manguazo & I & Jam \\
\hline 225 & 774467 & 9794444 & IJAm & Inceptisol & Unidad Manguazo & I & Jam \\
\hline 226 & 774398 & 9794715 & IJAm & Inceptisol & Unidad Manguazo & 1 & Jam \\
\hline 347 & 763746 & 9763955 & IJAm & Inceptisol & Unidad Manguazo & I & Jam \\
\hline 348 & 766074 & 9763743 & IJAm & Inceptisol & Unidad Manguazo & 1 & Jam \\
\hline 349 & 764416 & 9766524 & IJAm & Inceptisol & Unidad Manguazo & 1 & Jam \\
\hline 350 & 764783 & 9768720 & IJAm & Inceptisol & Unidad Manguazo & I & Jam \\
\hline 351 & 765108 & 9769558 & IJAm & Inceptisol & Unidad Manguazo & I & Jam \\
\hline 352 & 764854 & 9770677 & IJAm & Inceptisol & Unidad Manguazo & I & Jam \\
\hline 353 & 765207 & 9770859 & IJAm & Inceptisol & Unidad Manguazo & I & Jam \\
\hline 354 & 765461 & 9770350 & IJAm & Inceptisol & Unidad Manguazo & I & Jam \\
\hline 355 & 764108 & 9765011 & IJAm & Inceptisol & Unidad Manguazo & I & Jam \\
\hline 356 & 764650 & 9769996 & IJAm & Inceptisol & Unidad Manguazo & I & Jam \\
\hline 55 & 765640 & 9774555 & IJAp & Inceptisol & Unidad Pelpetec & I & JAp \\
\hline 56 & 765908 & 9774661 & IJAp & Inceptisol & Unidad Pelpetec & I & JAp \\
\hline 57 & 766722 & 9772868 & IJAp & Inceptisol & Unidad Pelpetec & I & JAp \\
\hline 58 & 765480 & 9774287 & IJAp & Inceptisol & Unidad Pelpetec & I & JAp \\
\hline 59 & 765484 & 9774346 & IJAp & Inceptisol & Unidad Pelpetec & I & JAp \\
\hline 60 & 765373 & 9777110 & IJAp & Inceptisol & Unidad Pelpetec & I & JAp \\
\hline 61 & 765646 & 9777975 & IJAp & Inceptisol & Unidad Pelpetec & 1 & JAp \\
\hline 62 & 766051 & 9779051 & IJAp & Inceptisol & Unidad Pelpetec & I & JAp \\
\hline 63 & 767622 & 9782192 & IJAp & Inceptisol & Unidad Pelpetec & 1 & JAp \\
\hline 64 & 767273 & 9781609 & IJAp & Inceptisol & Unidad Pelpetec & I & JAp \\
\hline 65 & 768664 & 9784238 & IJAp & Inceptisol & Unidad Pelpetec & I & JAp \\
\hline 66 & 769508 & 9785871 & IJAp & Inceptisol & Unidad Pelpetec & I & JAp \\
\hline 67 & 771822 & 9789359 & IJAp & Inceptisol & Unidad Pelpetec & 1 & JAp \\
\hline 68 & 770952 & 9788933 & IJAp & Inceptisol & Unidad Pelpetec & I & JAp \\
\hline 69 & 770291 & 9788230 & IJAp & Inceptisol & Unidad Pelpetec & I & JAp \\
\hline 70 & 770478 & 9786850 & IJAp & Inceptisol & Unidad Pelpetec & I & JAp \\
\hline 71 & 771466 & 9787645 & IJAp & Inceptisol & Unidad Pelpetec & I & JAp \\
\hline 72 & 771871 & 9788702 & IJAp & Inceptisol & Unidad Pelpetec & 1 & JAp \\
\hline
\end{tabular}




\begin{tabular}{|c|c|c|c|c|c|c|}
\hline 227 & 759714 & 9757581 & IJAp & Inceptisol & Unidad Pelpetec & 1 \\
\hline 228 & 761027 & 9760099 & IJAp & Inceptisol & Unidad Pelpetec & 1 \\
\hline 229 & 761848 & 9762228 & IJAp & Inceptisol & Unidad Pelpetec & 1 \\
\hline 230 & 762955 & 9764357 & IJAp & Inceptisol & Unidad Pelpetec & 1 \\
\hline 231 & 763700 & 9767430 & IJAp & Inceptisol & Unidad Pelpetec & 1 \\
\hline 232 & 763449 & 9768372 & IJAp & Inceptisol & Unidad Pelpetec & 1 \\
\hline 233 & 763491 & 9769267 & IJAp & Inceptisol & Unidad Pelpetec & 1 \\
\hline 234 & 763887 & 9769918 & IJAp & Inceptisol & Unidad Pelpetec & 1 \\
\hline 235 & 764398 & 9770926 & IJAp & Inceptisol & Unidad Pelpetec & 1 \\
\hline 236 & 764413 & 9771648 & IJAp & Inceptisol & Unidad Pelpetec & 1 \\
\hline 357 & 773459 & 9793497 & IJAp & Inceptisol & Unidad Pelpetec & 1 \\
\hline 358 & 773275 & 9793714 & IJAp & Inceptisol & Unidad Pelpetec & 1 \\
\hline 359 & 773194 & 9794352 & IJAp & Inceptisol & Unidad Pelpetec & 1 \\
\hline 360 & 773014 & 9794723 & IJAp & Inceptisol & Unidad Pelpetec & 1 \\
\hline 361 & 773263 & 9794588 & IJAp & Inceptisol & Unidad Pelpetec & 1 \\
\hline 362 & 773126 & 9794938 & IJAp & Inceptisol & Unidad Pelpetec & 1 \\
\hline 363 & 772885 & 9795034 & IJAp & Inceptisol & Unidad Pelpetec & 1 \\
\hline 364 & 772544 & 9795100 & IJAp & Inceptisol & Unidad Pelpetec & 1 \\
\hline 365 & 772250 & 9795127 & IJAp & Inceptisol & Unidad Pelpetec & 1 \\
\hline 366 & 771856 & 9795295 & IJAp & Inceptisol & Unidad Pelpetec & 1 \\
\hline 145 & 765001 & 9777139 & IJGC & Inceptisol & Unidad Cebadas & 1 \\
\hline 146 & 765100 & 9777827 & IJGC & Inceptisol & Unidad Cebadas & 1 \\
\hline 147 & 765309 & 9779027 & IJGC & Inceptisol & Unidad Cebadas & 1 \\
\hline 148 & 764814 & 9778609 & $\mathrm{IJGC}$ & Inceptisol & Unidad Cebadas & 1 \\
\hline 149 & 764968 & 9778873 & IJGC & Inceptisol & Unidad Cebadas & 1 \\
\hline 150 & 765857 & 9780714 & IJGC & Inceptisol & Unidad Cebadas & 1 \\
\hline 151 & 765504 & 9780849 & IJGC & Inceptisol & Unidad Cebadas & 1 \\
\hline 152 & 765708 & 9780851 & IJGC & Inceptisol & Unidad Cebadas & 1 \\
\hline 153 & 767111 & 9783139 & IJGC & Inceptisol & Unidad Cebadas & 1 \\
\hline 154 & 766000 & 9783543 & IJGC & Inceptisol & Unidad Cebadas & 1 \\
\hline 155 & 767102 & 9783428 & IJGC & Inceptisol & Unidad Cebadas & 1 \\
\hline 156 & 767286 & 9785189 & IJGC & Inceptisol & Unidad Cebadas & 1 \\
\hline 157 & 767181 & 9785605 & IJGC & Inceptisol & Unidad Cebadas & 1 \\
\hline 158 & 767278 & 9785299 & IJGC & Inceptisol & Unidad Cebadas & 1 \\
\hline 159 & 765553 & 9787652 & $\mathrm{IJGC}$ & Inceptisol & Unidad Cebadas & 1 \\
\hline 160 & 765461 & 9787962 & IJGC & Inceptisol & Unidad Cebadas & 1 \\
\hline 161 & 769057 & 9789335 & $\mathrm{IJGC}$ & Inceptisol & Unidad Cebadas & 1 \\
\hline 162 & 768999 & 9789131 & IJGC & Inceptisol & Unidad Cebadas & 1 \\
\hline 367 & 762719 & 9768258 & IJGp & Inceptisol & Unidad Guasuntos & 1 \\
\hline 368 & 762668 & 9768766 & $I J G p$ & Inceptisol & Unidad Guasuntos & 1 \\
\hline 369 & 762916 & 9769344 & IJGp & Inceptisol & Unidad Guasuntos & 1 \\
\hline 370 & 762458 & 9769547 & IJGp & Inceptisol & Unidad Guasuntos & 1 \\
\hline 371 & 762370 & 9770063 & IJGp & Inceptisol & Unidad Guasuntos & 1 \\
\hline 372 & 762058 & 9770531 & IJGp & Inceptisol & Unidad Guasuntos & 1 \\
\hline 373 & 761341 & 9770188 & $I J G p$ & Inceptisol & Unidad Guasuntos & 1 \\
\hline 374 & 761646 & 9771242 & IJGp & Inceptisol & Unidad Guasuntos & 1 \\
\hline 375 & 760299 & 9770214 & $I J G p$ & Inceptisol & Unidad Guasuntos & 1 \\
\hline 376 & 761201 & 9770988 & $I J G p$ & Inceptisol & Unidad Guasuntos & 1 \\
\hline 407 & 740326 & 9806525 & IKy & Inceptisol & Unidad Yunguilla & 1 \\
\hline 408 & 739204 & 9808448 & IKy & Inceptisol & Unidad Yunguilla & 1 \\
\hline
\end{tabular}




\begin{tabular}{|c|c|c|c|c|c|c|c|}
\hline 409 & 740616 & 9810901 & IKy & Inceptisol & Unidad Yunguilla & 1 & Ky \\
\hline 410 & 740829 & 9812841 & IKy & Inceptisol & Unidad Yunguilla & 1 & Ky \\
\hline 411 & 741595 & 9813586 & IKy & Inceptisol & Unidad Yunguilla & 1 & Ky \\
\hline 412 & 742295 & 9813806 & IKy & Inceptisol & Unidad Yunguilla & 1 & Ky \\
\hline 413 & 741212 & 9814888 & IKy & Inceptisol & Unidad Yunguilla & 1 & Ky \\
\hline 414 & 741967 & 9815660 & IKy & Inceptisol & Unidad Yunguilla & 1 & Ky \\
\hline 415 & 741450 & 9816466 & IKy & Inceptisol & Unidad Yunguilla & 1 & Ky \\
\hline 416 & 742268 & 9817054 & IKy & Inceptisol & Unidad Yunguilla & 1 & Ky \\
\hline 377 & 760869 & 9771475 & IMcn & Inceptisol & Formación Cisarán & 1 & Mcn \\
\hline 378 & 759889 & 9772876 & IMcn & Inceptisol & Formación Cisarán & 1 & Mcn \\
\hline 379 & 743465 & 9780056 & IMcn & Inceptisol & Formación Cisarán & 1 & Mcn \\
\hline 380 & 743514 & 9785971 & IMcn & Inceptisol & Formación Cisarán & 1 & Mcn \\
\hline 381 & 741121 & 9790021 & IMcn & Inceptisol & Formación Cisarán & 1 & Mcn \\
\hline 382 & 742089 & 9795189 & IMcn & Inceptisol & Formación Cisarán & 1 & Mcn \\
\hline 383 & 742753 & 9800008 & IMcn & Inceptisol & Formación Cisarán & 1 & Mcn \\
\hline 384 & 740928 & 9801284 & IMcn & Inceptisol & Formación Cisarán & 1 & Mcn \\
\hline 385 & 740918 & 9803570 & IMcn & Inceptisol & Formación Cisarán & 1 & Mcn \\
\hline 386 & 742115 & 9806166 & IMcn & Inceptisol & Formación Cisarán & 1 & Mcn \\
\hline 37 & 774294 & 9758209 & IMTq & Inceptisol & Formación Tarqui & 1 & MTq \\
\hline 38 & 766776 & 9775359 & IMTq & Inceptisol & Formación Tarqui & 1 & MTq \\
\hline 39 & 771047 & 9774994 & IMTq & Inceptisol & Formación Tarqui & 1 & MTq \\
\hline 40 & 770499 & 9765614 & IMTq & Inceptisol & Formación Tarqui & 1 & MTq \\
\hline 41 & 770227 & 9764599 & IMTq & Inceptisol & Formación Tarqui & 1 & MTq \\
\hline 42 & 770753 & 9763523 & IMTq & Inceptisol & Formación Tarqui & 1 & MTq \\
\hline 43 & 777378 & 9775203 & IMTq & Inceptisol & Formación Tarqui & 1 & MTq \\
\hline 44 & 774756 & 9758123 & IMTq & Inceptisol & Formación Tarqui & 1 & MTq \\
\hline 45 & 765861 & 9746463 & IMTq & Inceptisol & Formación Tarqui & 1 & MTq \\
\hline 46 & 766360 & 9745945 & IMTq & Inceptisol & Formación Tarqui & 1 & MTq \\
\hline 47 & 766939 & 9745462 & IMTq & Inceptisol & Formación Tarqui & 1 & MTq \\
\hline 48 & 774435 & 9758113 & IMTq & Inceptisol & Formación Tarqui & 1 & MTq \\
\hline 49 & 766718 & 9748057 & IMTq & Inceptisol & Formación Tarqui & 1 & MTq \\
\hline 50 & 774578 & 9758115 & IMTq & Inceptisol & Formación Tarqui & 1 & MTq \\
\hline 51 & 775189 & 9788701 & IMTq & Inceptisol & Formación Tarqui & 1 & MTq \\
\hline 52 & 778218 & 9784673 & IMTq & Inceptisol & Formación Tarqui & 1 & MTq \\
\hline 53 & 768609 & 9746247 & IMTq & Inceptisol & Formación Tarqui & 1 & MTq \\
\hline 54 & 766609 & 9774560 & IMTq & Inceptisol & Formación Tarqui & 1 & MTq \\
\hline 337 & 760296 & 9753777 & IMTq & Inceptisol & Formación Tarqui & 1 & MTq \\
\hline 338 & 760963 & 9754952 & IMTq & Inceptisol & Formación Tarqui & 1 & MTq \\
\hline 339 & 762106 & 9753798 & IMTq & Inceptisol & Formación Tarqui & 1 & MTq \\
\hline 340 & 763323 & 9753142 & IMTq & Inceptisol & Formación Tarqui & 1 & MTq \\
\hline 341 & 763415 & 9761899 & IMTq & Inceptisol & Formación Tarqui & 1 & MTq \\
\hline 342 & 763598 & 9763020 & IMTq & Inceptisol & Formación Tarqui & 1 & MTq \\
\hline 343 & 764063 & 9760852 & IMTq & Inceptisol & Formación Tarqui & 1 & MTq \\
\hline 344 & 764064 & 9752930 & IMTq & Inceptisol & Formación Tarqui & 1 & MTq \\
\hline 345 & 766415 & 9761516 & IMTq & Inceptisol & Formación Tarqui & 1 & MTq \\
\hline 346 & 766914 & 9760942 & IMTq & Inceptisol & Formación Tarqui & 1 & MTq \\
\hline 267 & 771260 & 9795908 & IPA & Inceptisol & Volcánicos del Altar & 1 & PA \\
\hline 268 & 771699 & 9798610 & IPA & Inceptisol & Volcánicos del Altar & 1 & PA \\
\hline 269 & 772482 & 9798906 & IPA & Inceptisol & Volcánicos del Altar & 1 & PA \\
\hline 270 & 773370 & 9803176 & IPA & Inceptisol & Volcánicos del Altar & 1 & PA \\
\hline
\end{tabular}




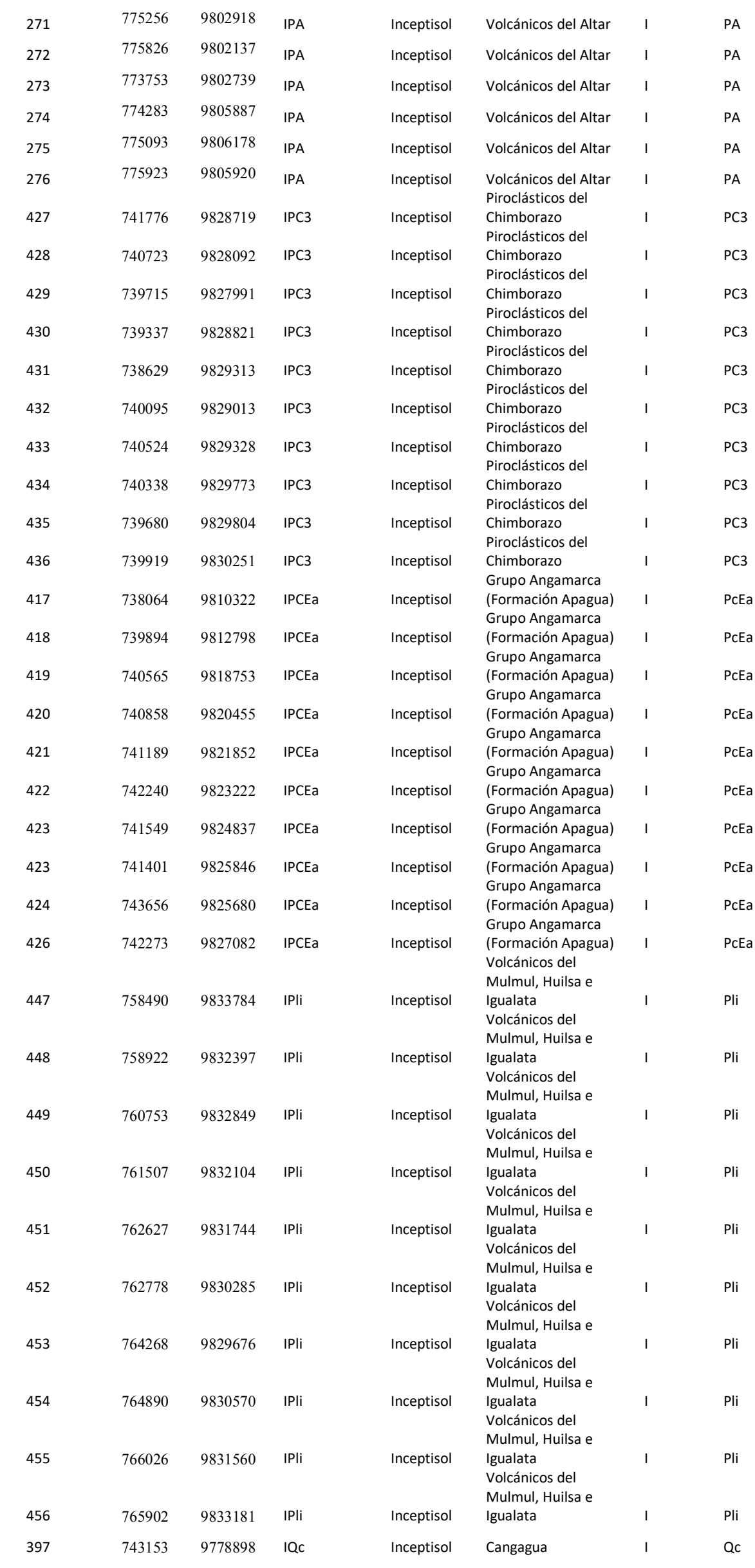




\begin{tabular}{|c|c|c|c|c|c|c|c|}
\hline 398 & 744149 & 9779400 & IQc & Inceptisol & Cangagua & 1 & Qc \\
\hline 399 & 744110 & 9782176 & IQc & Inceptisol & Cangagua & 1 & Qc \\
\hline 400 & 745228 & 9784848 & IQc & Inceptisol & Cangagua & 1 & Qc \\
\hline 401 & 745487 & 9787158 & IQc & Inceptisol & Cangagua & 1 & Qc \\
\hline 402 & 745495 & 9799780 & IQc & Inceptisol & Cangagua & 1 & Qc \\
\hline 403 & 743746 & 9802240 & IQc & Inceptisol & Cangagua & 1 & Qc \\
\hline 404 & 744650 & 9803324 & IQc & Inceptisol & Cangagua & 1 & Qc \\
\hline 405 & 744574 & 9804799 & IQc & Inceptisol & Cangagua & 1 & Qc \\
\hline 406 & 743538 & 9805983 & IQc & Inceptisol & Cangagua & 1 & Qc \\
\hline 109 & 764970 & 9787888 & MJGc & Mollisol & Unidad Cebadas & $M$ & $J G c$ \\
\hline 110 & 765051 & 9788009 & MJGc & Mollisol & Unidad Cebadas & M & JGc \\
\hline 111 & 765388 & 9787989 & MJGc & Mollisol & Unidad Cebadas & M & JGc \\
\hline 112 & 765500 & 9787673 & MJGc & Mollisol & Unidad Cebadas & M & $J G c$ \\
\hline 113 & 765953 & 9789191 & MJGc & Mollisol & Unidad Cebadas & $M$ & $\mathrm{JGc}$ \\
\hline 114 & 766117 & 9789003 & MJGc & Mollisol & Unidad Cebadas & M & JGc \\
\hline 115 & 766090 & 9788624 & MJGc & Mollisol & Unidad Cebadas & M & JGc \\
\hline 116 & 766878 & 9788946 & MJGc & Mollisol & Unidad Cebadas & M & $J G c$ \\
\hline 117 & 766773 & 9788626 & MJGc & Mollisol & Unidad Cebadas & M & $J G c$ \\
\hline 118 & 767492 & 9788181 & MJGc & Mollisol & Unidad Cebadas & M & JGc \\
\hline 119 & 767511 & 9788297 & MJGc & Mollisol & Unidad Cebadas & $M$ & JGc \\
\hline 120 & 768667 & 9789814 & MJGc & Mollisol & Unidad Cebadas & $M$ & JGc \\
\hline 121 & 769310 & 9789586 & MJGc & Mollisol & Unidad Cebadas & $M$ & JGc \\
\hline 122 & 769767 & 9789683 & MJGc & Mollisol & Unidad Cebadas & $M$ & JGc \\
\hline 123 & 770401 & 9789760 & MJGc & Mollisol & Unidad Cebadas & M & $J G c$ \\
\hline 124 & 769042 & 9789439 & MJGc & Mollisol & Unidad Cebadas & $M$ & $J G c$ \\
\hline 125 & 768585 & 9790407 & MJGc & Mollisol & Unidad Cebadas & M & JGc \\
\hline 126 & 768495 & 9790289 & MJGc & Mollisol & Unidad Cebadas & M & JGc \\
\hline 387 & 758505 & 9771480 & MMcn & Mollisol & Formación Cisarán & M & Mcn \\
\hline 388 & 757453 & 9773058 & MMcn & Mollisol & Formación Cisarán & M & Mcn \\
\hline 389 & 759233 & 9773550 & MMcn & Mollisol & Formación Cisarán & M & Mcn \\
\hline 390 & 758597 & 9774235 & MMcn & Mollisol & Formación Cisarán & M & Mcn \\
\hline 391 & 758694 & 9775800 & MMcn & Mollisol & Formación Cisarán & $M$ & Mcn \\
\hline 392 & 759461 & 9776468 & MMcn & Mollisol & Formación Cisarán & M & Mcn \\
\hline 393 & 758495 & 9777446 & MMcn & Mollisol & Formación Cisarán & $M$ & Mcn \\
\hline 394 & 760077 & 9777193 & MMcn & Mollisol & Formación Cisarán & $M$ & Mcn \\
\hline 395 & 759230 & 9778176 & MMcn & Mollisol & Formación Cisarán & $M$ & Mcn \\
\hline 396 & 760128 & 9779030 & MMcn & Mollisol & Formación Cisarán & $M$ & Mcn \\
\hline 287 & 770840 & 9795698 & MPA & Mollisol & Volcánicos del Altar & $M$ & PA \\
\hline 288 & 771257 & 9798894 & MPA & Mollisol & Volcánicos del Altar & M & PA \\
\hline 289 & 771004 & 9799011 & MPA & Mollisol & Volcánicos del Altar & M & PA \\
\hline 290 & 771709 & 9798693 & MPA & Mollisol & Volcánicos del Altar & $M$ & PA \\
\hline 291 & 771964 & 9798934 & MPA & Mollisol & Volcánicos del Altar & $M$ & PA \\
\hline 292 & 772345 & 9798775 & MPA & Mollisol & Volcánicos del Altar & M & PA \\
\hline 293 & 772747 & 9802733 & MPA & Mollisol & Volcánicos del Altar & $M$ & PA \\
\hline 294 & 772469 & 9802887 & MPA & Mollisol & Volcánicos del Altar & $M$ & PA \\
\hline 295 & 773234 & 9802892 & MPA & Mollisol & Volcánicos del Altar & $M$ & PA \\
\hline 296 & 772800 & 9803093 & MPA & Mollisol & Volcánicos del Altar & $M$ & PA \\
\hline F1 & 759179 & 9740087 & Edg & Andosoles & Formación Alausí & A & $\mathrm{Pg}$ \\
\hline F2 & 759429 & 9739837 & Edg & Andosoles & Formación Alausí & $A$ & $\mathrm{Pg}$ \\
\hline F3 & 759179 & 9739837 & Edg & Andosoles & Formación Alausí & A & $\mathrm{Pg}$ \\
\hline
\end{tabular}




\begin{tabular}{|c|c|c|c|c|c|c|c|}
\hline F4 & 759038 & 9736130 & Edg & Andosoles & Formación Alausí & $A$ & $\mathrm{Pg}$ \\
\hline F5 & 758786 & 9736382 & Edg & Andosoles & Formación Alausí & $A$ & $\mathrm{Pg}$ \\
\hline F6 & 758788 & 9736132 & Edg & Andosoles & Formación Alausí & $A$ & $\mathrm{Pg}$ \\
\hline F7 & 767484 & 9749854 & Edg & Andosoles & Formación Alausí & $A$ & $\mathrm{Pg}$ \\
\hline F8 & 767483 & 9750105 & Edg & Andosoles & Formación Alausí & $A$ & $\mathrm{Pg}$ \\
\hline F9 & 767734 & 9749853 & Edg & Andosoles & Formación Alausí & $A$ & $\mathrm{Pg}$ \\
\hline F10 & 764921 & 9749597 & Edg & Andosoles & Formación Alausí & $A$ & $\mathrm{Pg}$ \\
\hline F11 & 764921 & 9749347 & Edg & Andosoles & Formación Alausí & $A$ & $\mathrm{Pg}$ \\
\hline F12 & 765171 & 9749347 & Edg & Andosoles & Formación Alausí & $A$ & $\mathrm{Pg}$ \\
\hline F13 & 747973 & 9743065 & Edg & Andosoles & Formación Alausí & $A$ & $\mathrm{Pg}$ \\
\hline F14 & 747723 & 9743064 & Edg & Andosoles & Formación Alausí & $A$ & $\mathrm{Pg}$ \\
\hline F15 & 747723 & 9743315 & Edg & Andosoles & Formación Alausí & $A$ & $\mathrm{Pg}$ \\
\hline F16 & 758771 & 9733251 & Edg & Andosoles & Formación Alausí & $A$ & $\mathrm{Pg}$ \\
\hline F17 & 758771 & 9733001 & Edg & Andosoles & Formación Alausí & $A$ & $\mathrm{Pg}$ \\
\hline F18 & 759021 & 9733001 & Edg & Andosoles & Formación Alausí & $A$ & $\mathrm{Pg}$ \\
\hline F19 & 753673 & 9738616 & Edg & Andosoles & Formación Alausí & $A$ & $\mathrm{Pg}$ \\
\hline F20 & 753925 & 9738613 & Edg & Andosoles & Formación Alausí & $A$ & $\mathrm{Pg}$ \\
\hline F21 & 753671 & 9738866 & Edg & Andosoles & Formación Alausí & $A$ & $\mathrm{Pg}$ \\
\hline F22 & 755726 & 9732916 & Edg & Andosoles & Formación Alausí & $A$ & $\mathrm{Pg}$ \\
\hline F23 & 755726 & 9732665 & Edg & Andosoles & Formación Alausí & $A$ & $\mathrm{Pg}$ \\
\hline F24 & 755981 & 9732663 & Edg & Andosoles & Formación Alausí & $A$ & $\mathrm{Pg}$ \\
\hline F25 & 763050 & 9737830 & Edg & Andosoles & Formación Alausí & $A$ & $\mathrm{Pg}$ \\
\hline F26 & 763047 & 9738086 & Edg & Andosoles & Formación Alausí & $A$ & $\mathrm{Pg}$ \\
\hline F27 & 763302 & 9737829 & Edg & Andosoles & Formación Alausí & $A$ & $\mathrm{Pg}$ \\
\hline F28 & 755925 & 9744597 & Edg & Andosoles & Formación Alausí & $A$ & $\mathrm{Pg}$ \\
\hline F29 & 755678 & 9744592 & Edg & Andosoles & Formación Alausí & $A$ & $\mathrm{Pg}$ \\
\hline F30 & 755678 & 9744845 & Edg & Andosoles & Formación Alausí & $A$ & $\mathrm{Pg}$ \\
\hline F31 & 760796 & 9747358 & Edg & Andosoles & Formación Alausí & $A$ & $\mathrm{Pg}$ \\
\hline F32 & 760793 & 9747609 & Edg & Andosoles & Formación Alausí & $A$ & $\mathrm{Pg}$ \\
\hline F33 & 761042 & 9747358 & Edg & Andosoles & Formación Alausí & A & $\mathrm{Pg}$ \\
\hline
\end{tabular}




\section{Anexo B}

\section{Índices Espectrales}

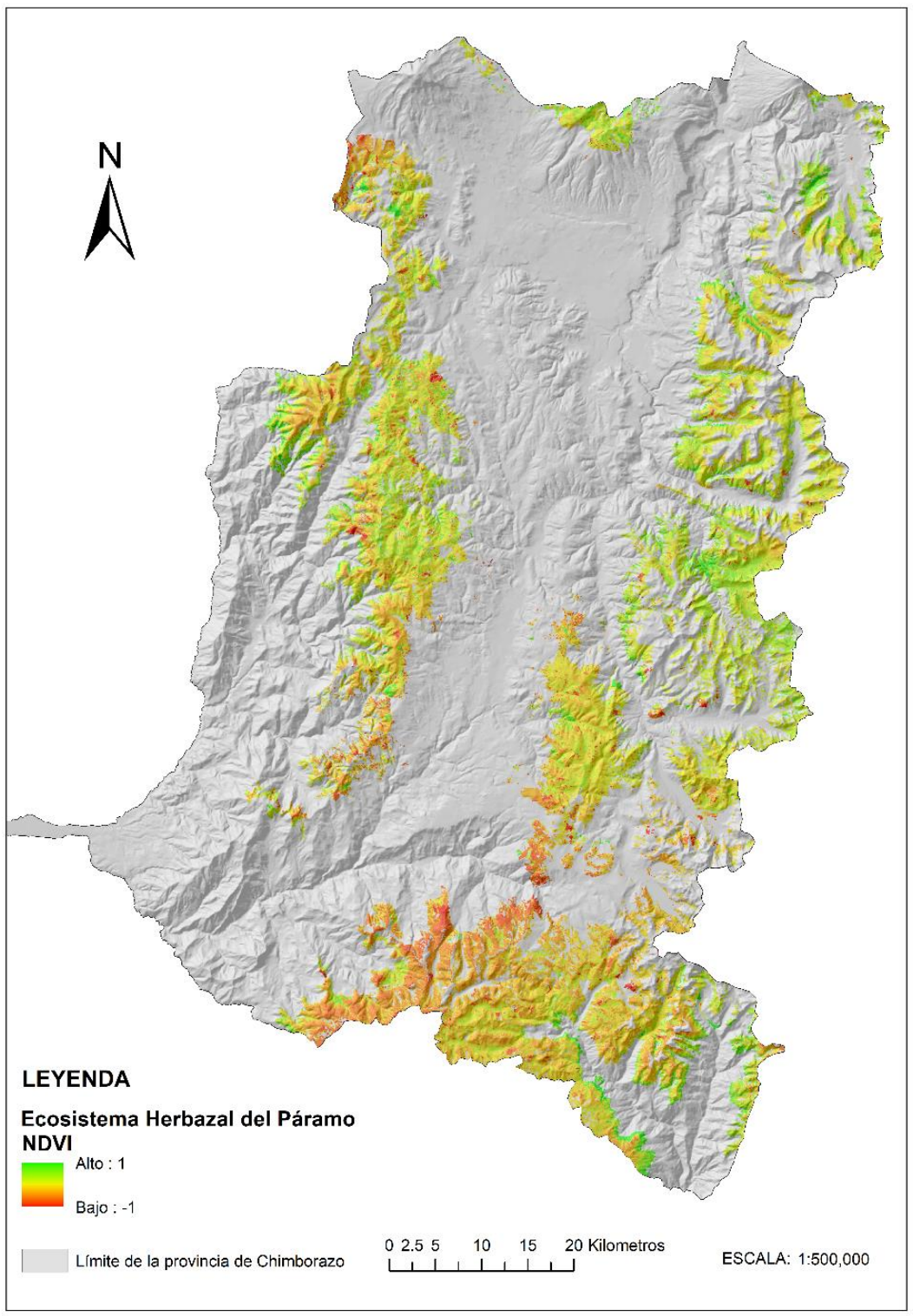

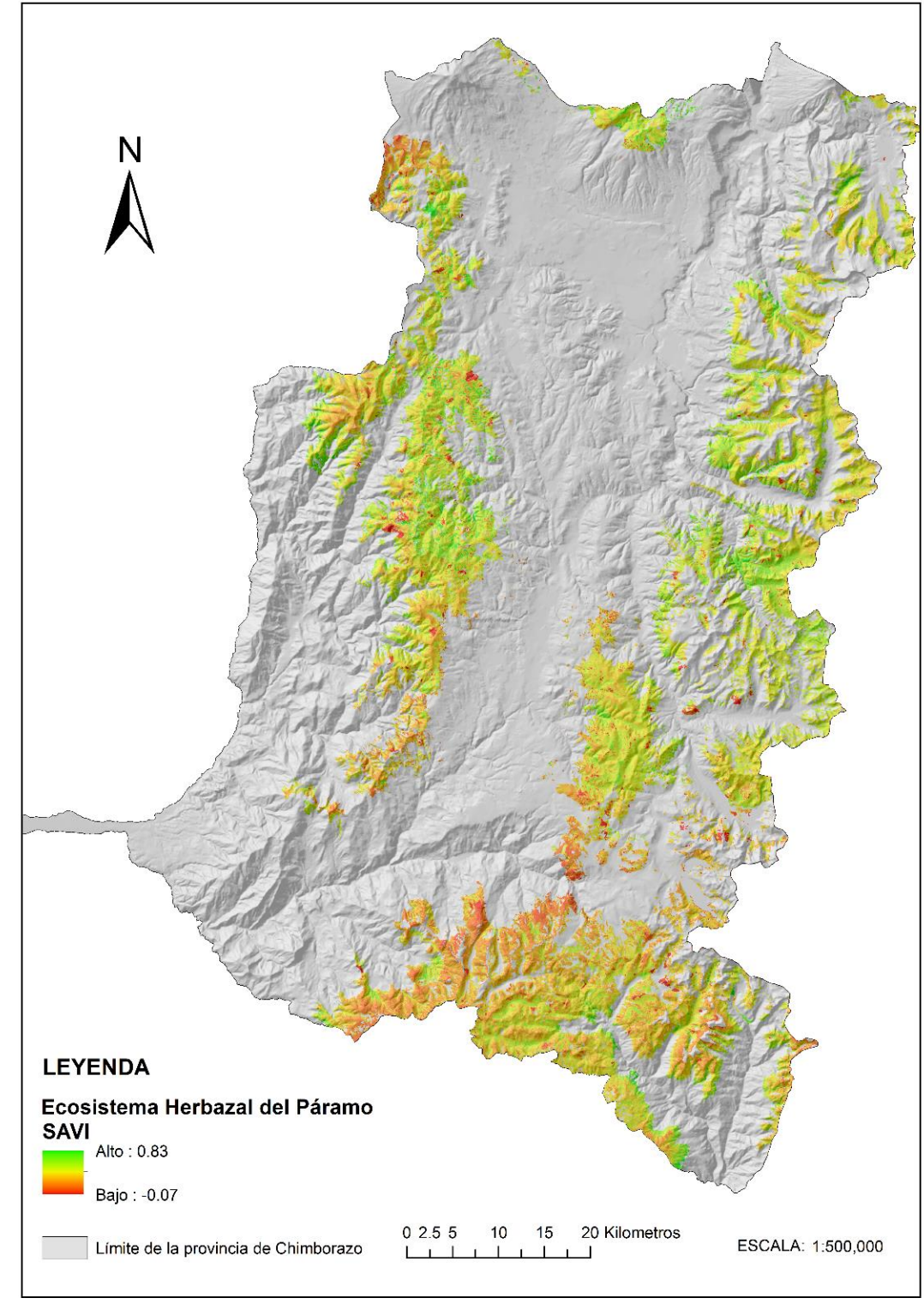



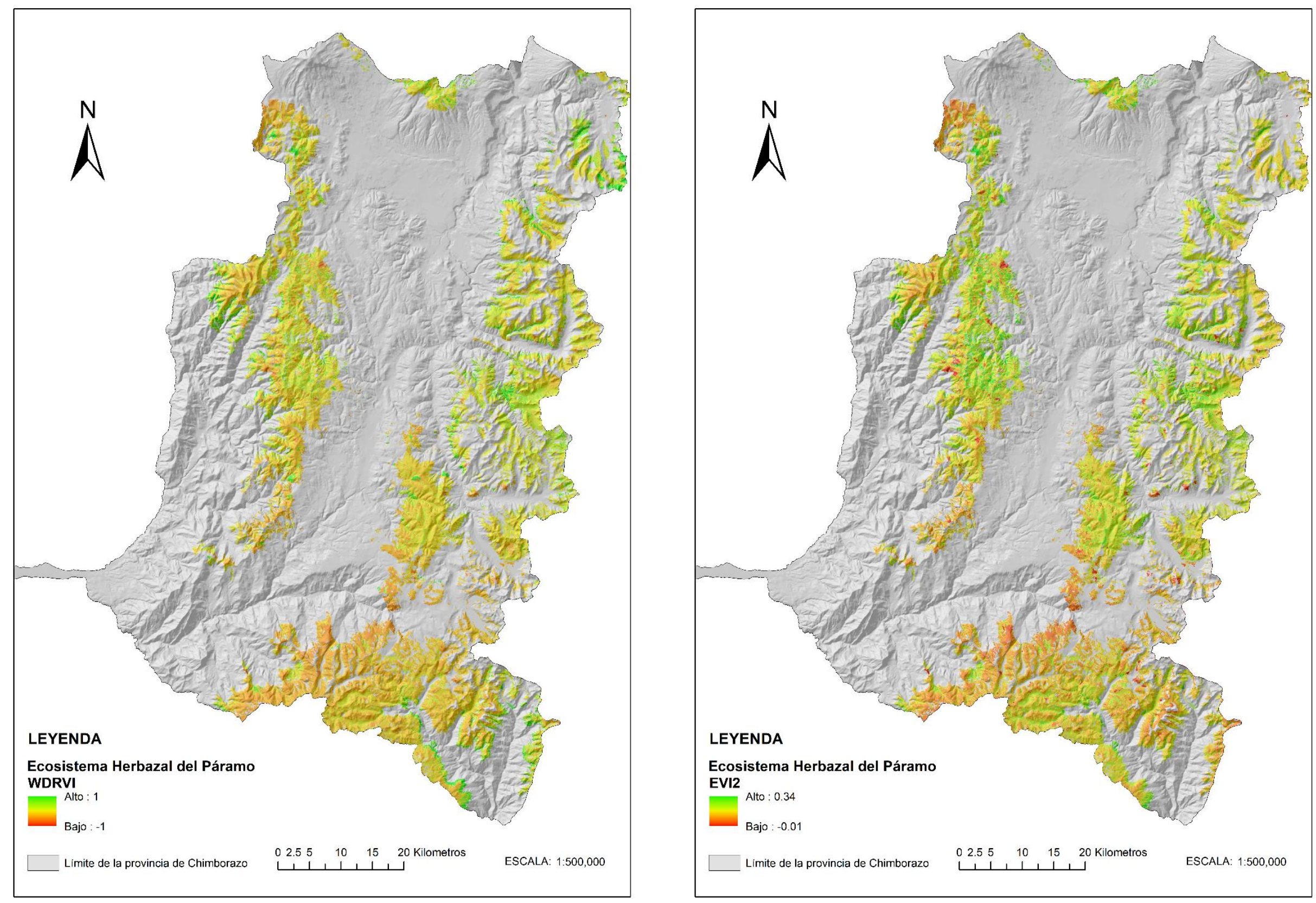

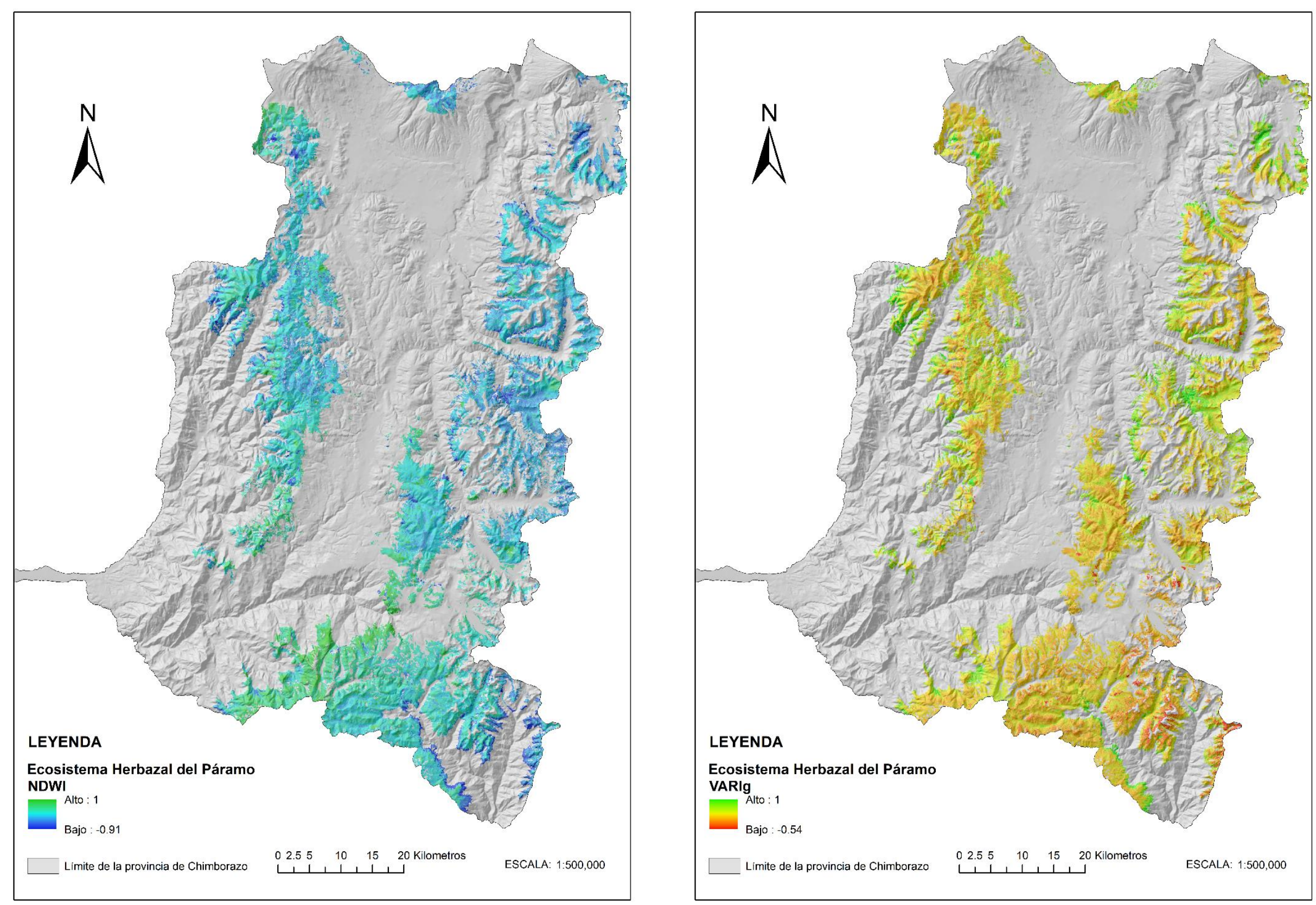


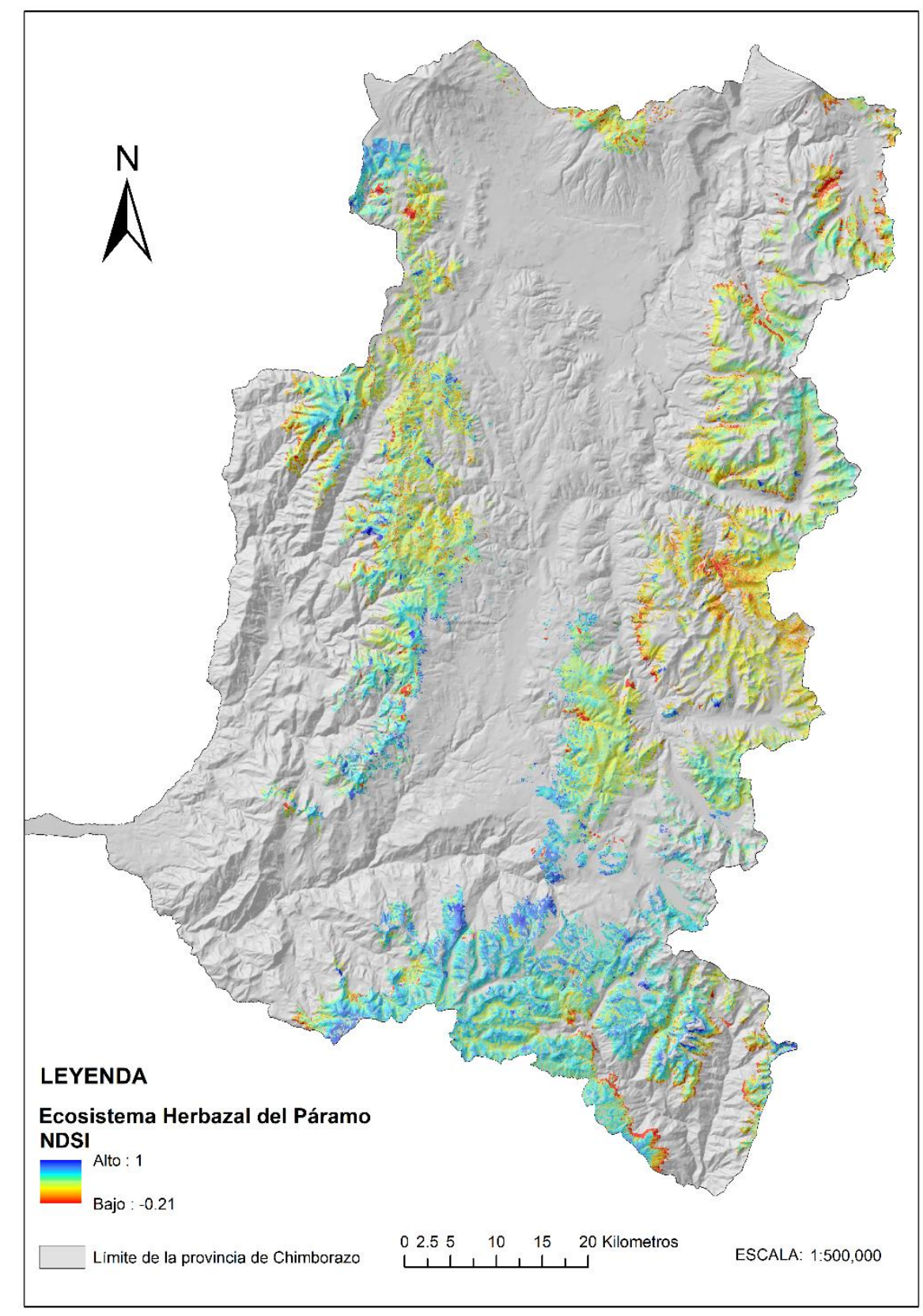

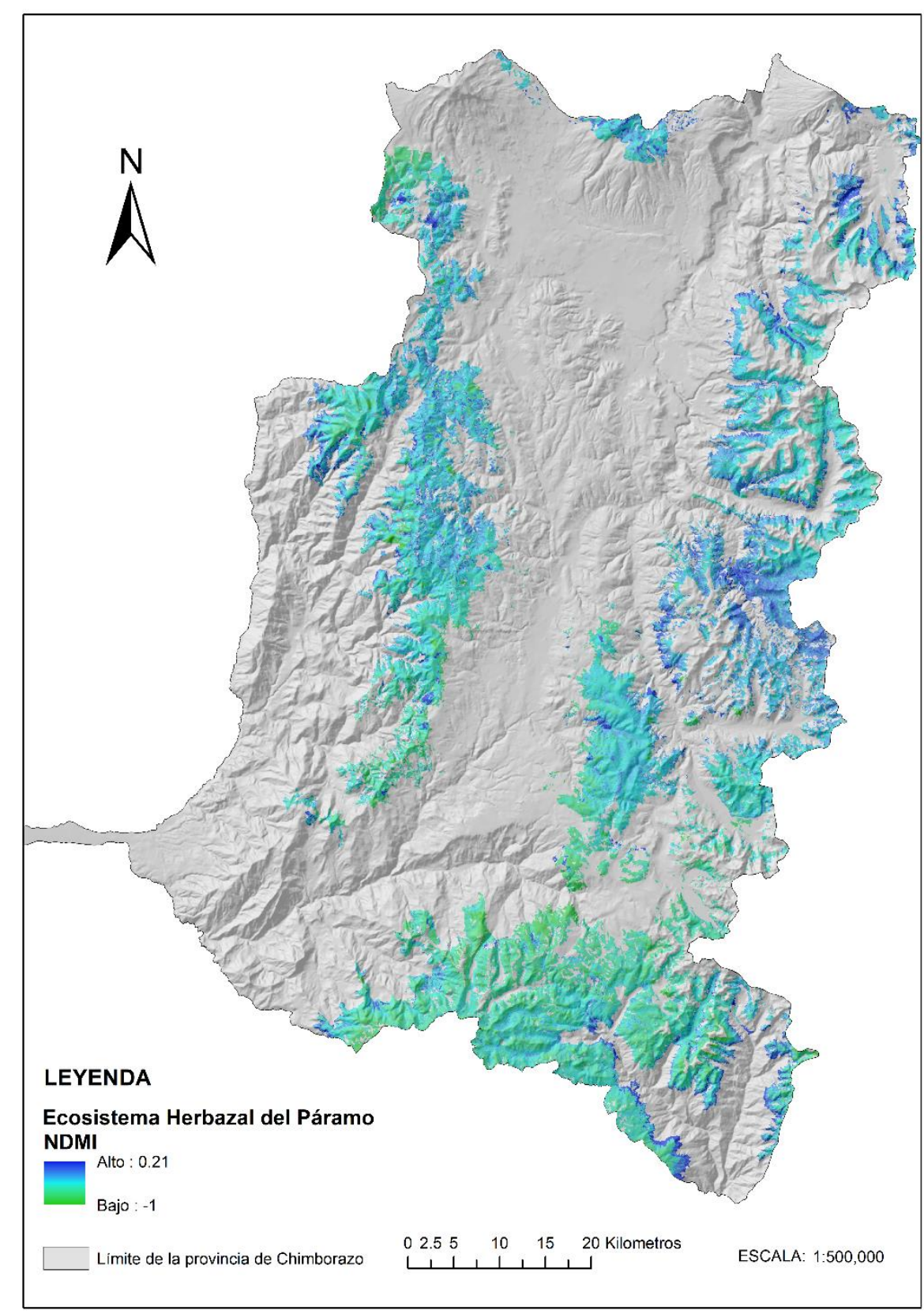

79 

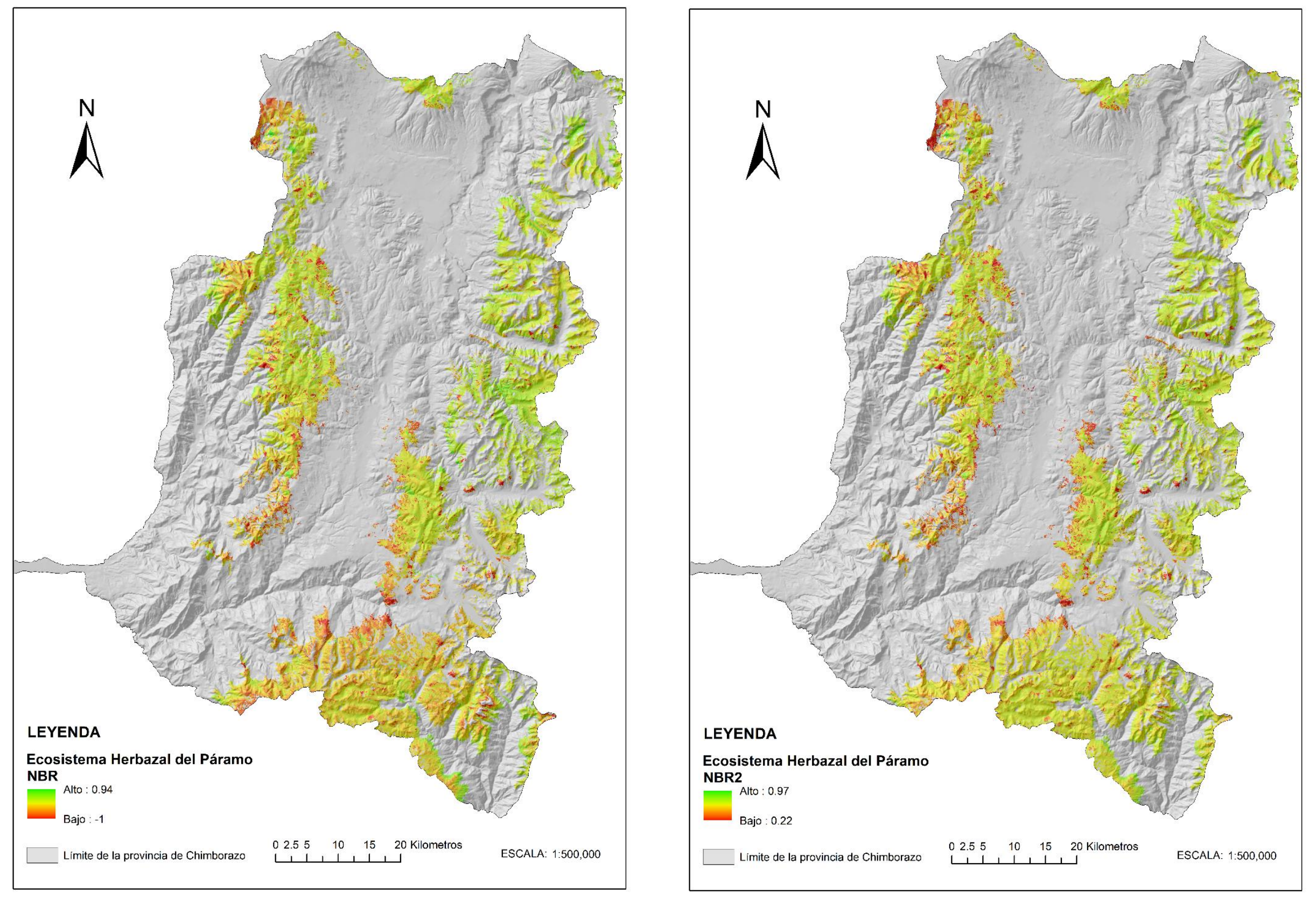


\section{Anexo C}

Estaciones meteorológicas usadas para la estimación de la superficie de temperatura en el Ecosistema Herbazal del Páramo - HP

\begin{tabular}{|c|c|c|c|}
\hline CÓDIGO ID & ALTITUD & $\begin{array}{l}\text { ALTITUD } \\
\text { (msnm) }\end{array}$ & $\begin{array}{l}\text { INTITUCIÓN } \\
\text { PROPIETARIO }\end{array}$ \\
\hline M0129 & CALUMA & 350 & INAMHI \\
\hline M0130 & CHILLANES & 2330 & INAMHI \\
\hline M0136 & $\mathrm{CHUNCHI}$ & 2177 & INAMHI \\
\hline M0391 & PALLATANGA & 1523 & INAMHI \\
\hline M1117 & INSTITUTO TECNICO 3 DE MARZO & 2504 & INAMHI \\
\hline M1095 & INGENIO AZTRA (LA TRONCAL) & 50 & INAMHI \\
\hline M0031 & CAÑAR & 3083 & INAMHI \\
\hline M1260 & QUIMIAG & 2725 & INAMHI \\
\hline M1261 & ILAPO & 3466 & INAMHI \\
\hline M0029 & BAÑOS & 1695 & INAMHI \\
\hline M0126 & PATATE & 2220 & INAMHI \\
\hline M0128 & PEDRO FERMIN CEVALLOS(COLEGIO) & 2910 & INAMHI \\
\hline M0133 & GUASLAN & 2850 & INAMHI \\
\hline M0258 & QUEROCHACA(UTA) & 2865 & INAMHI \\
\hline M1036 & RIOBAMBA POLITECNICA-SPOCH & 2850 & INAMHI \\
\hline M1069 & CALAMACA CONVENIO INAMHI HCPT & 3402 & INAMHI \\
\hline M1130 & SHIRY XII & 3028 & INAMHI \\
\hline M1209 & TOTORILLAS & 3207 & INAMHI \\
\hline M1243 & CUNCHIBAMBA-ITLAM (INST.LUIS A. MARTINEZ) & 2688 & INAMHI \\
\hline M0137 & BIBLIAN & 2640 & INAMHI \\
\hline M0189 & GUALAQUIZA INAMHI & 750 & INAMHI \\
\hline M1040 & MACAS SAN ISIDRO-PNS & 1110 & INAMHI \\
\hline M1265 & SAN JOSE DE MORONA-INAMHI-COL.REAL AUDIENCIA & 200 & INAMHI \\
\hline M5140 & ACHUPALLAS & 3376 & UNACH \\
\hline M5138 & JUBAL & 3462 & UNACH \\
\hline M5139 & OZOGOCHE & 3790 & UNACH \\
\hline
\end{tabular}

Estaciones meteorológicas con pluviómetro, usadas para la estimación de la superficie de precipitación en el Ecosistema Herbazal del Páramo - HP

\begin{tabular}{llrl}
\hline CÓDIGO & NOMBRE & $\begin{array}{l}\text { ALTITUD } \\
\text { (msnm) }\end{array}$ & $\begin{array}{l}\text { INSTITUCIÓN } \\
\text { PROPIETARIO }\end{array}$ \\
\hline M0029 & BAÑOS & 1695 & INAMHI \\
M0031 & CAÑAR & 3083 & INAMHI \\
M0126 & PATATE & 2220 & INAMHI \\
M0128 & PEDRO FERMIN CEVALLOS(COLEGIO) & 2910 & INAMHI \\
M0129 & CALUMA & 350 & INAMHI \\
M0130 & CHILLANES & 2330 & INAMHI \\
M0133 & GUASLAN & 2850 & INAMHI \\
\hline
\end{tabular}




\begin{tabular}{|c|c|c|c|}
\hline M0136 & $\mathrm{CHUNCHI}$ & 2177 & INAMHI \\
\hline M0137 & BIBLIAN & 2640 & INAMHI \\
\hline M0189 & GUALAQUIZA INAMHI & 750 & INAMHI \\
\hline M0197 & JACARIN (SOLANO) & 2700 & INAMHI \\
\hline M0258 & QUEROCHACA(UTA) & 2865 & INAMHI \\
\hline M0376 & PILAHUIN & 3314 & INAMHI \\
\hline M0377 & TISALEO & 3266 & INAMHI \\
\hline M0378 & RIO VERDE & 1529 & INAMHI \\
\hline M0380 & HUAMBALO & 2880 & INAMHI \\
\hline M0383 & ECHEANDIA & 308 & INAMHI \\
\hline M0385 & SALINAS-BOLIVAR & 3600 & INAMHI \\
\hline M0388 & RIO SAN ANTONIO-MONJAS & 2200 & INAMHI \\
\hline M0390 & URBINA & 3610 & INAMHI \\
\hline M0391 & PALLATANGA & 1523 & INAMHI \\
\hline M0392 & HUIGRA & 1331 & INAMHI \\
\hline M0393 & SAN JUAN-CHIMBORAZO & 3220 & INAMHI \\
\hline M0395 & CEBADAS & 2930 & INAMHI \\
\hline M0396 & ALAO & 3200 & INAMHI \\
\hline M0397 & COMPUD & 2402 & INAMHI \\
\hline M0399 & ACHUPALLAS-CHIMBORAZO & 3178 & INAMHI \\
\hline M0402 & CHIMBO DJ PANGOR & 2266 & INAMHI \\
\hline M0403 & ALAUSI & 2267 & INAMHI \\
\hline M0404 & CAÑI-LIMBE & 2800 & INAMHI \\
\hline M0405 & GUASUNTOS & 2438 & INAMHI \\
\hline M0407 & LICTO & 2865 & INAMHI \\
\hline M0408 & GUANO & 2620 & INAMHI \\
\hline M0409 & PANGOR-J.DE VELASCO(H.TEPEYAC) & 3109 & INAMHI \\
\hline M0410 & RIO MAZAR-RIVERA & 2450 & INAMHI \\
\hline M0411 & INGAPIRCA & 3100 & INAMHI \\
\hline M0412 & SUSCALPAMBA(CAPILLA DOLOROSA) & 2620 & INAMHI \\
\hline M0414 & CHANIN & 3270 & INAMHI \\
\hline M0415 & ANGAS LA UNION & 2900 & INAMHI \\
\hline M0501 & MENDEZ INAMHI & 665 & INAMHI \\
\hline M0535 & LAS HERRERIAS & 3650 & INAMHI \\
\hline M0794 & LAS NAVES & 108 & INAMHI \\
\hline M1036 & RIOBAMBA POLITECNICA-SPOCH & 2850 & INAMHI \\
\hline M1040 & MACAS SAN ISIDRO-PNS & 1110 & INAMHI \\
\hline M1069 & CALAMACA CONVENIO INAMHI HCPT & 3402 & INAMHI \\
\hline M1095 & INGENIO AZTRA (LA TRONCAL) & 50 & INAMHI \\
\hline M1107 & LAGUACOTO-GUARANDA & 2608 & INAMHI \\
\hline M1117 & INSTITUTO TECNICO 3 DE MARZO & 2504 & INAMHI \\
\hline M1130 & SHIRY XII & 3028 & INAMHI \\
\hline M1155 & LAS MONJAS (CEDEGE) & 1497 & INAMHI \\
\hline M1209 & TOTORILLAS & 3207 & INAMHI \\
\hline M1243 & CUNCHIBAMBA-ITLAM (INST.LUIS A. MARTINEZ) & 2688 & INAMHI \\
\hline M1260 & QUIMIAG & 2725 & INAMHI \\
\hline
\end{tabular}




\begin{tabular}{llr}
\hline M1261 & ILAPO & 3466 INAMHI \\
& SAN JOSE DE MORONA-INAMHI-COL.REAL & 200 INAMHI \\
M1265 & AUDIENCIA & 3376 UNACH \\
M5140 & ACHUPALLAS & 3462 UNACH \\
M5138 & JUBAL & 3790 UNACH \\
M5139 & OZOGOCHE & \\
\hline
\end{tabular}

